\title{
Analyzing Reduced Teenage Employment, 2000-2013
}

\author{
Abigail Haddad
}

This document was submitted as a dissertation in December 2015 in partial fulfillment of the requirements of the doctoral degree in public policy analysis at the Pardee RAND Graduate School. The faculty committee that supervised and approved the dissertation consisted of Nelson Lim (Chair), Lou Mariano, and Paul Heaton. 
For more information on this publication, visit http://www.rand.org/pubs/rgs_dissertations/RGSD368.html

Published by the RAND Corporation, Santa Monica, Calif.

C Copyright 2016 RAND Corporation

RAND $^{\circledR}$ is a registered trademark

\section{Limited Print and Electronic Distribution Rights}

This document and trademark(s) contained herein are protected by law. This representation of RAND intellectual property is provided for noncommercial use only. Unauthorized posting of this publication online is prohibited. Permission is given to duplicate this document for personal use only, as long as it is unaltered and complete. Permission is required from RAND to reproduce, or reuse in another form, any of its research documents for commercial use. For information on reprint and linking permissions, please visit www.rand.org/pubs/permissions.html.

The RAND Corporation is a research organization that develops solutions to public policy challenges to help make communities throughout the world safer and more secure, healthier and more prosperous. RAND is nonprofit, nonpartisan, and committed to the public interest.

RAND's publications do not necessarily reflect the opinions of its research clients and sponsors.

Support RAND

Make a tax-deductible charitable contribution at

www.rand.org/giving/contribute

www.rand.org 
Employment among 16-19 year-olds declined from about $41 \%$ in 2000 to $28 \%$ in 2013 . Research regarding the possible negative effects of this is mixed: there is a significant literature on how working as a teenager affects later employment outcomes, but it is far from definitive. This dissertation builds a teenage labor market model and presents evidence regarding five different hypotheses for this decline in employment. These are: a reduction in the supply of teenage labor stemming from increased returns to education; decreased demand for teenage labor due to increased competition from immigrants; decreased demand for teenage labor due to increased competition from less-skilled workers; decreased demand for teenage labor due to increased competition from adult workers in general; and minimum wages that are increasingly binding. I find mixed evidence, with the strongest evidence in favor of lower supply due to higher returns to education. There is also evidence that demand for teenage labor has fallen, with a small amount of evidence specifically supporting the hypothesis that adult immigrants are increasingly competing with teenagers.

Because the evidence for the importance of working as a teenager on later employment outcomes and contribution to family finances is weak, public policy should not focus on getting teenagers in general to work. Instead, youth employment programs should focus specifically on the subset of teenagers who are disengaged from work and school. These teenagers differ in a variety of ways from their more-engaged peers. Among existing programs, there is significant variance in both degree of targeting and the extent to which program evaluation is occurring. The low-hanging fruit in terms of policy improvement is better evaluation of existing youth employment programs, with results informing funding. 



\section{Table of Contents}

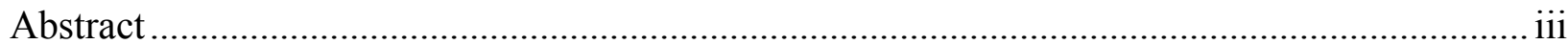

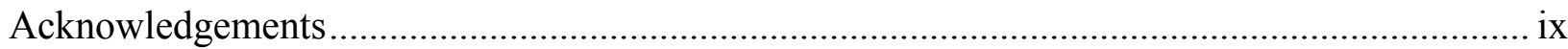

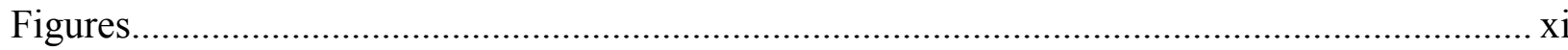

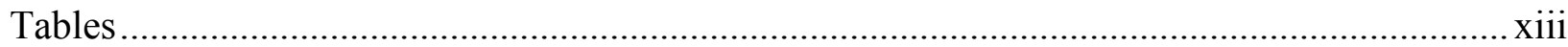

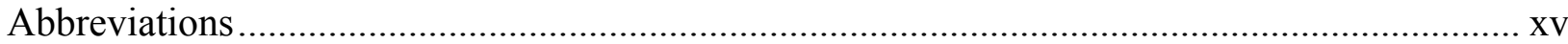

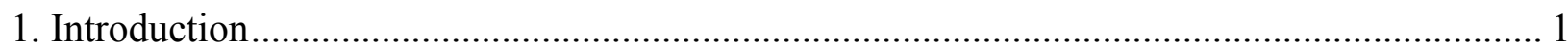

The Possible Negative Effects of Lower Teenage Employment ......................................................... 2

Effect of the Decline of Teenage Employment on Future Earnings and Educational Attainment....... 2

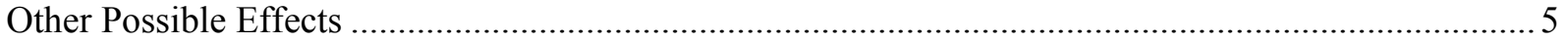

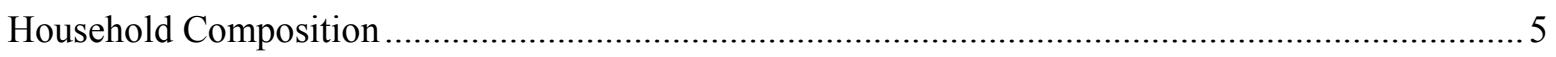

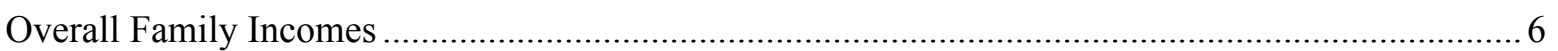

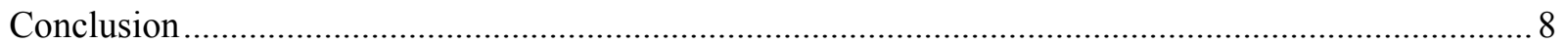

Chapter 2: Modeling Teenage Employment ........................................................................ 9

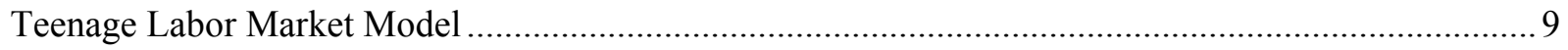

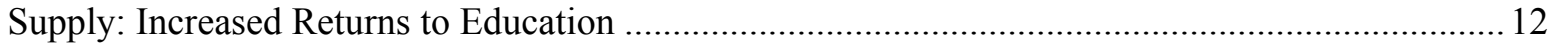

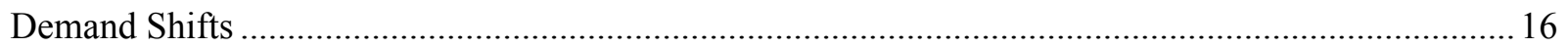

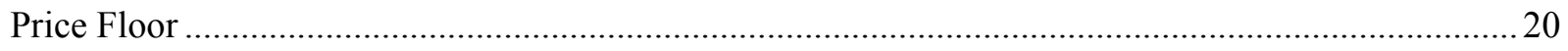

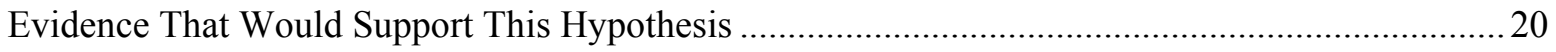

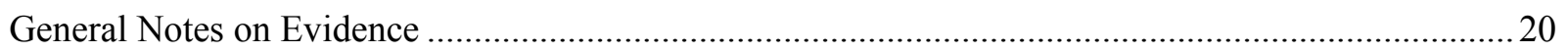

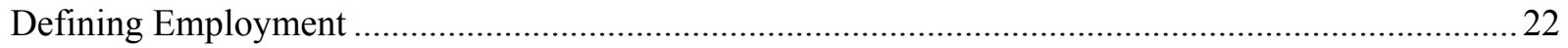

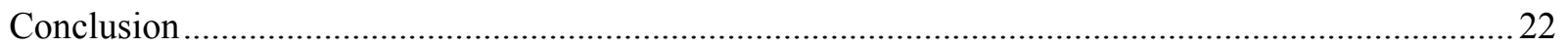

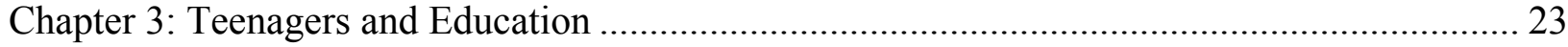

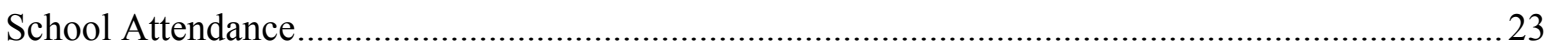

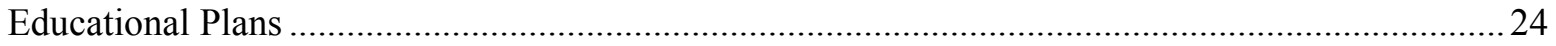

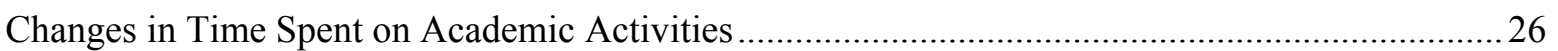

Changes in Employment by Educational Status......................................................................29

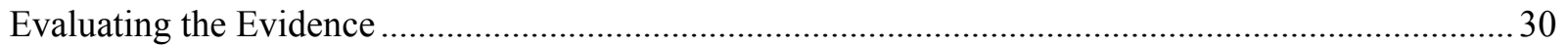

Chapter 4: Teenage Jobs: What Happened to Them, Who is Working Them? .......................... 31

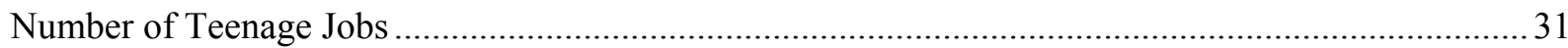

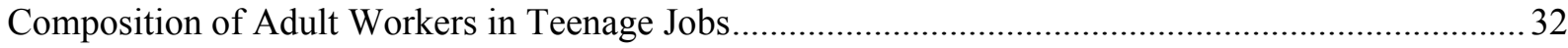

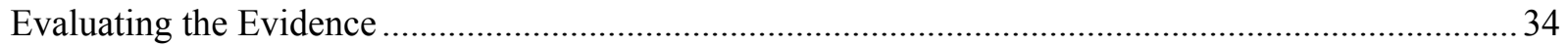

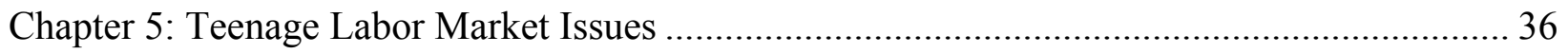

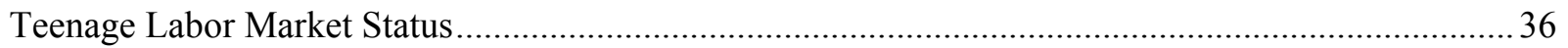

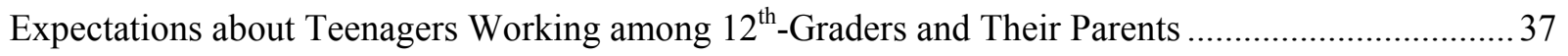

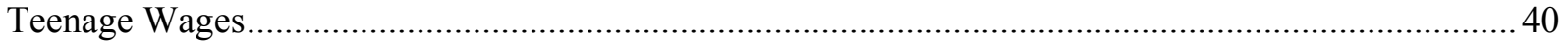

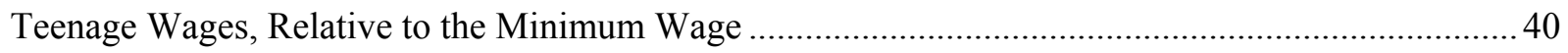

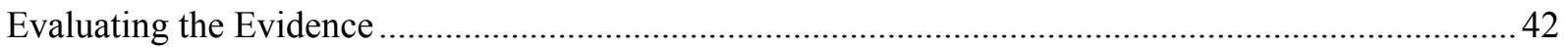




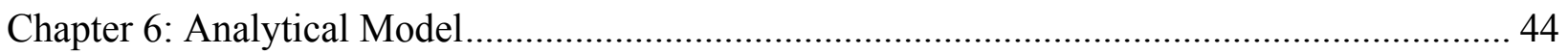

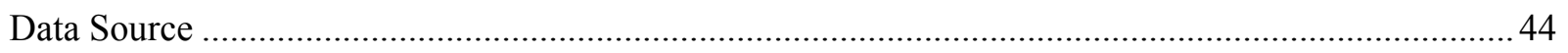

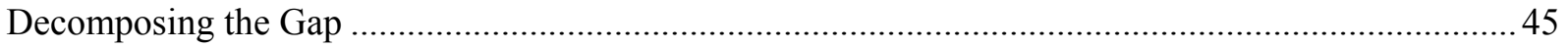

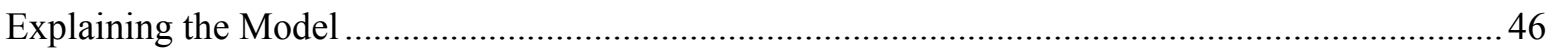

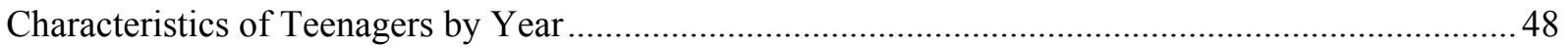

Modeling Employment Separately by Year …………………………………………………….... 49

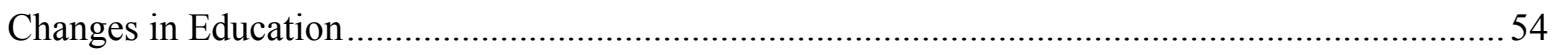

Proportion of High School Dropouts........................................................................................ 55

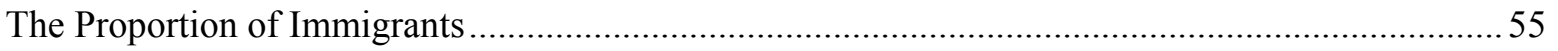

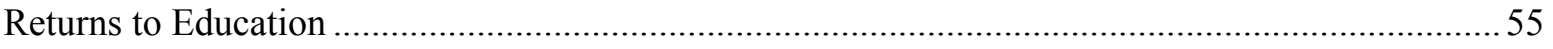

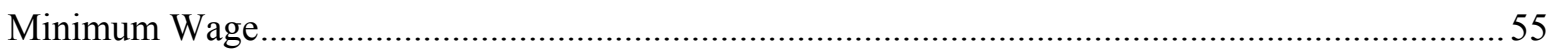

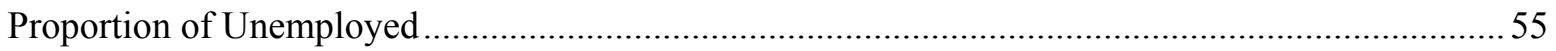

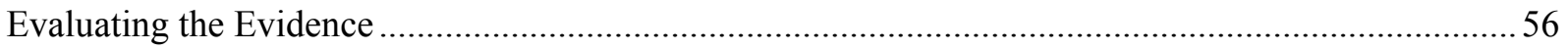

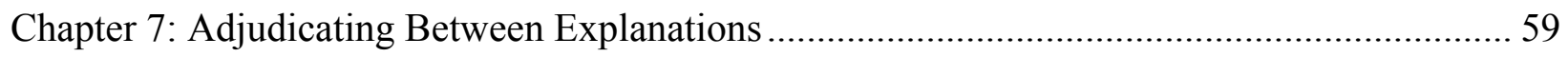

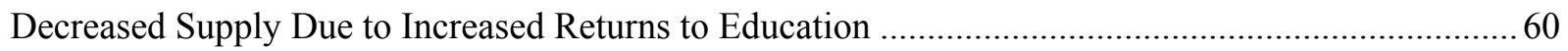

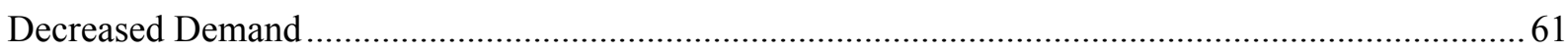

Competition from Unskilled Labor ................................................................................................. 61

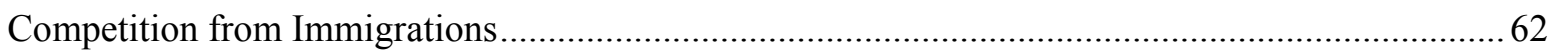

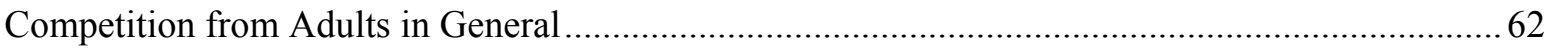

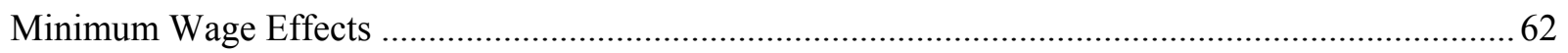

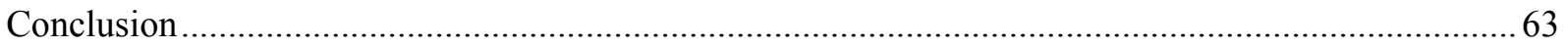

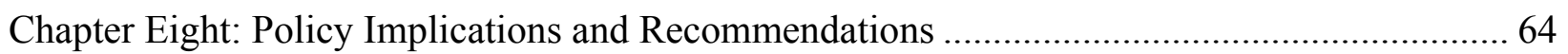

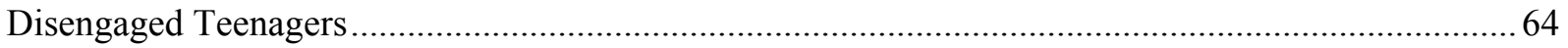

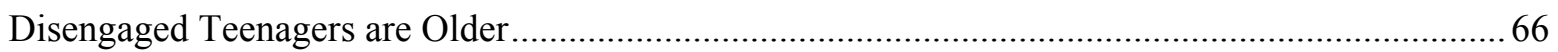

Disengaged Teenagers are more likely to be Black or Hispanic.......................................................66

Disengaged Teenagers are more likely to come from Households below the Poverty Line ............... 67

Disengaged Teenagers Are More Likely To Be Imprisoned, Less Likely to Live in Dorms.............. 68

Disengaged Teenagers Are More Likely To Be High School Graduates, Less Likely to Have Any

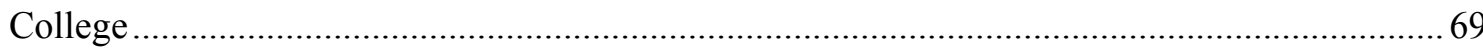

Disengaged Teenagers Are Urban, Rural, and Suburban ............................................................. 70

Disengaged Teenagers Are Different in Other Ways: More Likely to Have Children, More Likely to

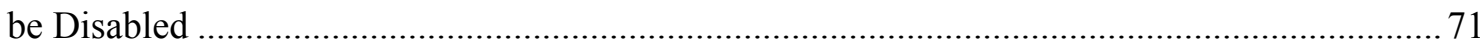

Lack of Engagement Likely Stems from a Variety of Factors …………………………………......... 72

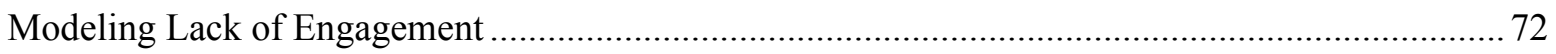

Programs to Increase Youth Employment Vary Significantly in Terms of Program Evaluation,

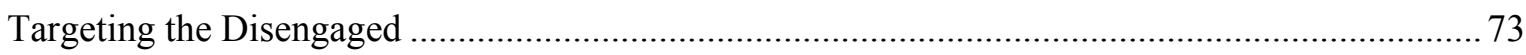

Direct-Hire Programs …………………………………………………………………..... 73

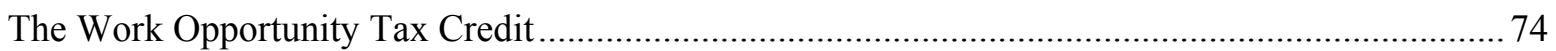

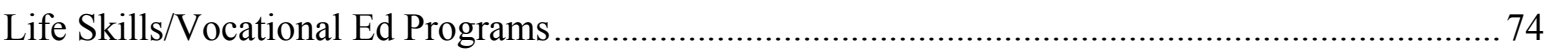

Existing Program Evaluation is Limited, Not Encouraging .........................................................

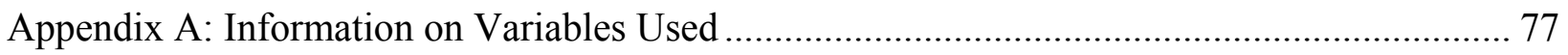

Appendix B: Deriving Hourly Wage and Alternative Specifications........................................... 80 


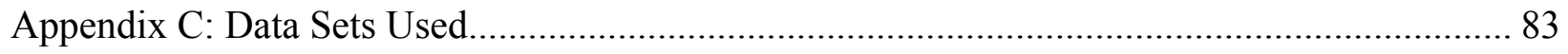

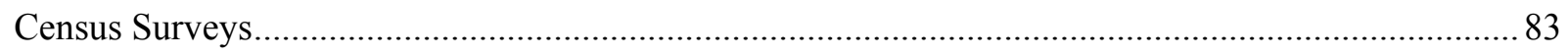

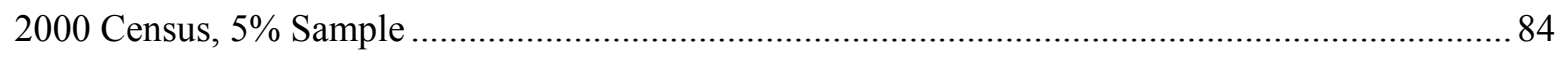

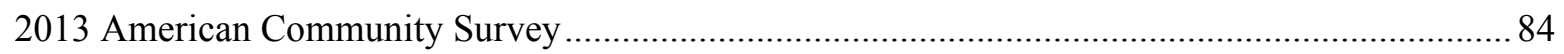

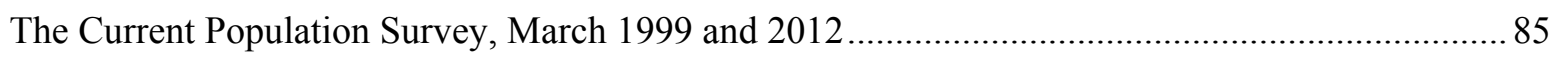

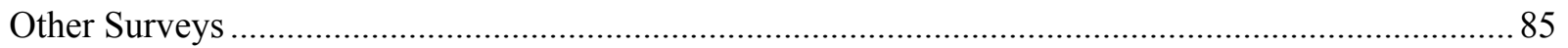

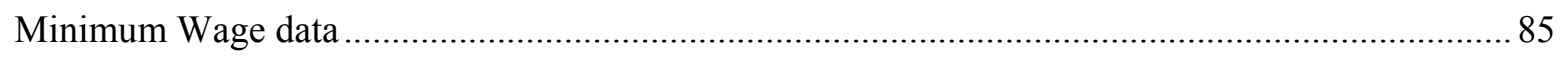

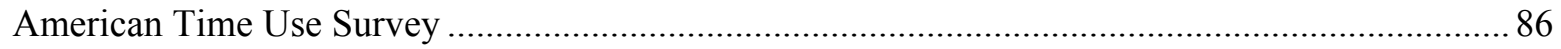

Monitoring the Future: A Continuing Study of American Youth (12th-Grade Survey) ................... 86

Appendix D: Literature on the Effects of Teenage Employment ......................................... 87

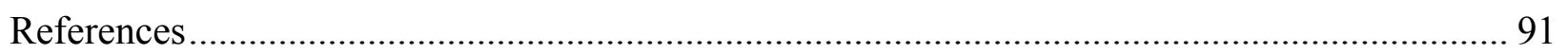





\section{Acknowledgements}

I wish to thank Nelson Lim, who told me the following in 2013: "There is no reason to not get a PhD. I cannot think of anything. We have empirical evidence that you can do this." I also wish to thank Lou Mariano and Paul Heaton for closely reading two drafts and giving me very many helpful, detailed comments, and to Andrew Biggs as well for reading and comments. I would also like to thank Cynthia Cook for her dissertation-writing advice and encouragement. 



\section{Figures}

Figure 1.1: Employment Rates, 1962-2013 ........................................................................... 2

Figure 1.2: Proportion of Teenagers Living on Their Own, 2000-2013 ................................... 6

Figure 1.3: Proportion of Teenagers Earning At Least 5\%, 10\%, 20\%, and 50\% of Total

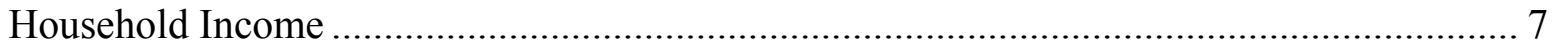

Figure 2.1: Representation of Initial Problem: School-Goer ................................................. 11

Figure 2.2: Representation of Initial Problem: Non School-Goer .......................................... 12

Figure 2.3: Effect of Increased Returns to Education on School-Goer ...................................... 13

Figure 2.4: Effect of Increased Returns to Education: Shifting the Non-School-goer to School. 14

Figure 2.5: Effect of Increased Returns to Education: the Non-School-goer............................ 15

Figure 2.6: Effect of Reduced Teenage Wages: the School-goer ............................................ 17

Figure 2.7: Effect of Reduced Teenage Wages: Shifting the Non-School-goer to School.......... 18

Figure 2.8 Effect of Reduced Teenage Wages: the Non-School-goer...................................... 18

Figure 3.1: Proportion of Teenagers Attending School, March and July 2000 and 2013 ........... 24

Figure 3.2: Likelihood of Attending Two- or Four-year College ............................................. 25

Figure 3.3: Likelihood of Attending Four-year College ........................................................ 26

Figure 3.4: Average Daily Minutes on Academic Activities............................................... 28

Figure 3.5: Employment by Educational Status, March and July 2000 and 2013 .................... 29

Figure 4.1: Proportion of Immigrants among Adults In Jobs with Teen Overrepresentation from

Two to Five 33

Figure 4.2: Proportion of High School Dropouts among Adults In Jobs with Teen

Overrepresentation from Two to Five ........................................................................ 34

Figure 5.1: Labor Market Status and Reason for NILF ..................................................... 37

Figure 5.2: Preferences Regarding Weekly Hours Worked, $12^{\text {th }}$ Graders ................................. 38

Figure 5.3: Preferences Regarding Weekly Hours Worked, Parents of $12^{\text {th }}$ Graders................. 39

Figure 5.4: Distribution of Hourly Wage among Teenagers Who Reported Having Earned

Income, Inflation-Adjusted to Year 2000 Dollars, 2000 and 2013 ................................. 40

Figure 5.5: Teenage Hourly Wages as a Proportion of Minimum Wage, 2000 and 2013........... 41

Figure 6.1: Decomposing the Employment Gap............................................................ 52

Figure 8.1: Proportion of Teenagers in neither Work nor School, 1986-2014 ......................... 65

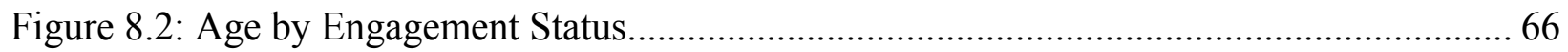

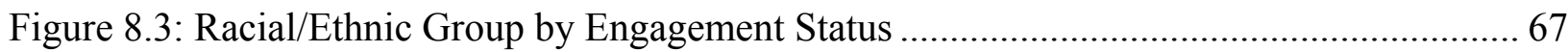

Figure 8.4: Household Income by Engagement Status ......................................................... 68

Figure 8.5: Group Quarters by Engagement Status ............................................................. 69 
Figure 8.6: Educational Attainment by Engagement Status .............................................. 70

Figure 8.7: Educational Attainment by Geographical Status.................................................. 71

Figure B.1: Summary Statistics for Hourly Wage: CPS (2013) ............................................... 81

Figure B.2: Summary Statistics for Hourly Wage: Monitoring the Future (12 ${ }^{\text {th }}$ Graders, 2013). 82 


\section{Tables}

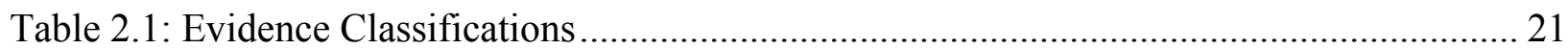

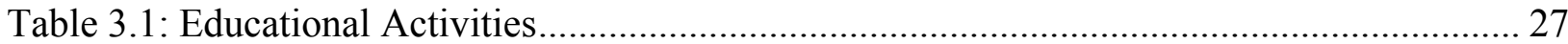

Table 3.2: Comparing Minutes/Day Spent on Education, 2003-2013 .................................... 28

Table 3.3: Teenagers and Schooling: Evaluating the Evidence............................................... 30

Table 4.1: Number of Teen Jobs, 2000 and 2013 .................................................................. 32

Table 4.2: Evaluating the Evidence: Labor Market Changes ................................................... 35

Table 5.1: Preferences Regarding Weekly Hours Worked, $12^{\text {th }}$ Graders, ANOVA................... 38

Table 5.2: Parental Preferences Regarding Weekly Hours Worked, $12^{\text {th }}$ Graders, ANOVA...... 39

Table 5.3: Evaluating the Evidence: Teen Labor Market Issues ........................................... 42

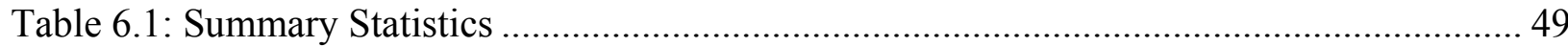

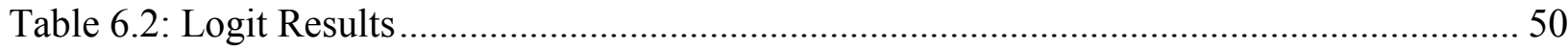

Table 6.3: Decomposition Results ......................................................................................... 53

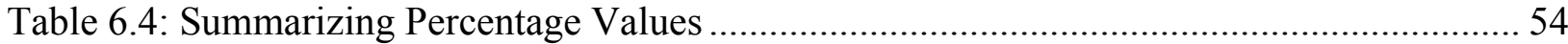

Table 6.5: Evaluating the Evidence: Analytical Model Results .............................................. 57

Table 7.1: Evaluating the Evidence: All .................................................................................... 59

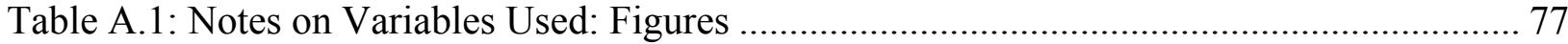

Table A.2: Notes on Variables Used: Tables......................................................................... 79

Table D.1: Papers on Adolescent Work Behavior and Later Employment and Educational

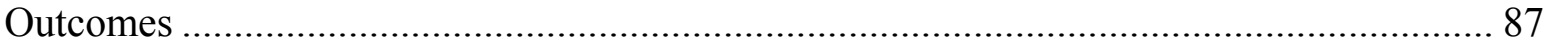

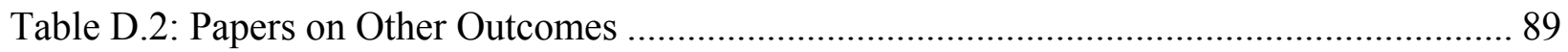





\section{Abbreviations}

ACS

ATUS

CPS

MTF

NILF

NLSY

PSID
American Community Survey

American Time Use Survey

Current Population Survey

Monitoring the Future

not in the labor force

National Longitudinal Survey of Youth

Panel Study of Income Dynamics 



\section{Introduction}

Employment among American teenagers has declined significantly over the past fifteen years. As shown in Figure 1.1, for decades the teenage employment rate ran roughly parallel to but below the adult employment rate. But more recently, they have separated, with teenage employment generally failing to increase even in years when adult employment increased.

This dissertation will analyze some possible drivers of reduced teenage employment, its possible effects, and programs which attempt to increase employment among teenagers. It is structured as follows: Chapter One summarizes the changes in teenage employment and discusses the possible effects of working for teenagers who do so. Chapter Two introduces hypotheses, explains the theoretical basis for each one, and outlines what evidence would support or contradict each hypothesis. Chapter Three, Chapter Four, and Chapter Five each go through some of the evidence on this topic and explain whether it supports or contradicts each of the hypotheses. Chapter Six presents a formal statistical model and discusses how the results relate to each hypothesis. Chapter Seven adjudicates between all of the evidence presented to evaluate each of the hypotheses, concluding that the strongest hypothesis is that teenagers are supplying less labor because of higher returns to education, but that there is also evidence for some type of demand shift. Chapter Eight focuses on the subset of teenagers who are disengaged from work and school, describes several categories of programs focused on youth employment, and argues for more program evaluation. The appendices go through some of the more technical elements such as variable construction.

The proportion of sixteen to nineteen-year-old Americans ${ }^{1}$ who are employed was lower in 2013 than at any point since 1962, when the Census began annually collecting this data as part of their March Current Population Survey (CPS) ${ }^{2}$. In the period from 1962 to 2000, there were various decreases, generally paralleling decreases in the employment to population ratio, as shown in Figure 1.1. However, since 2001, the employment to population ratio among teenagers has broken with the adult rate, with steeper decreases, as well as decreases even when the adult rate of employment was increasing. In 2013, about $24 \%$ of teenagers were employed, compared to a local maximum, or peak, of $43 \%$ in 2000 and an average of about $40 \%$ over the period from 1962 to 2000.

\footnotetext{
1 "Teenagers" in this paper refers to 16-19 year-olds unless otherwise specified: data on employment of younger teenagers is significantly more limited. Adults, unless otherwise specified, refers to 20-65 year-olds, or working-age adults.

2 The formal model developed in Chapter Seven uses Census and ACS data rather than March CPS data for teenage employment because ACS is significantly larger. The decline in employment it shows is somewhat less dramatic, possibly because the population it covers is slightly different or because ACS is full-year rather. I show CPS data here because CPS has annual data going back significantly further than ACS.
} 
Figure 1.1: Employment Rates, 1962-2013

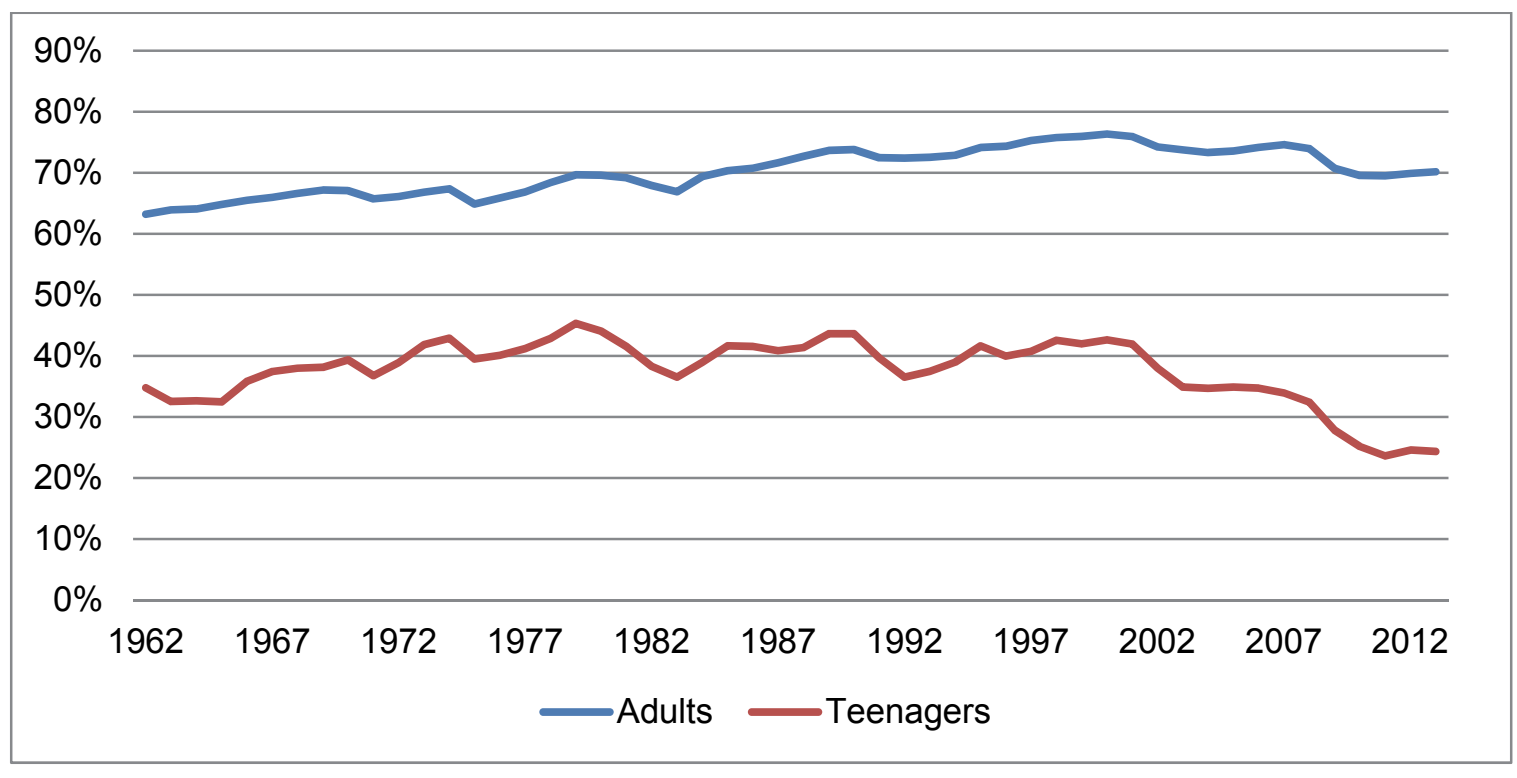

CPS, 1962-2013 (March)

\section{The Possible Negative Effects of Lower Teenage Employment}

Teenage employment is associated with various economic, educational, and householdrelated outcomes for teenagers. First, American teenagers with jobs generally go on to complete more education, work at higher rates, and earn higher wages than their non-working peers (Hotz, $2002^{3}$ ). However, while there is a significant literature on this, for various reasons it does not resolve the degree to which these differences are actually caused by teenage employment. Additionally, teenagers who work also have the potential to contribute more financially to their households, and form their own households at higher rates. There is much less of a literature on this second set of outcomes, but it points to teenage employment likely having small effects related to these outcomes as well.

\section{Effect of the Decline of Teenage Employment on Future Earnings and Educational Attainment}

In the United States, in the latter half of the 20th century, people who worked as teenagers tended to have better adult labor market outcomes, like increased likelihood of employment and higher wages (Hotz, 2002). There are several theories as to why this might be the case. Human capital theory suggests that getting either general work experience or training in specific tasks, increases productivity, thus improving labor market outcomes by making workers more valuable

${ }^{3}$ See Table 2 and Table 3. This paper just looks at outcomes for young men. 
employees. Socialization theory posits that early labor market experiences change peoples' preferences and aspirations, changing how they behave in the labor market. Finally, screening or signaling theory argues that if working is a sign of higher productivity, it would be appealing to employers even if working does not actually produce any changes in teenagers. (Alon, 2001; Baum, 2014). Alternatively, working as a young person could lead to worse labor market outcomes if it reduces educational attainment either because teenagers who work have less time to spend on schooling or because the ability to earn income in the present makes deferring that income in order to get more education less appealing.

While there is a significant literature on the effects of teen employment on outcomes like educational attainment and future wages, no consensus view emerges from this field and there are several major limitations to it.

First, only a few data sets contain sufficiently comprehensive information on teen employment and later educational and labor outcomes to credibly attempt to establish these effects, meaning that most of the literature uses those same few data sets. The two most popular of these are the National Longitudinal Survey of Youth 1979 (NSLY79) and the National Longitudinal Survey of Youth 1997 (NLSY97).

Second, because these data sets have so many variables and years of data, using them requires researchers to make many decisions regarding which sub-groups to study, what controls to use, and what outcomes to focus and in what years, in addition to what types of statistical models to use. Because there are no standard decisions to make regarding these, and almost no work on replication, it's extremely difficult in the case of differing results to tell which decisions are driving those results, much less to adjudicate between them ${ }^{4}$.

Third, none of the literature is experimental, and even the abundant variables are no substitute for being able to do experiments: it is still plausible that omitted variable bias exists in the form of some variables distinguishing teenagers who work from those who don't and which also affect later educational and work outcomes ${ }^{5}$.

Two representative and highly-cited papers using NSLY79 to study the adult labor market outcomes of working as a teenager are Carr (1996) and Hotz (2002). Carr looks at respondents who were 16-19 in 1979 and finds that, even though those who worked in high school were somewhat less likely to attend college or attain a four-year degree, they were still more likely to be in the labor force and employed in 1991, as well as to earn higher wages. These differences

\footnotetext{
${ }^{4}$ For more on the concept of researcher degrees of freedom, read "The garden of forking paths: Why multiple comparisons can be a problem, even when there is no "fishing expedition" or "p-hacking" and the research hypothesis was posited ahead of time" (Gelman and Loken). http://www.stat.columbia.edu/ gelman/research/unpublished/p_hacking.pdf

${ }^{5} \mathrm{Mroz}$ (2006) on the somewhat different set of literature on youth unemployment describes as the problems: small/non-random samples, inadequate controls, insufficient time horizons, overly restrictive models, lack of theoretical foundation, and a lack of policy conclusions.
} 
could not be explained by controls for poverty status in adolescence, parental education, race, AFQT score, and educational expectations.

Hotz (2002) looks at a slightly younger subset of NSLY79 respondents: young men who were 13 to 16 in 1978. His outcome of interest is labor market outcomes in 1990. He finds that the young men who worked more in high school or college went on to obtain more education and earn higher wages, but attributes much of this to selection issues. After conditioning on a similar set of controls as Carr (1996), he then adds some additional controls for heterogeneity and concludes that much of the difference in labor market outcomes is attributable to personal and family characteristics between young people who worked more as teenagers and those who worked less. Because Carr and Hotz use different controls and different subsets of the NSLY79 subjects, we can not necessarily conclude that Carr's results are a function of the different models.

A newer paper which argues that differences in future labor market outcomes between people who worked more as teenagers and those who worked less were real but have significantly diminished is "The changing benefits of early work experience." Here, Baum (2014) looks at both NLSY79 and the younger cohort of NLSY97 and concludes that the wage benefits for the NSLY79 group of working 20 hours per week or more as a senior in high school were $8.3 \%$, in contrast to $4.4 \%$ for the younger group. In the older group, working as a senior in high school was negatively associated with later working low-skill jobs, but in the younger group, there was a positive association. That is, working as a senior in high school used to be associated with being less likely to later work low-skill jobs, but among the more recent cohort, working was associated with a higher probability of working low-skill jobs as an adult.

A broader survey of the recent literature ${ }^{6}$ shows no clear conclusions about the effect of working on education, with a common theme being the heterogeneity of the effects of working based on either the intensity of respondent's work experiences or demographic variables. For instance, in "Employment, Motherhood, and School Continuation Decisions of Young White, Black, and Hispanic Women" (Ahituv and Tienda, 2004), researchers conclude that the relationships between work intensity and dropping out of school are different across racial/ethnic groups, while "Twelfth-Grade Student Work Intensity Linked to Later Educational Attainment and Substance Use: New Longitudinal Evidence" (Freedman-Doan, 2011) also concludes that teenagers who worked more hours were less likely to complete at least two years of college, relative to teenagers who worked at a lower intensity.

\footnotetext{
${ }^{6}$ See Appendix D for more on this literature.
} 


\section{Other Possible Effects}

There are other aspects of economic and family life that a decline in teenage employment may negatively impact ${ }^{7}$ and that go relatively unexplored in the literature. Two of these are teenagers forming their own households and teenagers contributing to household income. I find that the decline in teenage employment has possibly contributed to lower teenage household formation, but that this is difficult to disentangle from declines in the broader economic climate. In the case of teenagers contributing to household income, I am particularly concerned with the possibility that teenagers working less may mean that teenagers are able to contribute less to households that are already at or below the poverty line. However, I find that the proportion of household income earned by teenagers tends to be quite low, even in low-income households, and evidence suggests that it doesn't go to general household expenses. Appendix D has more information on this literature.

\section{Household Composition}

Household formation declines during recessions, with one contributor being that young adults prolong living with their parents and put off forming their own households. While overall unemployment rates affect likelihood of household formation, whether the young adult has a job themselves is a much bigger factor, with unemployed young adults in the United States being significantly less likely to move from living with their parents to rental/ownership. Buck and Scott (1993), using the Panel Study of Income Dynamics (PSID), find that among women living with their parents, annual work hours are positively associated with leaving home to get married. Among men living with their parents, earned income is positively associated with leaving home to get married. Neither is significantly associated in either group with leaving home to live independently for reasons other than marriage. They also incorporate unemployment rates at the national and county level, finding that unemployment at the national level was negatively associated with leaving home for non-marriage reasons, for both men and women. Whittington and Peters (1996) also find that the child's predicted wage is positively associated with probability of leaving home. There is also international literature on this subject. Jacob (2008) surveys this topic, and also finds that in two West German youth cohorts, born in 1964 and 1971, unemployment as an adolescent was positively associated with likelihood of moving out for

${ }^{7}$ In addition to some possible downsides of diminishing teenage employment, there are also some possible upsides. For instance, academic literature explores the relationship between working and delinquent behavior, including smoking and committing crime. In general, most researchers conclude that working intensively is causally associated with these behaviors. The literature on this suffers from some of the same problems with identifying causality as the literature on the relationship between work and later employment outcomes. Paternoster (2003) reads the literature and analyses NLSY97, concluding from both that the case for the causal relationship between intensive work and these behaviors is weak. I don't further explore this literature because the two possible conclusions from it are "teenage employment does not cause these negative effects" and "teenage employment does cause these negative effects." Regardless, it does not bolster the case that teenage employment is positive and we should be concerned about its decline. 
young adults with partners and a lower likelihood for young adults without partners, compared to their peers with jobs.

And indeed, we do see via CPS data that there was an decrease in the proportion of teenagers living on their own from 2000 to 2013, as shown in the red line on Figure 1.2. I define respondents as "living on their own" if they are the head of their household, have a housemate or roommate, live with a spouse or unmarried partner, live with their children, or live with other non-relatives. This is in contrast to those living with relatives: parents, grandparents, siblings, foster parents, and other relatives. The proportion of teenagers living on their own declined from $11 \%$ to $8 \%$ from 2000 to 2013 . However, both employed teenagers and non-employed teenagers were less likely to live on their own in 2013 than in 2000, so much of the decline appears to be due not to lower teenage employment but to other issues.

Figure 1.2: Proportion of Teenagers Living on Their Own, 2000-2013

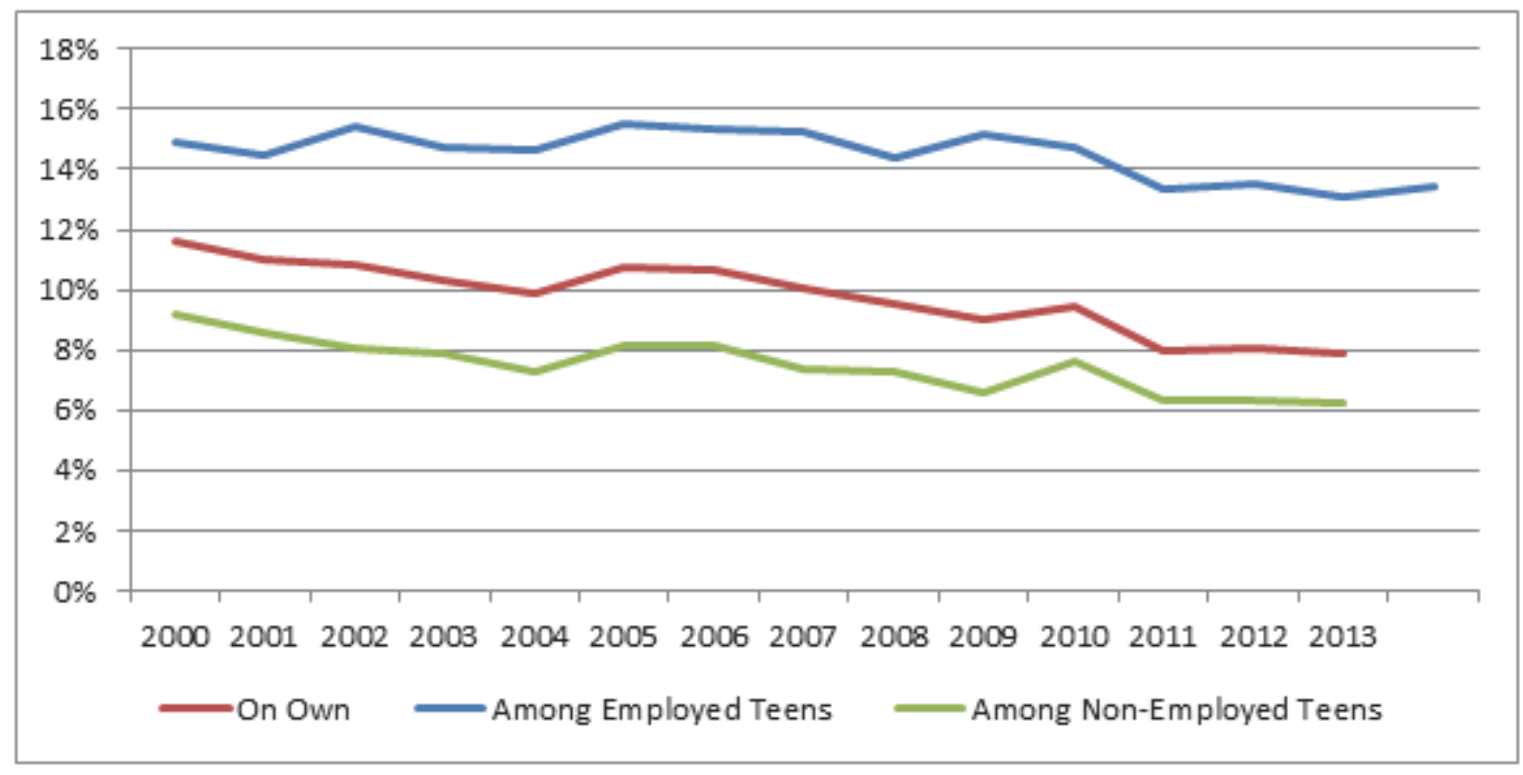

CPS, 2000-2013

\section{Overall Family Incomes}

With teenagers working less, they are naturally earning less as a proportion of family income. However, teenagers rarely earn a significant portion of household income, and it appears that additional teenage incomes mainly increase teenage expenses rather than family expenses more broadly. The literature on what teenage incomes go to is limited to one paper (Johnson and Lino, 2000) which uses the Consumer Expenditure Survey to document teenage contributions to household expenditures. In "Teenagers: employment and contributions to family spending" (Johnson, D. S., \& Lino, M., 2000) researchers compare households with working teenagers to 
similar households without working teenagers and conclude that working teenagers who live with a parent or parents are largely spending earned income on their own expenses in a way that increases the amount of household money spent on entertainment, teenage clothing, and food away from home, as opposed to crowding out money that would otherwise come from their parents. Teenage income generally does not increase household expenses on food at home, housing expenses, or other economic necessities. This is generally true for both low-income and non-low-income families.

Additionally, CPS data shows that most income-earning teenagers earn only a small proportion of income in their household, limiting the degree to which teenage contributions to household expenses could have declined from 2000 to 2013, even if teenagers do contribute to household expenses. As shown in Figure 1.3, in 2000, less than a quarter of teenagers reported earnings of at least $10 \%$ of their household income ${ }^{8}$ and less than $10 \%$ reported earning a quarter or more 9 .

Figure 1.3: Proportion of Teenagers Earning At Least 5\%, 10\%, 20\%, and 50\% of Total Household Income

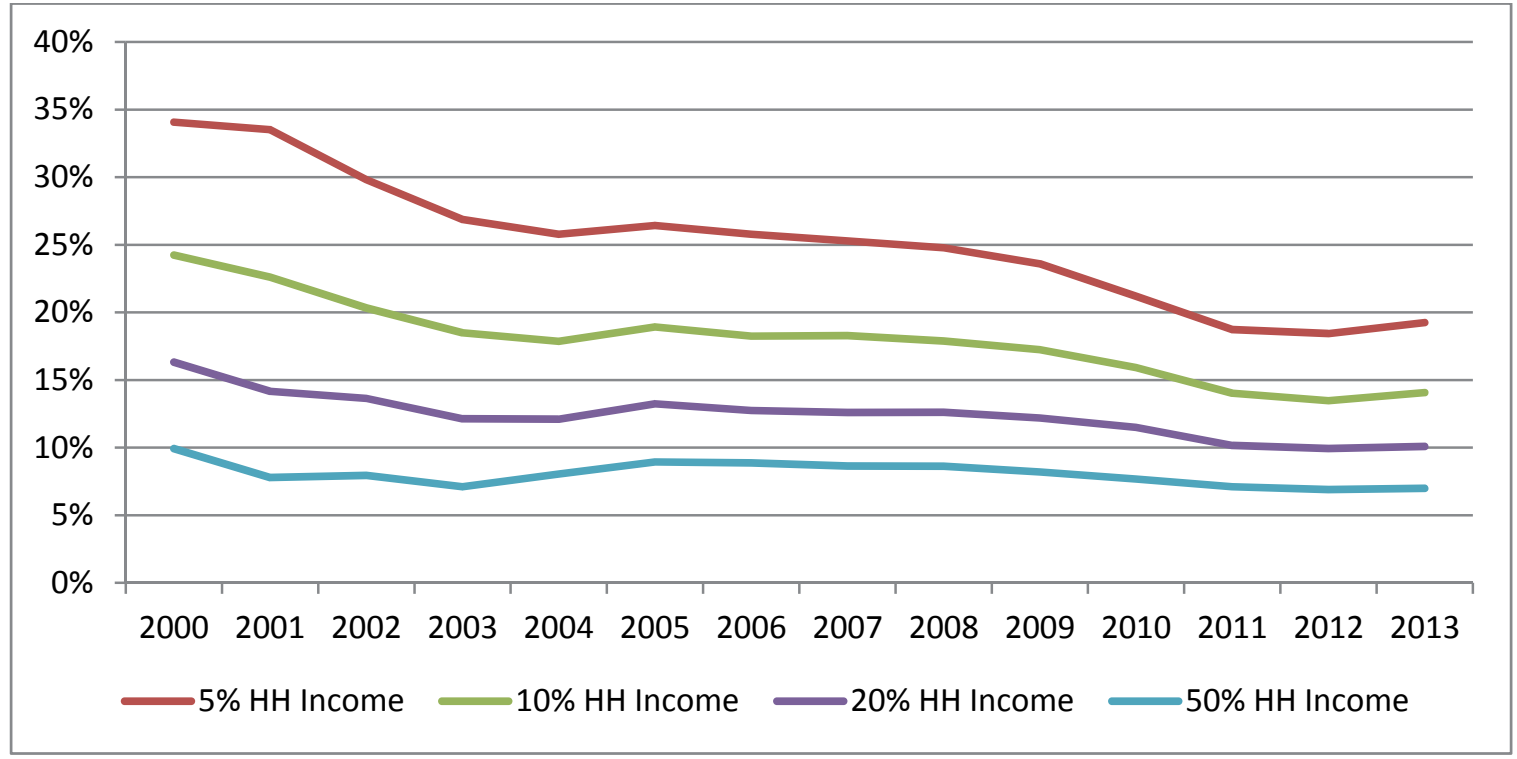

CPS, 2000-2013

${ }^{8}$ For this analysis, I looked only at households in which total income was greater than or equal to income earned by the teenager. It's unclear how to handle households with negative income or in which teenager income is higher than total income. This includes teenagers who did not earn any income. However, these make up a small proportion of overall households.

${ }^{9}$ See Appendix A for more on variable construction. 
Therefore, overall decline in teenage employment is much larger than the decline in contributions to family expenses since a) teenagers generally contribute little to family expenses and b) their earnings are relatively insignificant compared to overall family income.

\section{Conclusion}

Teenage employment declined significantly from 2000 to 2013, declining even as adult employment increased. The effects of this are ambiguous: it is plausible but unproven that working as a teenager improves future employment prospects. Additionally, it is likely that reductions in employment have had small negative effects on household formation by teenagers. However, the effects of lower teenage employment on contribution to household expenses are likely low, both because teenagers rarely earn significant proportions of household income and because what they do earn tends to raise expenses on entertainment and teenage clothing rather than on necessary household expenditure categories. In general, this argues for lower overall teenage employment not necessarily being negative. 


\section{Chapter 2: Modeling Teenage Employment}

This chapter will set up a theoretical model for employment among teenagers, introduce five possible explanations for the drop in teenage employment and place them into this model, and discuss what types of evidence would bolster each of these hypotheses. These potential explanations are: teenagers decreasing their supply of labor due to higher wage income returns to education; more competition for teenage jobs from adults without high school degrees; more competition for teenage jobs from adult immigrants; either declining demand for labor in general or more competition from adults in general; and minimum wages increasingly leading to a bigger gap between the number of teenagers who are willing to work at the prevailing wage and the number of teenagers who businesses wish to employ. In this chapter, I describe what evidence each of these hypotheses predict; in future chapters, I evaluate to what extent reality matches the predictions made by each of these hypotheses.

There are several points the reader should keep in mind regarding this methodology. First, these hypotheses are not comprehensive. They've been selected both because they all have some initial plausibility and because, with my data and methods, I can bring some additional evidence to bear on them. Second, other types of evidence already exist for or against these various hypotheses. For instance, the minimum wage literature include studies in which researchers have done in-depth local examinations of employment trends in areas either experiencing minimum wage increases or adjacent to those areas. Those methods are beyond the scope of this study: what evidence I do discuss should be read in the context of already-existing evidence. Finally, while some pieces of evidence only relate to one hypotheses, others support (or refute) multiple hypotheses. For instance, evidence regarding teenage wages will tend to support or refute all of the demand-related hypotheses at once, since they all predict lower teenage wages ${ }^{10}$.

\section{Teenage Labor Market Model}

This section will develop the general model for teenage labor market; later sections involve changes to the parameters described. This model is characterized by the following:

- Two periods. In the first period, individuals are teenagers.

- Individuals are optimizing utility, which is a function of the sum of income in both periods and leisure time in the first period.

Individuals choose both how much to work and whether to go to school in the first period.

\footnotetext{
${ }^{10}$ If there are both supply factors at work in addition to demand-side ones, we might see higher rather than lower wages. Nonetheless, lower wages present evidence in favor of the demand-side hypotheses, whereas higher wages present evidence against it.
} 
- Both going to school and working in the first period take time away from leisure.

- Individuals who attend school in the first period may or may be able to complete it. In either case, school consumes the same amount of time.

- In the second period, everyone works.

- There is a common wage rate available in the first period.

- In the second period, amount earned is dependent on whether the individual completed school.

The following equations describe this model:

(1) $\max u^{i}$ (Leisure, Income) wrt Work $_{1}^{\mathrm{i}}$, School $^{\mathrm{i}}$

s.t.

(2) Leisure ${ }_{1}^{\mathrm{i}}=24-$ Work $^{\mathrm{i}}-\mathrm{T}^{*}$ School $^{\mathrm{i}}$

(3) Income $^{i}=$ Wage $_{1}\left(24-\right.$ Leisure $_{1-}{ }_{1} T^{*}$ School $\left.{ }^{i}\right)+$ Base Income $+P^{i}($ School Income Premium * Schooli)

$\mathrm{P}^{\mathrm{i}}$ is the individual's probability of finishing school, contingent on attending school School is a binary variable representing whether the individual attends school

$\mathrm{T}$ is some constant representing how much time it takes to complete school

Below, I represent visually the initial decision about how much leisure to consume and whether to go to school, both for an individual who chooses to attend school and one who doesn't. Figure 2.1 represents possible choices for an individual who will decide to go to school. The Income (School) line represents the income/leisure pairs the individual has available if she attends school. The Income (No School) line represents the income/leisure pairs she will have available if she does not attend school. Indifference curves are represented by $\mathbf{U} \mathbf{1}$ and $\mathbf{U} \mathbf{2}$, with indifference curves further out from the origin representing the individual being better-off. In this scenario, the individual can reach a higher indifference curve by going to school in the first period, with her optimal point represented by the green dot. The purple dot represents the best outcome she could have reached if she had decided not to go to school. The individual can consume more leisure and have more income by going to school. Because the first period wage rate does not vary depending on whether the individual is attending school, the slopes of both lines representing income are the same: going to school, in this model, just shifts the income curve up or down. 
Figure 2.1: Representation of Initial Problem: School-Goer

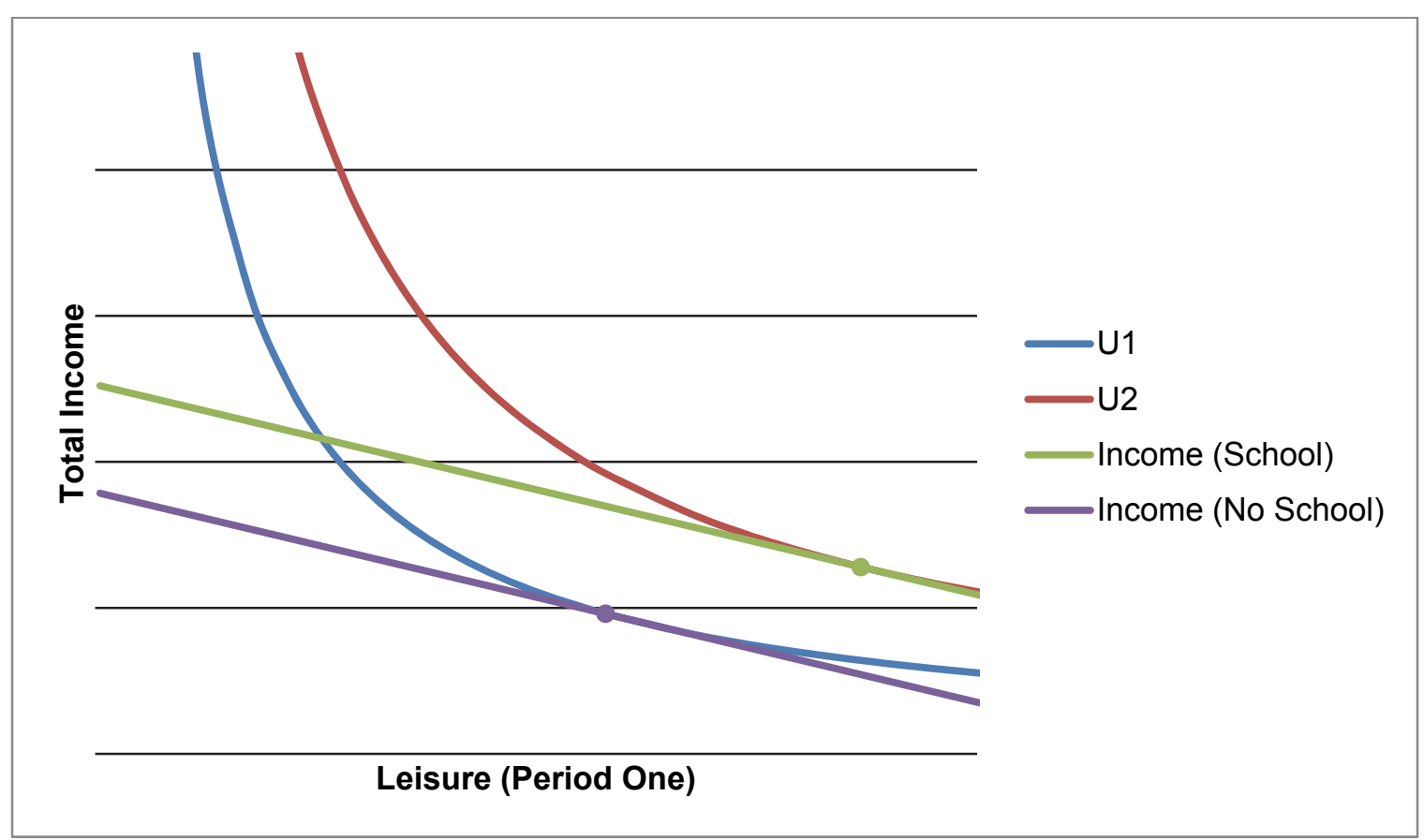

Figure 2.2 represents the same decision framework, but for someone whose chances of graduating from school are much lower, such that she chooses to forgo school in the first period. As shown, the wage rate and income associated with not going to school are the same, but the income associated with going to school is much lower because this individual is less likely to graduate than the person shown in Figure 2.1. Because her probability of graduating is low and attending school takes time that could otherwise be spent working or consumed as leisure, this individual can attain a higher indifference curve by not attending school. The choice that this individual makes is shown by the purple point. This individual enjoys less leisure and less total income than the individual from Figure 2.1. This model predicts that the individual in Figure 2.2 - that is, someone who isn't going to school - will work more than the individual who is. 
Figure 2.2: Representation of Initial Problem: Non School-Goer

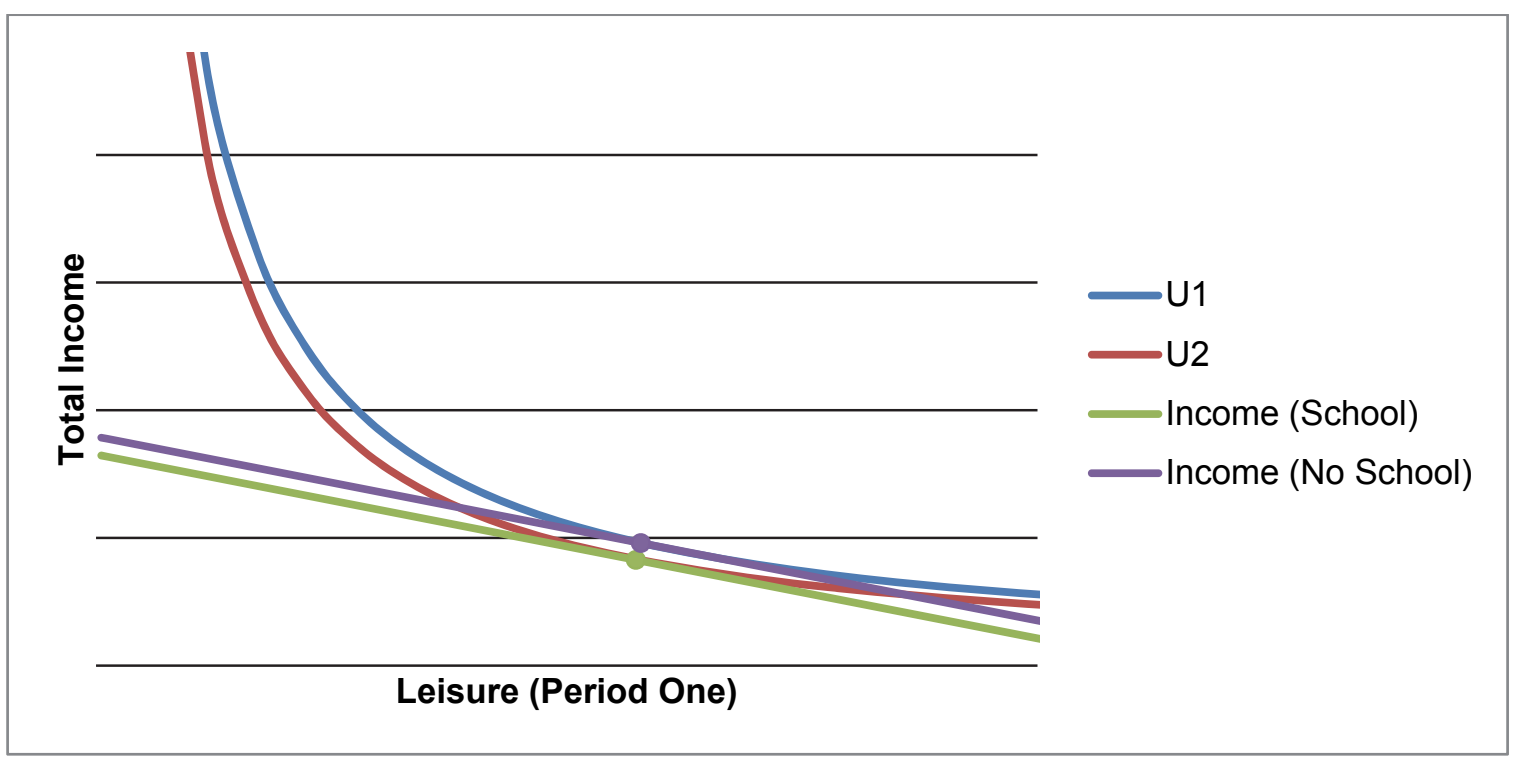

The following sections describe each of my hypotheses for reduced teenage employment, discussed in terms of what changes they represent to this model.

\section{Supply: Increased Returns to Education}

This hypothesis predicts that higher returns to education will reduce the supply of teenage labor. Using the model developed in the previous section, I conceptualize increased returns to education as consisting of an increase in the School Income Premium.

There are three possible scenarios which I'll explore here for how these changes would be expected to affect different individuals. In the first scenario, an individual who would previously have gone to school still goes to school, but also enjoys more leisure in the first period and more total income. In the second, an individual who previously would not have gone to school in the initial scenario is shifted toward going to school. This person may or may not enjoy more leisure or more income than previously, depending on the magnitude of the income changes as well as how time-consuming it is to go to school. In the third, an individual who previously would not have gone to school still does not go to school, and enjoys less leisure and income than they would have if the change in returns to education had not happened.

As shown in Figure 2.3, the individual who is already going to school, as was represented in Figure 2.1, will respond to a higher endowment in the form of higher future wages through enjoying some combination of more leisure and more income. While not directly shown, it is implicit that the individual is working less, since they are consuming more leisure and their school status has not changed. The heavier green line represents the new state of trade-offs 
between leisure and income, contingent on attending school. The lower green dot represents the initial income and amount of leisure, with the higher dot representing the new one.

Figure 2.3: Effect of Increased Returns to Education on School-Goer

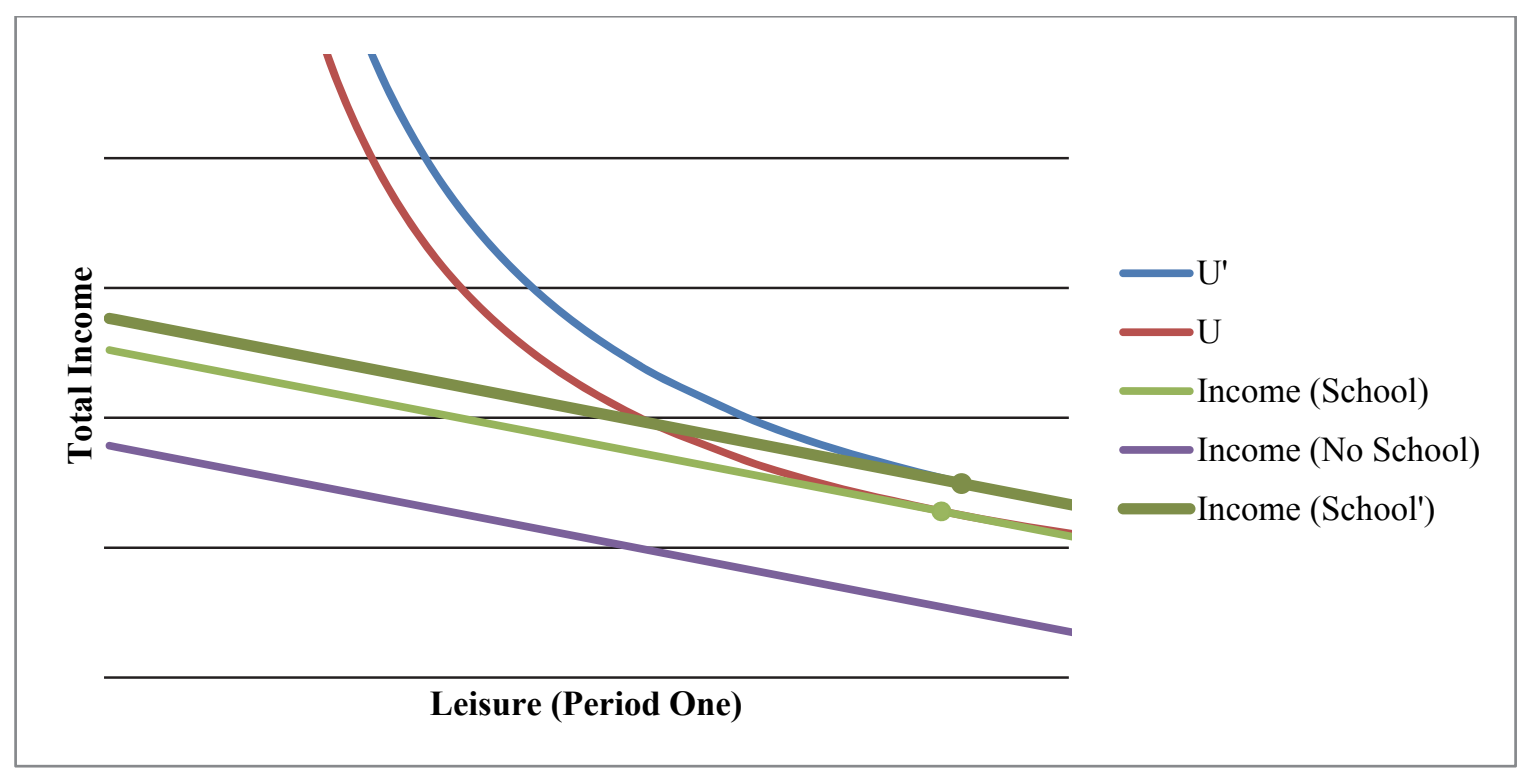

As shown in Figure 2.4, an individual who was not previously going to school, as was shown in Figure 2.2, might change their behavior toward going to school in response to the increased return to school. While not directly shown, it is implicit that the individual is working less, since they are consuming more leisure in addition to now attending school. In Figure 2.4, the heavier green line represents the new line after the change in second-period incomes. The purple dot represents the initial income and amount of leisure, with the higher green dot representing the new amounts. 
Figure 2.4: Effect of Increased Returns to Education: Shifting the Non-School-goer to School

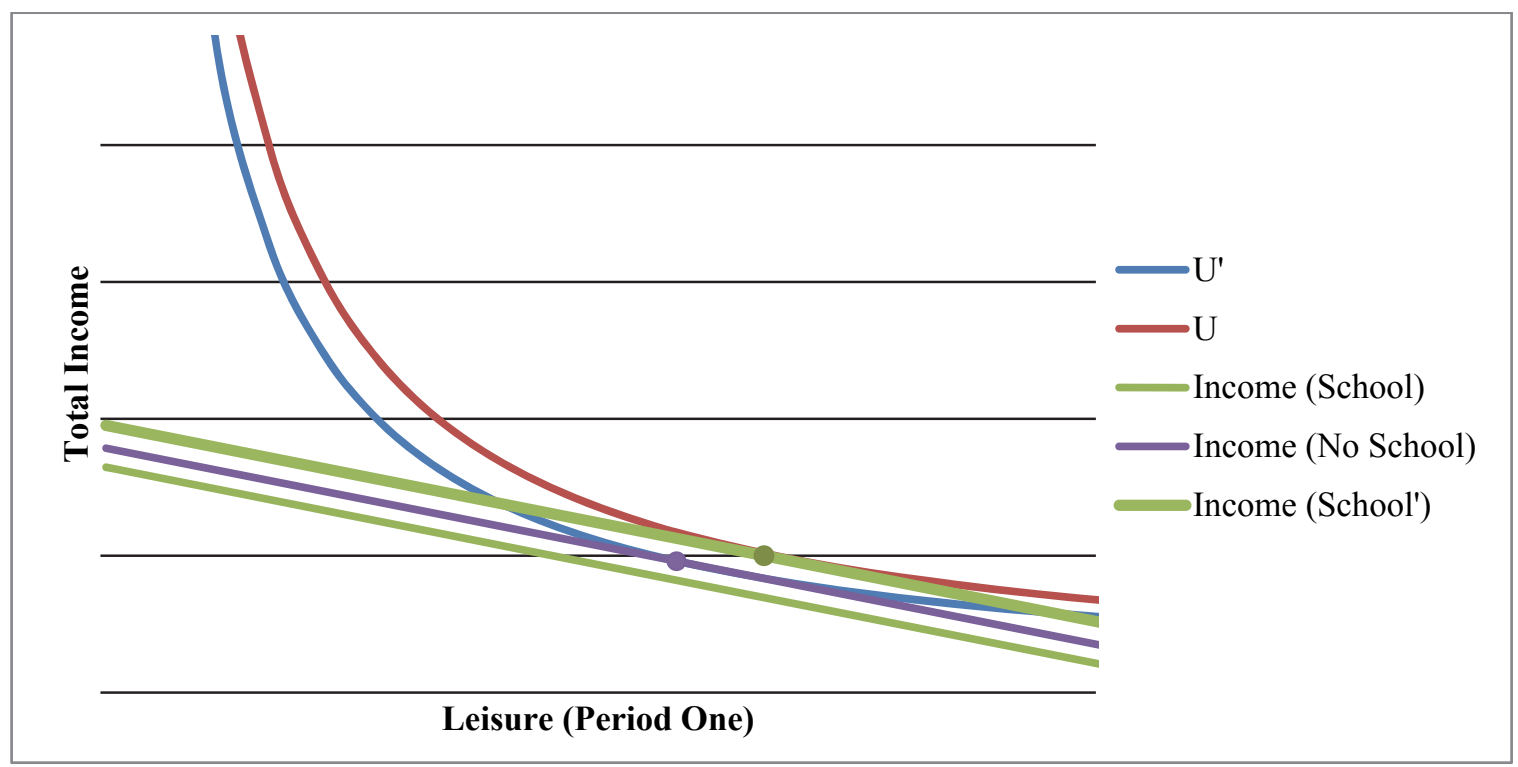

One other possibility for the non-school-goer of Figure 2.2 is that the change in relative income in the second period will not be enough to get her to go to school, in which case she will work more and consume less leisure in the first period, as shown in Figure 2.5. The heavy green line represents the new set of possibilities in terms of income vs. wages after the change in second-period incomes. Because this non-school-goers chances of graduating from school are still quite low, not going to school, as shown in the purple line, still represents a more favorable outcome than the new, heavier green line representing the new set of income vs. leisure tradeoffs associated with attending school. The upper purple dot represents the initial income and amount of leisure both under the initial set of circumstances and after the increase in returns to schooling. 
Figure 2.5: Effect of Increased Returns to Education: the Non-School-goer

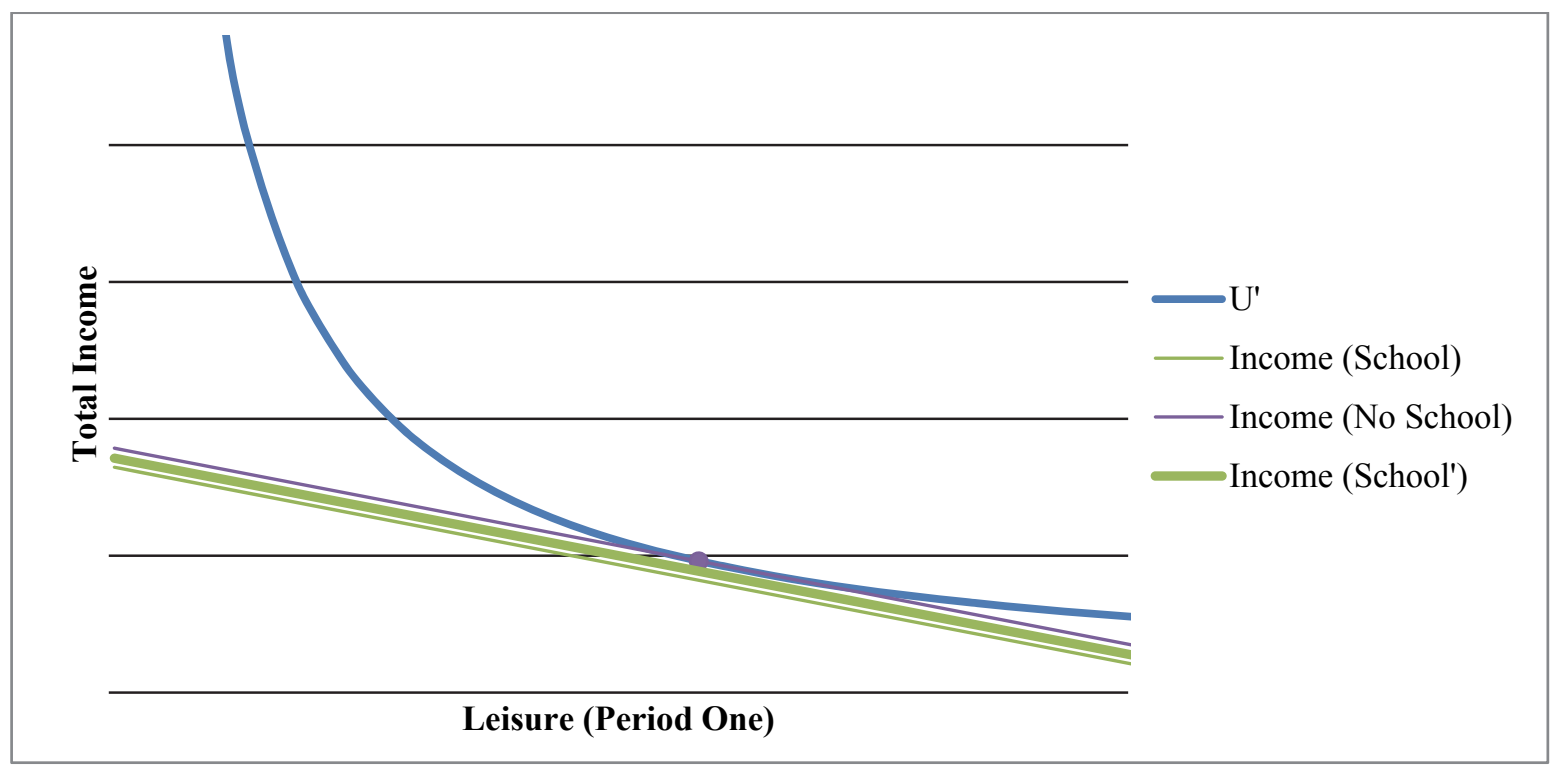

Evidence that Would Support This Hypothesis

If this theory has explanatory value for the decrease in teenage employment, we should expect to see various types of evidence.

Schooling, Teenage Employment by Educational Status (Chapter Three)

- Increase in school attendance among teenagers

- Increase in time spent on academic activities among teenagers

- Increase in proportion of high school students who plan to continue their education

- Decrease in employment confined to teenage non-students (that is, decrease in employment among students and increase among non-students)

Teenage Jobs (Chapter Four)

- A decrease in the number of teenage-type jobs ${ }^{11}$, as teenagers supply less total labor Teenage Labor Market Issues (Chapter Five)

- Increase in the wage rate (hourly wage) earned by teenagers, as teenagers supply less total labor

11 Teenage-type jobs, as discussed in more detail in Chapter Four, are jobs that teenagers were significantly overrepresented in in 2000, relative to their overall proportion among workers. In Chapter Four, I examine whether these types of jobs grew from 2000 to 2013, both in absolute numbers and relative to job and population growth. 
Statistical Model (Chapter Six)

- Decrease in teenage employment explained by increasing wage stratification by education

- Decrease in teenage employment explained by increases in the proportion of teenagers in school or increases in the association between being in school and not working

\section{Demand Shifts}

There are three demand-related hypotheses that I evaluate in this report, all of which all having to do with lower demand for particular groups of adults (20-65 years old) shifting them into competing for jobs that previously would have gone to teenagers. These three groups are immigrants, less-skilled workers (people without a high school diploma), and adults in general. Using the model developed in the first section of the chapter, I conceptualize decreased demand for teenagers as a downward shift in demand for teenagers, resulting in both a reduction in teenage employment, a reduction in the teenage wage rate, an increase in the total number of teenage-type jobs. This is because in addition to the same supply of teenagers, there are now more adults competing in these labor markets), and an increase in the proportion of these jobs worked by adults (for the same reason). There are three possible scenarios which I'll explore here for how these changes would be expected to affect different individuals. In the first scenario, an individual who would previously have gone to school still goes to school, but also works less and has less income and more leisure. In the second scenario, an individual who would not have gone to school now goes to school, works less, and has less income: the effect on leisure is ambiguous, since she is working less, but going to school consumes some amount of leisure time. In the third scenario, an individual who wouldn't have gone to school still doesn't go to school, but works less and has more leisure and less income.

In each of these scenarios, the assumption, although I do not formally model this, is that poor labor market conditions push adults into competing for lower-skill jobs they previously would not have done - jobs like cashier, which are heavily done by teenagers. Smith argues that increased immigration is a major explanation for decreased employment among 16- and 17-yearolds in the period from 1980-2007. Autor (2006) describes the polarization of the U.S. labor market, with middle-wage jobs disappearing at the expense of both high- and low-wage jobs.

In some ways, a reduction in demand for teenage labor presents similarly as in the supplyshift scenarios. In both cases, more individuals go to school in the first period. However, there are also some key differences. First, in the demand shifts, because wage goes down, fewer teenagers from both groups - in and out of school - choose to work. (Whereas in the supply shift scenario, because I've conceptualized the cause as a changes in endowment effect such that people who are students in the first period have higher future income and those who are not have lower future income, only those in school are less likely to work. Second, in the demand 
scenario, because demand for teenagers has gone down, the wages teenagers earn also go down. This is in contrast to the supply scenario, where teenagers reduce their supply of labor, leading to an increase in the wages working teenagers earn. Additionally, there are some differences in the expected labor market outcomes of the various groups of adults involved in these hypotheses: these are described in more detail in this section.

As shown in Figure 2.6, the individual who is already going to school, as was represented in Figure 2.1, will respond to a lower wage rate by working less and consuming more leisure in the first period, as well as having less total income. The heavier lines represent the new state after the change in second-period incomes. The lower green dot represents the initial income and amount of leisure, with the higher dot representing the new one.

Figure 2.6: Effect of Reduced Teenage Wages: the School-goer

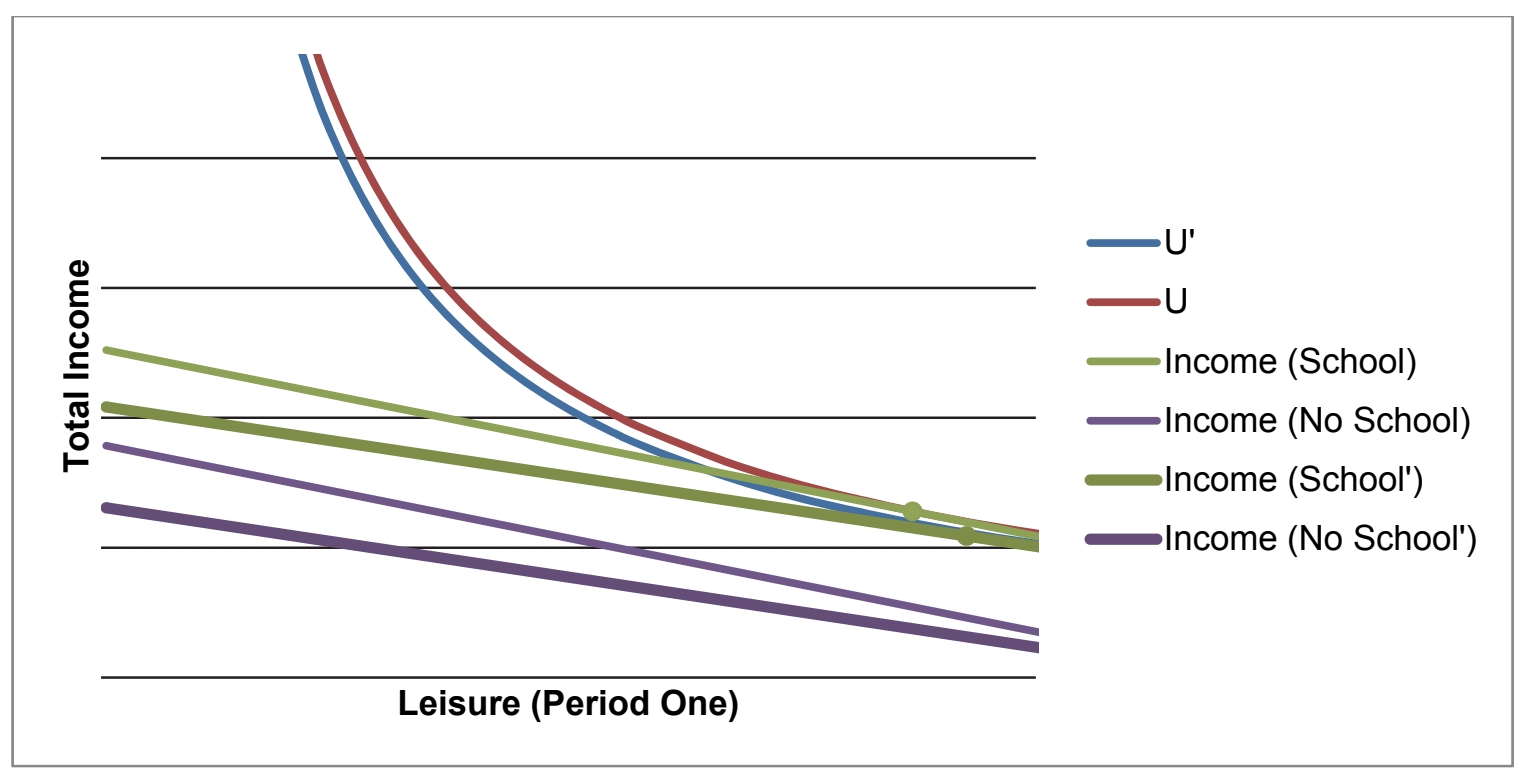

Another possible scenario that follows from this model is that, as shown in Figure 2.7, the initial non-school-goer may respond to a reduction in teenage wages by going to school. This individual responds to a lower wage rate by working less, consuming less leisure, and having less income - but also going to school. The heavier lines represent the new state after the change in second-period incomes. The higher green dot represents the initial income and amount of leisure, with the lower green dot representing the new one. 
Figure 2.7: Effect of Reduced Teenage Wages: Shifting the Non-School-goer to School

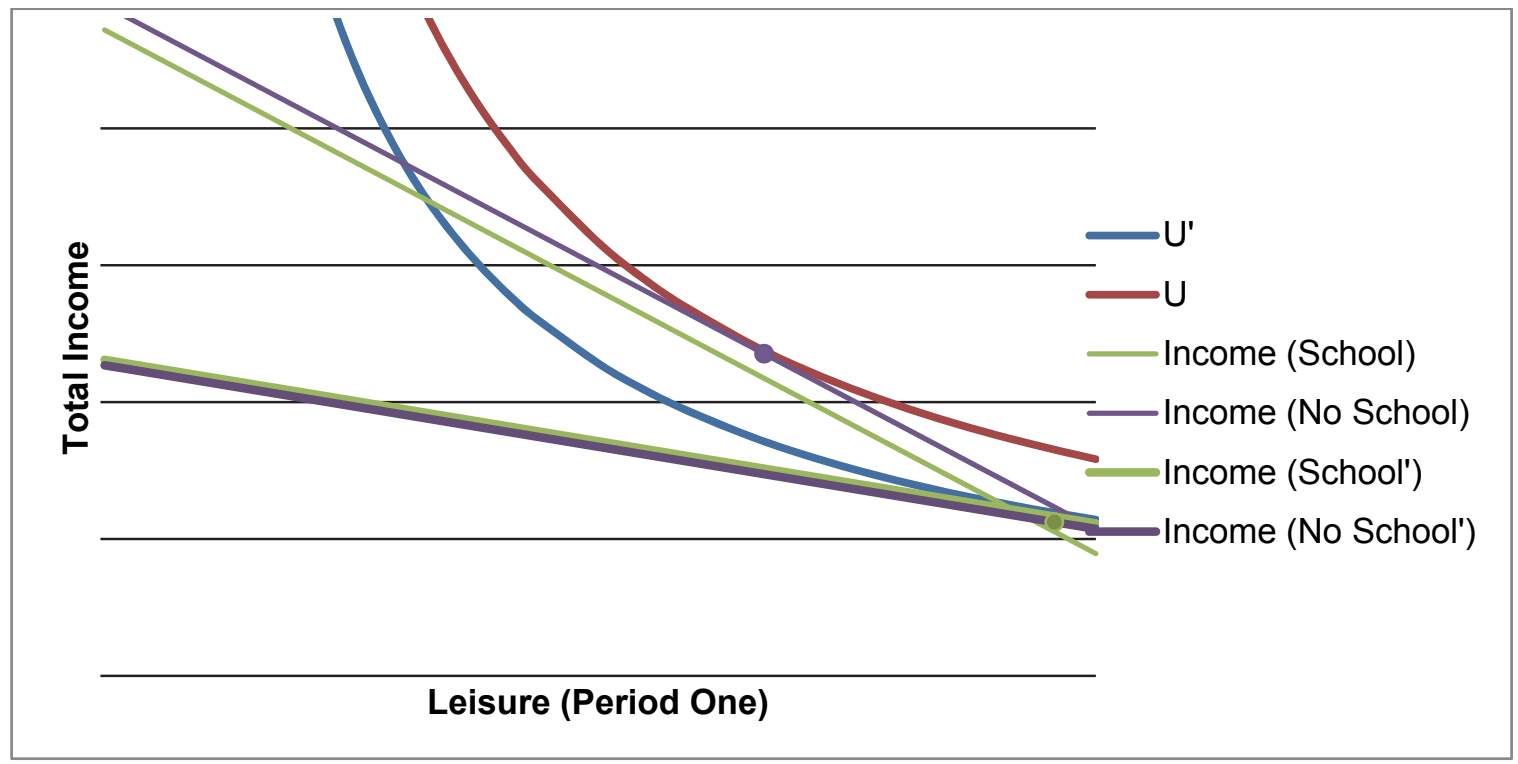

The final scenario that follows from this model is that, as shown in Figure 2.8, the initial nonschool-goer may respond to a reduction in teenage wages by continuing to not go to school. This individual responds to a lower wage rate by working less, consuming less leisure, and having less income. The heavier lines represent the new state after the change in second-period incomes. The higher purple green dot represents the initial income and amount of leisure, with the lower purple dot representing the new one.

Figure 2.8 Effect of Reduced Teenage Wages: the Non-School-goer

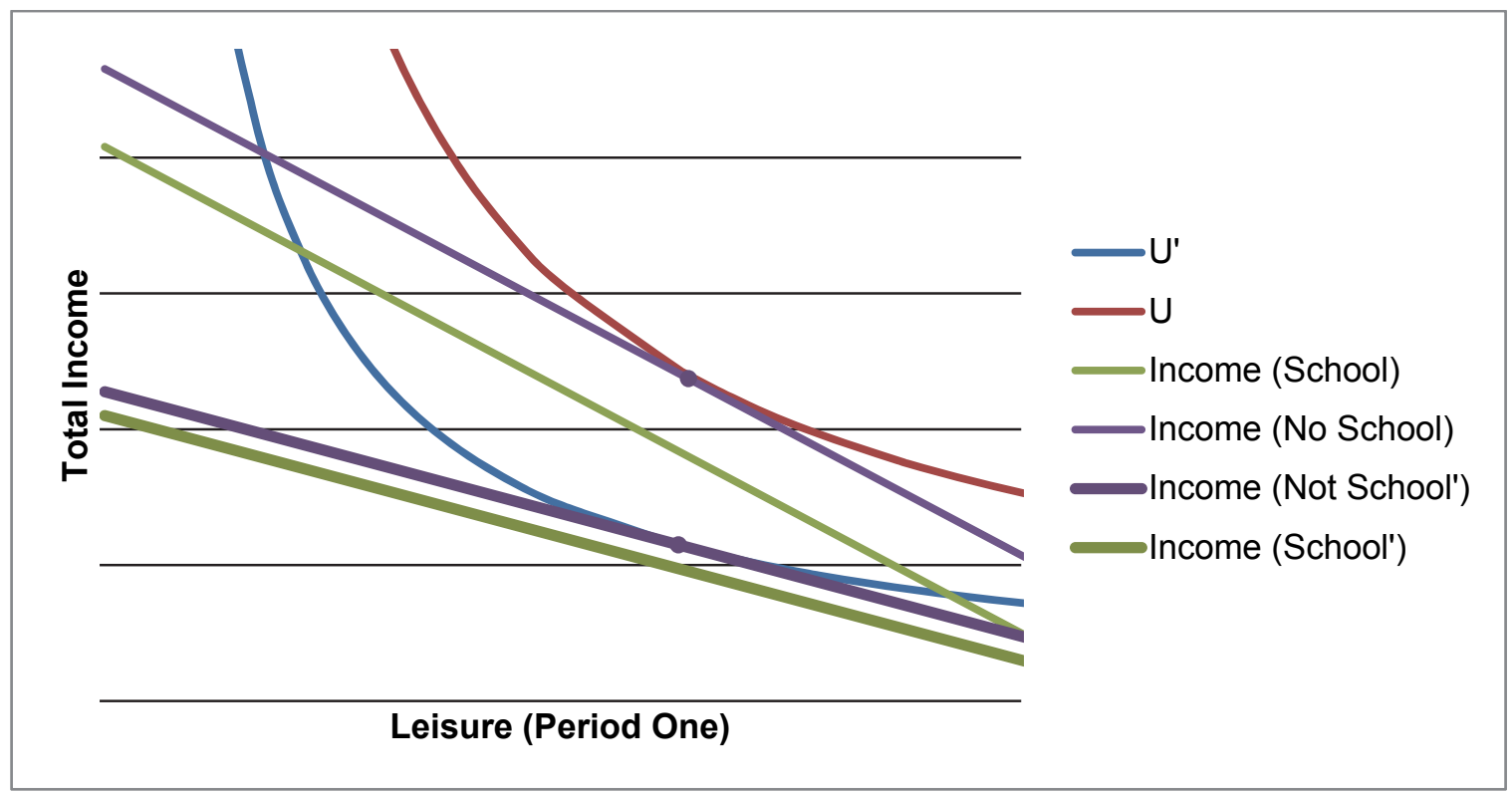




\section{Evidence that Would Support This Hypothesis}

If these theories have explanatory value for the decrease in teenage employment, this is what we would expect to see.

Schooling, Teenage Employment by Educational Status (Chapter Three)

- Increase in school attendance among teenagers

- Increase in time spent on academic activities among teenagers. This is another way of looking at whether teenagers are actually spending more time on school, as opposed to shifting their time spent - for instance, to less time during the school year and more time during the summer.

- Increase in proportion of high school students who plan to continue their education

- Decrease in employment in both teenagers who are in school and those not in school

Teenage Jobs (Chapter Four)

- An increase in the number of teenage-type jobs, because teenagers not reduced their supply, but adults are now increasingly competing in these teenage-type labor markets

- An increase in the proportion of teenage-type jobs being done by adult high school dropouts (demand: unskilled labor hypothesis)

- An increase in the proportion of teenage jobs being done by adult immigrants (demand: immigrants hypothesis)

Teenage Labor Market Issues (Chapter Five)

- Decrease in teenage wage rate

Statistical Model (Chapter Six)

- Decrease in teenage employment explained by increasing proportion of adult immigrants and/or increases in the association between adult immigrants and teenagers not working (demand: immigrants hypothesis)

- Decrease in teenage employment explained by increasing proportion of adult high school dropouts and/or increases in the association between adult high school dropouts and teenagers not working (demand: unskilled workers hypothesis)

- Decrease in teenage employment explained by adult employment and/or increases in the degree to which adult unemployment is associated with not working among teenagers (demand: adult workers in general) 


\section{Price Floor}

A final possible mechanism by which teenage employment could decrease is a price floor in the form of a minimum wage that is higher than the wage rate that would otherwise prevail. This leads to a lower quantity of workers employed and a higher wage rate. In the initial model, I conceptualize this as a higher wage rate for some combined with no available jobs for others (or, a zero wage rate). The previous section on demand shifts covers the effect of changes in wage rate: because a price floor is a lower wage rate (zero) for some and a higher wage rate for others, we can't say from this model regarding the overall effect on schooling. However, this hypothesis predicts that overall fewer teenagers will be working.

\section{Evidence That Would Support This Hypothesis}

Schooling, Teenage Employment by Educational Status (Chapter Three)

- Decrease in employment in both teenagers who are in school and those not in school

Teenage Jobs (Chapter Four)

- A decrease in the number of teenage-type jobs

Teenage Labor Market Issues (Chapter Five)

- Employment reduction is a function of teenagers reporting they want to work but cannot find employment

- No reduction in how much teenagers or their parents report they want to work

- Increase in teenage wage rate

- Increased clustering around the minimum wage

Statistical Model (Chapter Six)

- Decrease in teenage employment explained by increases in minimum wage and/or increases in the degree to which minimum wages are associated with not working among teenagers

\section{General Notes on Evidence}

Table 2.1 describes possible classifications for how evidence relates to hypotheses. I use four classifications for how evidence relates to hypotheses. Each of these is represented by a color. In the next four chapters, I will discuss each piece of evidence and why I picked the classification. At the end of each chapter will be a color-coded chart summarizing these findings. These hypotheses are not mutually exclusive: it is possible that multiple hypotheses may have some explanatory value, in which case we would expect to see a mix of supportive and contradictory evidence for multiple hypotheses. 
Additionally, while evidence is only useful if it allows us to distinguish between hypotheses, it doesn't necessarily need to allow us to distinguish between all hypotheses. For instance, most of the evidence discussed in Chapter Five on teenage labor markets only relates to the minimum wage hypothesis, because this hypothesis is the only one to make predictions about teenagers wanting to work who cannot find jobs, or more generally about actual employment outcomes going in a different direction than attitudes toward employment. This evidence is useful. On the other hand, all of the hypotheses predict that employment will decline among teenagers in school. Therefore, evaluating whether employment has declined among students does not let us distinguish between these hypotheses ${ }^{12}$.

Throughout this paper, I also use the terminology of evidence supporting, contradicting, or being consistent with a hypothesis. Evidence supports a hypothesis if it should cause us to update our views on the explanatory power of that hypothesis upward, even minimally. As discussed, that there is evidence supporting a hypothesis does not mean the hypothesis is correct: there could be multiple possible explanations for that evidence. But that we see this evidence makes it more likely that the hypothesis is correct. Evidence supporting a hypothesis is coded green in the end-of-chapter figures. Evidence contracting a hypothesis is the opposite: evidence which should cause us to re-evaluate the hypothesis in a downward direction. This is coded red. Evidence that is consistent with a hypothesis is the most complicated: this is evidence that does not cause us to reevaluate a hypothesis. This could be because it consists of multiple effects which push in different directions, or because it consists of an effect which is not statistically significant, in which case it is coded as yellow. Alternatively, this could be because it is unrelated to the hypothesis, in which case it is coded as gray.

Table 2.1: Evidence Classifications

\begin{tabular}{|c|l|}
\hline Color & Meaning \\
\hline Green & $\begin{array}{l}\text { The evidence shows an effect that is statistically significant and goes in the direction predicted by } \\
\text { the hypothesis. }\end{array}$ \\
\hline Yellow & $\begin{array}{l}\text { This evidence either shows multiple statistically significant effects going in different directions or no } \\
\text { statistically significant effects. }\end{array}$ \\
\hline Red & $\begin{array}{l}\text { The evidence shows an effect that is statistically significant and goes in opposite of the direction } \\
\text { predicted by the hypothesis. }\end{array}$ \\
\hline Gray & \begin{tabular}{l} 
This hypothesis makes no predictions regarding this evidence. \\
\hline
\end{tabular} \\
\hline
\end{tabular}

Finally, to the extent that there are regional differences in drivers of lower employment, this methodology will not be able to distinguish those. For instance, if supply factors are driving lower employment in one area of the country and demand factors driving lower employment in

${ }^{12}$ As a note, however, employment has declined among students. 
another area of the country, this will appear similarly to if there were no regional differences, but rather supply and demand factors active across the country. If a particular state were of interest, some of this analysis could be reproduced just for that state. However, it would be particularly difficult to evaluate the effect of the minimum wage, since there is no year-to-year variation in terms of the minimum wage within a state. Also, the statistical model in Chapter Six, which relies on variations across counties and states, would also be difficult to replicate.

\section{Defining Employment}

Across these chapters, our definition of employment captures a variety of different employment situations, but may not capture teenagers who work intermittently ${ }^{13}$. Survey respondents are classified as employed if they are active duty members of the armed forces, hold paid jobs in the civilian workforce and are working this week, or work for at least fifteen hours in a family business or farm. They are also classified as employed if they have jobs they're not currently working due to reasons like illness or vacation. Someone who has an unpaid internship in a non-family business would not count as employed. The question text specifically asks whether the respondent did any work for pay or profit in the previous week. Therefore, someone who babysat or mowed lawns in the last week should report employment, but someone who does that periodically but did not in the past week should report that they were not employed. About $10 \%$ of employed teenagers reported typically working eight hours a week or less, so it's apparent that some teenagers who work very few hours are identifying as employed.

\section{Conclusion}

This chapter described the five hypotheses this report will evaluate: lower teenage supply due to increased returns to education; lower demand for teenage labor due to increased competition from immigrants, high-school dropouts, and adults in general; and an increasingly-binding minimum wage. The next three chapters will discuss various non-formal evidence for these hypotheses.

\footnotetext{
${ }^{13}$ Appendix A presents each of the variables used in this dissertation in more depth, including what data set was used and what variables it was derived from in that data set.
} 


\section{Chapter 3: Teenagers and Education}

This chapter will present evidence regarding changes to education among teenagers between 2000 and 2013 and relate them to the five hypotheses regarding decreases in teenage employment. The types of evidence this chapter will consider regarding teenage educational outcomes are as follows: school attendance, time spent on academic activities, plans for college attendance among high school students and their parents, and employment by educational status.

As discussed in Chapter Two, the hypotheses predict different outcomes regarding teenagers and education. The supply and demand-related hypotheses both predict increases in teenage schooling and associated issues, such as plans for college attendance and time spent on academic activities. The supply hypothesis predicts that employment among students will decline but employment among non-students will increase, whereas the demand and minimum wage hypotheses predict a drop in employment among both students and those not in school.

The evidence we find is mixed, with some support for each of the hypotheses. Regarding school status, the proportion of teenagers in school increased, which supports both the supplyand demand-related hypotheses. Additionally, more teenagers intend to go to college, which also supports these hypotheses. Our estimate of the average amount of time that teenagers spend on academic activities has increased, but this increase is not statistically significant and we find no general trend over time, so we categorize this evidence as ambiguous. Finally, drops in employment are significant both for students and for non-students. This contradicts the supply hypothesis and supports the demand-related hypotheses and the minimum wage hypothesis.

\section{School Attendance}

School attendance increased from 2000 to 2013, both during the school year and during the summer. The data for this is from the CPS, from March and July of 2000 and 2013. As shown in Figure 3.1, school attendance is up from March 2000 to March 2013 and July 2000 to July 2013. The proportion of teenagers not attending school fell from 20\% to $15 \%$ in March and $75 \%$ to $62 \%$ in July. 
Figure 3.1: Proportion of Teenagers Attending School, March and July 2000 and 2013

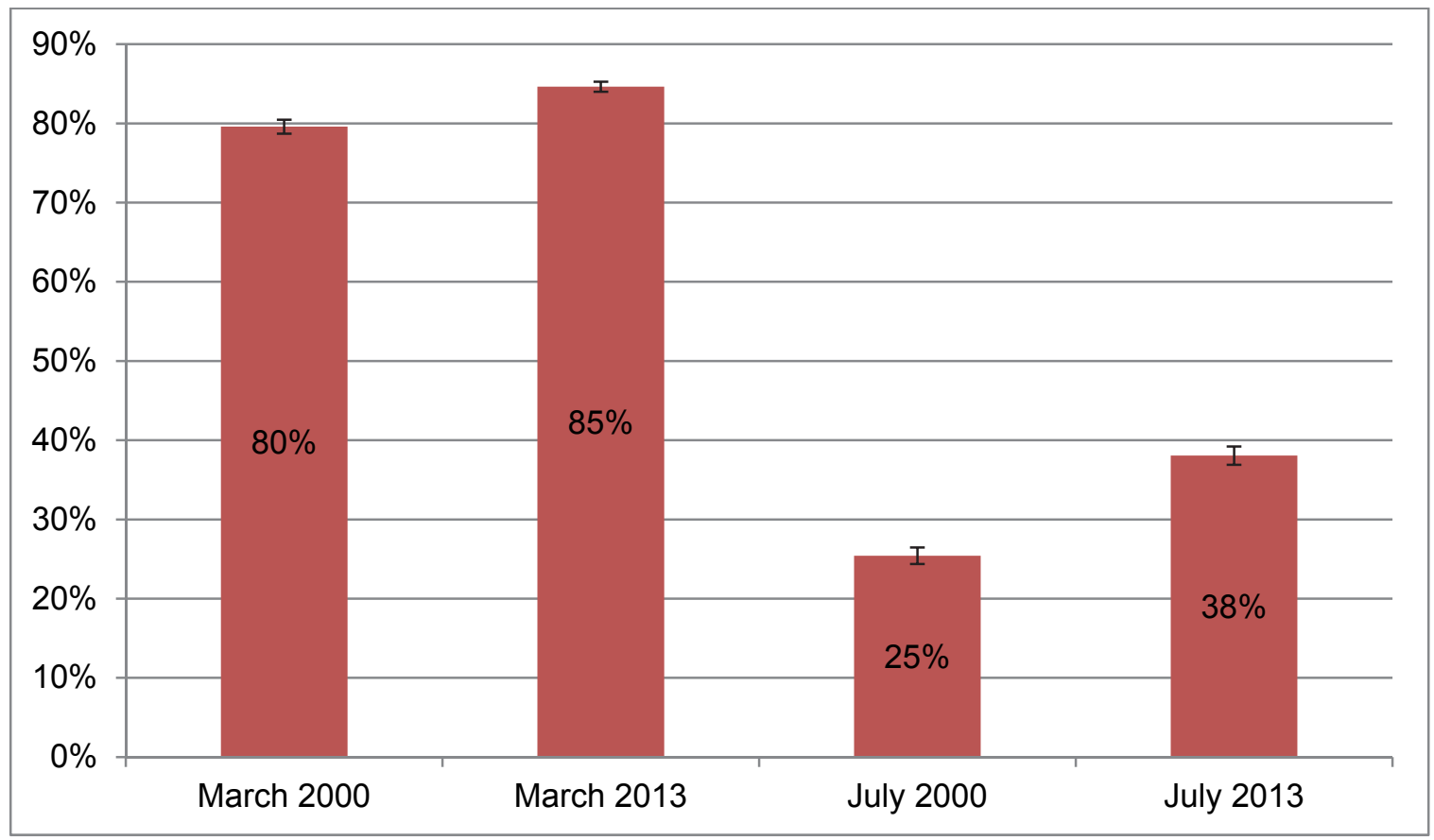

CPS, March and July, 2000 and 2013.

Error bars reflect $95 \%$ confidence intervals.

This evidence supports both the supply- and the demand-related hypotheses, which predict teenagers will be more likely to attend school. It is consistent with but does not support the minimum wage hypothesis, which made no predictions about school status.

\section{Educational Plans}

A higher proportion of twelfth grade students reported planning to go to college in 2013 than in 2000. In order to assess changes in attitudes and plans regarding higher education among teenagers, I use surveys of twelfth graders conducted as part of the University of Michigan's Monitoring the Future (MTF) project. Teenagers were asked "How likely is it that you will do each of the following things after high school?" The options included "Graduate from a two-year college program" and "Graduate from a four-year college program." There are also questions describing other educational and work options.

In Figure 3.2, I aggregate both of these two-year and four-year educational plans into one variable, classifying twelfth-grade students by their highest-category response to either the twoyear or four-year question. For instance, a student who responded that he "probably won't" attend two-year college but "probably will" attend four-year college is classified as reporting that he "probably will" attend either a two- or four-year college. 
The results show a small but statistically significant increase in students who report they "definitely will" attend some form of college, and small but insignificant declines in the other categories. Figure 3.3, which just shows responses to the four-year college question, shows similar results: statistically significant declines in the bottom two categories, combined with increases in the top two categories. (The increase in the top category is not statistically significant.) In total, these show a small increase in intent to go to college among high school seniors.

Figure 3.2: Likelihood of Attending Two- or Four-year College

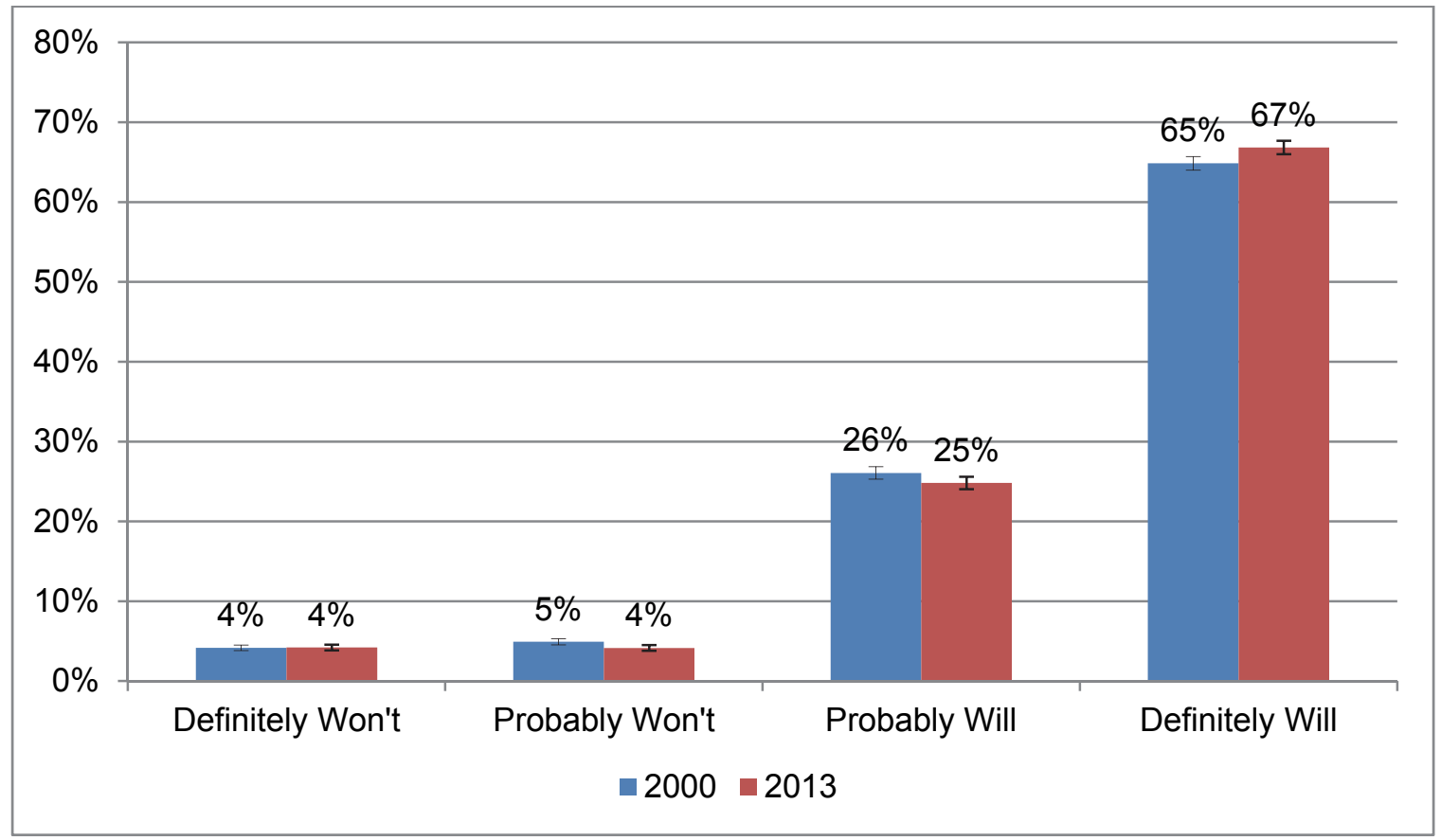

Monitoring the Future $12^{\text {th }}$-Grade Survey, 2000 and 2013

Error bars reflect $95 \%$ confidence intervals. 
Figure 3.3: Likelihood of Attending Four-year College

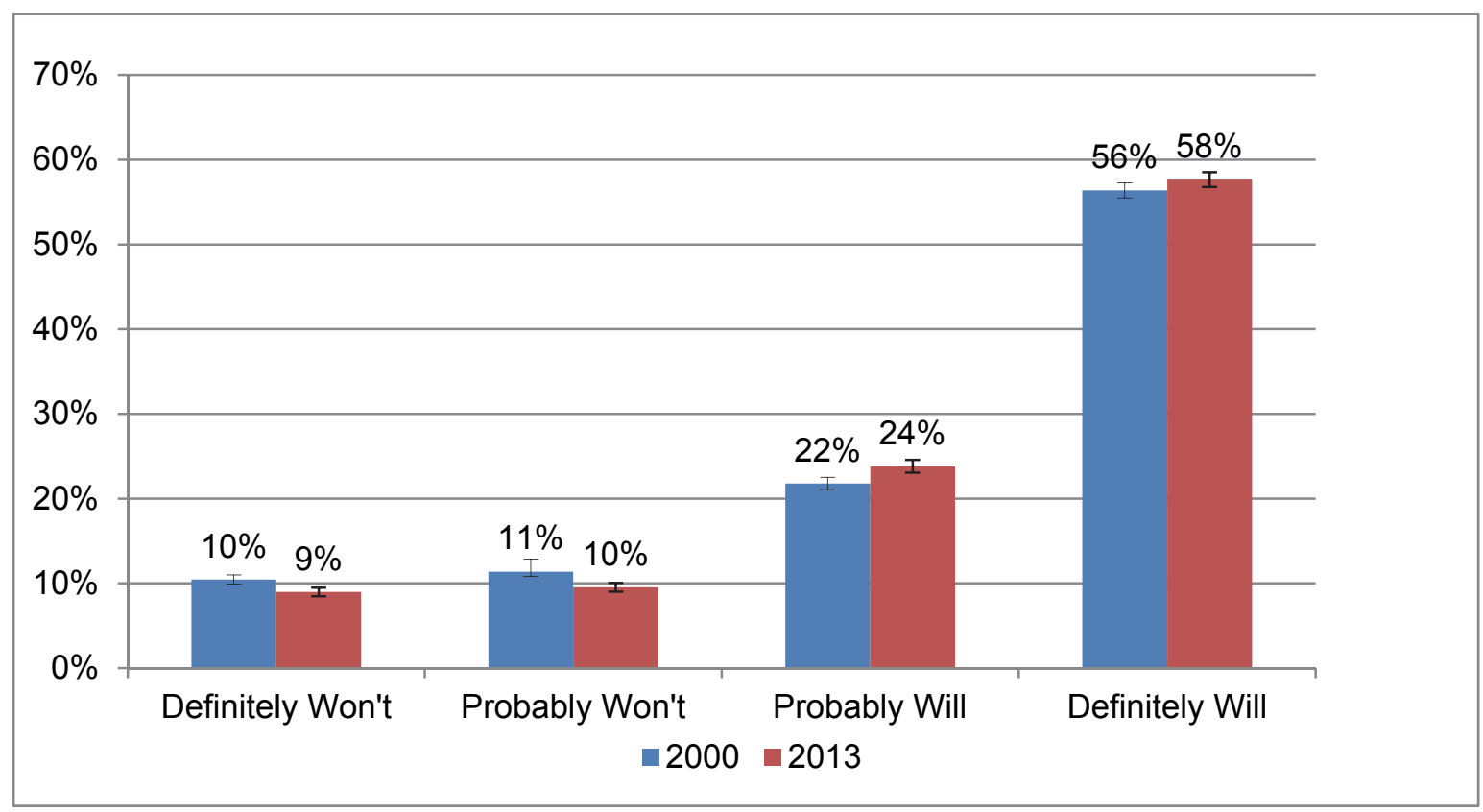

Monitoring the Future $12^{\text {th }}-$ Grade Survey, 2000 and 2013

Error bars reflect $95 \%$ confidence intervals.

This evidence supports both the supply- and the demand-related hypotheses. It is consistent with but does not support the minimum wage hypothesis, which made no predictions about changing school status.

\section{Changes in Time Spent on Academic Activities}

There has been a slight but not statistically significant increase in the amount of time that teenagers spend on educational activities. To assess this, I examine time-use data on 16-19 yearolds from the American Time Use Survey (ATUS) from 2003 to $2013^{14}$. These are based on 24 hour time diaries of a subset of CPS respondents, taken throughout the calendar year of the survey. The activities classified as educational are listed in Table 3.1. These include both time in school and time out of school spent doing homework or studying, as well as various other school-related activities.

${ }^{14}$ ATUS began in 2003. 
Table 3.1: Educational Activities

\begin{tabular}{|l|}
\hline Description \\
\hline Taking class for degree, certification, or licensure \\
\hline Taking class for personal interest \\
\hline Waiting associated with taking classes \\
\hline Security procedures rel. to taking classes \\
\hline Taking class, not elsewhere classified \\
\hline Extracurricular club activities \\
\hline Extracurricular music \& performance activities \\
\hline Extracurricular student government activities \\
\hline Education-related extracurricular activities, not elsewhere classified \\
\hline Research/homework for class for degree, certification, or licensure \\
\hline Research/homework for class for pers. interest \\
\hline Waiting associated with research/homework \\
\hline Research/homework not elsewhere classified \\
\hline Administrative activities: class for degree, certification, or licensure \\
\hline Administrative activities: class for personal interest \\
\hline
\end{tabular}

The average number of minutes that teenagers reported spending on educational activities did increase slightly, as shown in Figure 3.4: the average number of minutes reported on educational per day was 172 in 2003, up to 179 in 2013. However, the increase was not statistically significant. 
Figure 3.4: Average Daily Minutes on Academic Activities

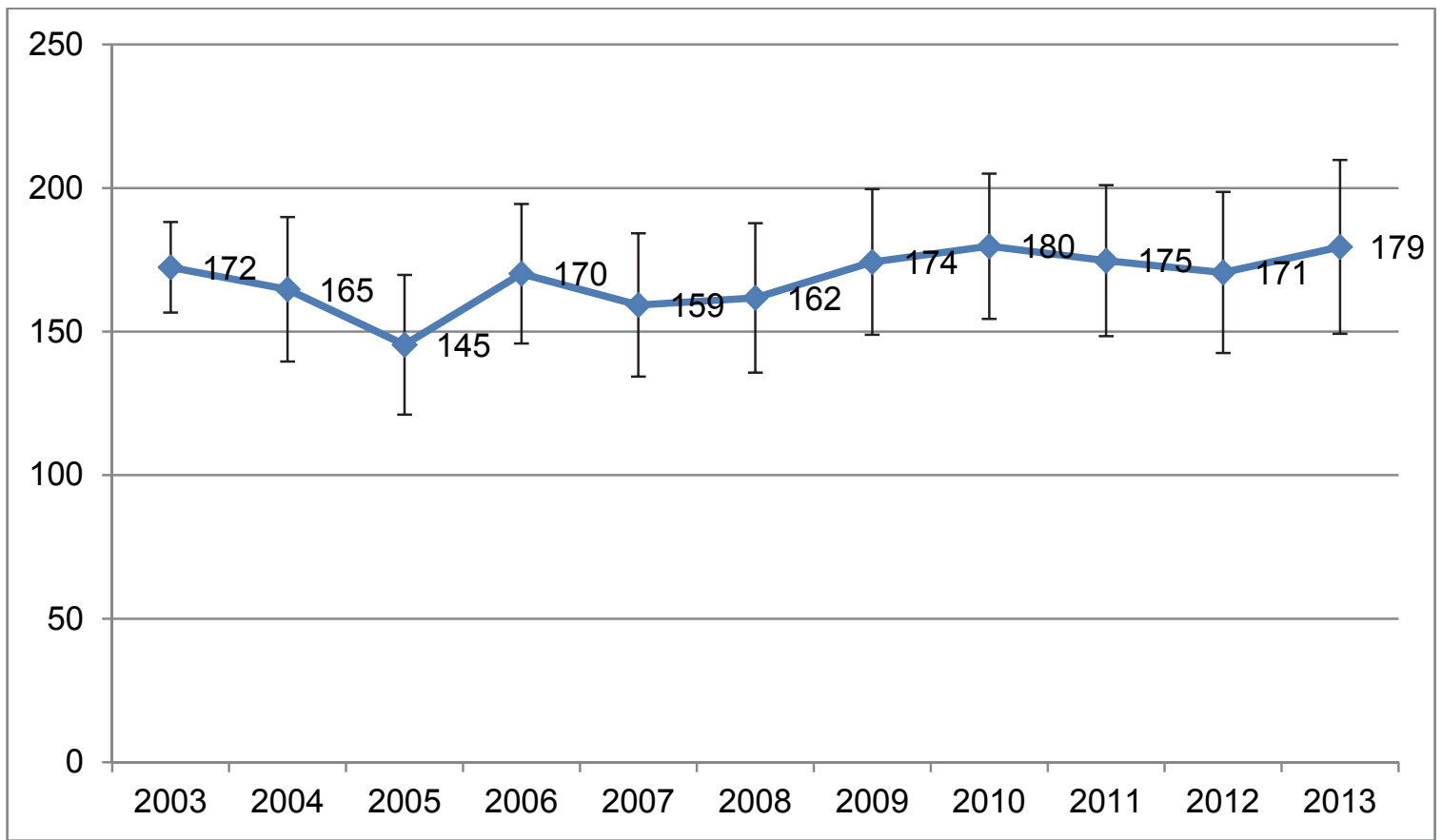

Monitoring the Future $12^{\text {th }}$-Grade Survey, 2000 and 2013

Error bars reflect $95 \%$ confidence intervals.

Additionally, there is limited evidence for an upward trend in amount of time spent on educational activities from 2003 to 2013. Results for this are shown in Table 3.2: the coefficient on the year term is positive, showing that there has been an upward trend in time spent on educational activities of .9 minutes per year. However, that term is not statistically significant.

Table 3.2: Comparing Minutes/Day Spent on Education, 2003-2013

\begin{tabular}{|}
\begin{tabular}{|c|c|}
\hline VARIABLES & education \\
\hline & $0.902(1.028)$ \\
\hline year & $-1,644(2,063)$ \\
\hline Constant & 7,666 \\
\hline Observations & 0.000 \\
\hline R-squared & Srade Survey, 2000-2013 \\
Monitoring the Future $12^{\text {th }}$-Grandard errors in parentheses \\
${ }^{* * *} p<0.01,{ }^{* *} p<0.05,{ }^{*} p<0.1$
\end{tabular}
\end{tabular}

We see these results both because the samples are relatively small, with fewer than 1,000 respondents on average per year, but also because the method of collection creates very high variance. In ATUS, each respondent only logs their time-use for 24 hours. More than half of teenage respondents generally report spending zero time on educational activities during that day, which could reflect it being a weekend, holiday, or break, but for the most part does not 
reflect lack of school enrollment: in each year most of the teenagers who report spending zero minutes on education also report being enrolled in school. But because of both the small size and high variance, it would take a very large change to be statistically significant.

I classify this evidence, which shows an increase in time spent on education both from 2003 to 2013 and a general upward trend during that time, as ambiguous in its support of the supply and demand-related hypotheses due to the lack of statistical significance.

\section{Changes in Employment by Educational Status}

There have been significant declines in employment among teenagers in high school, in college, and not in school at all. As shown in Figure 3.5, the biggest drops in teenage employment have been among high school students. However, there have also been significant drops among teenagers who are not in school, particularly from March 2000 to March 2013.

Figure 3.5: Employment by Educational Status, March and July 2000 and 2013

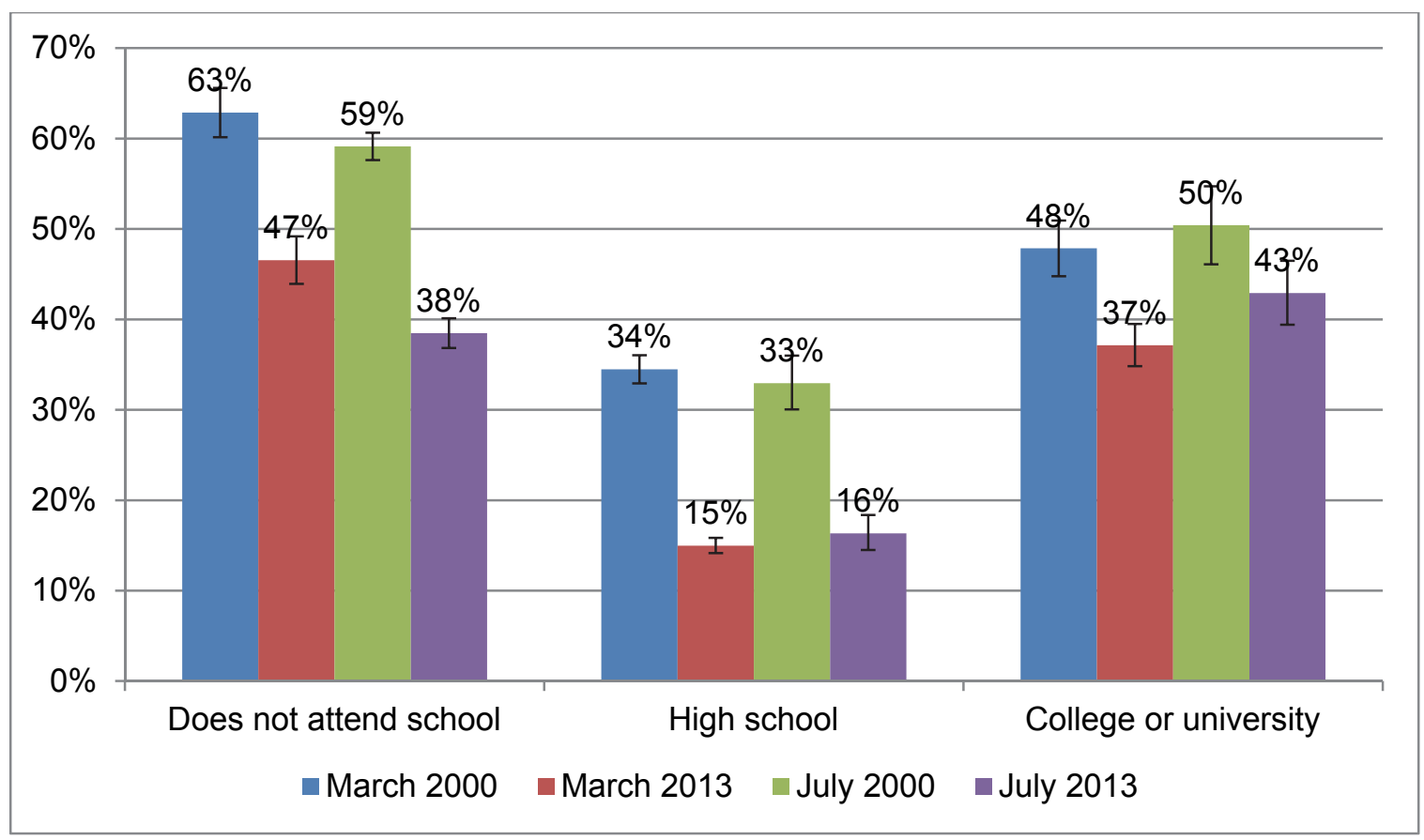

CPS, 2000 and 2013

Error bars reflect $95 \%$ confidence intervals.

This supports the demand-side and minimum wage hypotheses rather than supply-side hypotheses: while we see decreases in employment among those in school, we also see significant decreases those not attending school. 


\section{Evaluating the Evidence}

The following table, Table 3.3, summarizes each of the pieces of evidence shown in this chapter and how it relates to each of the hypotheses regarding the drivers of reduced teenage employment.

Table 3.3: Teenagers and Schooling: Evaluating the Evidence

\begin{tabular}{|c|c|c|c|c|}
\hline Evidence & $\begin{array}{l}\text { The } \\
\text { proportion of } \\
\text { teenagers in } \\
\text { school has } \\
\text { increased. }\end{array}$ & $\begin{array}{l}\text { More } \\
\text { teenagers } \\
\text { intend to go } \\
\text { to college. }\end{array}$ & $\begin{array}{l}\text { There has been a } \\
\text { non-statistically- } \\
\text { significant increase in } \\
\text { time teenagers } \\
\text { spend on academic } \\
\text { activities. }\end{array}$ & $\begin{array}{l}\text { Drops in employment } \\
\text { are significant both } \\
\text { among students and } \\
\text { non-students. }\end{array}$ \\
\hline $\begin{array}{l}\text { Supply: } \\
\text { Education }\end{array}$ & \multirow{2}{*}{\multicolumn{2}{|c|}{$\begin{array}{l}\text { The evidence shows an effect that } \\
\text { is statistically significant and goes } \\
\text { in the direction predicted by the } \\
\text { hypothesis. }\end{array}$}} & \multirow{2}{*}{$\begin{array}{l}\text { This evidence either } \\
\text { shows multiple } \\
\text { statistically significant } \\
\text { effects going in } \\
\text { different directions or } \\
\text { no statistically } \\
\text { significant effects. }\end{array}$} & $\begin{array}{l}\text { The evidence shows } \\
\text { an effect that is } \\
\text { statistically significant } \\
\text { and goes in opposite } \\
\text { of the direction } \\
\text { predicted by the } \\
\text { hypothesis. }\end{array}$ \\
\hline $\begin{array}{l}\text { Demand: } \\
\text { Unskilled } \\
\text { Labor } \\
\text { Demand: } \\
\text { Immigrants } \\
\text { Demand: } \\
\text { Other Adult } \\
\text { Workers }\end{array}$ & & & & \multirow[t]{2}{*}{$\begin{array}{l}\text { The evidence shows } \\
\text { an effect that is } \\
\text { statistically significant } \\
\text { and goes in the } \\
\text { direction predicted by } \\
\text { the hypothesis. }\end{array}$} \\
\hline $\begin{array}{l}\text { Wage Floor: } \\
\text { Minimum } \\
\text { Wage }\end{array}$ & \multicolumn{3}{|c|}{ This hypothesis makes no predictions regarding this evidence. } & \\
\hline
\end{tabular}

The findings of this chapter are mixed, but show more support for the demand-related hypotheses. The increase in schooling and schooling intentions among teenagers support both the supply and the demand hypotheses, whereas the findings on time-use are ambiguous. The drop in employment among both students and those out of school support the demand hypotheses and the minimum wage hypothesis while contradicting the supply hypothesis. 


\section{Chapter 4: Teenage Jobs: What Happened to Them, Who is Working Them?}

This chapter will present evidence regarding changes in teenage jobs between 2000 and 2013. I will look at changes in the number of teenage jobs and changes in which adults are working those jobs. As discussed in Chapter Two, supply-side and minimum wage hypotheses would be supported by an overall reduction in the number of teenage-type jobs, whereas demand-side hypotheses would be supported by more teenage jobs. The specific demand-side hypotheses regarding immigrant workers and low-skill workers increasingly competing for teenage jobs would be supported if those groups in particular were increasingly working teenage jobs.

The evidence we find supports demand-side hypotheses in general, and particular the immigrant hypothesis, while arguing against the supply-side and minimum wage hypotheses. First, we show that teenage jobs grew from 2000 to 2013. Additionally, adult immigrants make up a higher proportion of workers in teen jobs, which supports the demand: immigration hypothesis. However, adult high-school dropouts make up a lower proportion of workers in teen jobs, which argues against the demand: unskilled worker hypothesis.

\section{Number of Teenage Jobs}

There were more jobs of the types teenagers worked in 2013 than in 2000. Using ACS data from 2000 to 2013, I define teenage jobs as those categories (occupation combined with industry) that teenagers were overrepresented in in 2000 relative to among employees overall. In 2000 , teenagers made up almost 5.2\% of workers aged 16-65. I use several different categories of teenage jobs based on degree of overrepresentation, from jobs categories in which teenagers made up at least $10.4 \%$ of workers ( $\mathrm{x} 2$ representation) to those in which they made up at least $26 \%$ of workers ( $\mathrm{x} 5$ representation).

Table 4.1 shows the growth in teen jobs from 2000 to 2013. This was robust across how stringently we defined teenage jobs. This finding also holds whether we look at the absolute number of teenage jobs, the proportion of total jobs that are classified as teenage jobs, and the ratio of teenage jobs to teenagers. In all cases, across all definitions, teenage jobs grew from 2000 to 2013. 
Table 4.1: Number of Teen Jobs, 2000 and 2013

\begin{tabular}{|c|c|c|c|c|c|c|}
\hline $\begin{array}{l}\text { Degree of Teen } \\
\text { Overrepresentation }\end{array}$ & Year & $\begin{array}{l}\% \text { of Jobs that } \\
\text { are Teen Jobs }\end{array}$ & $95 \% \mathrm{Cl}$ & & $\begin{array}{l}\text { Number of } \\
\text { Teen Jobs }\end{array}$ & $\begin{array}{l}\text { Ratio of } \\
\text { Teen Jobs to } \\
\text { Teens }\end{array}$ \\
\hline \multirow{2}{*}{2} & 2000 & $14.4 \%$ & $14.3 \%$ & $14.4 \%$ & $18,264,085$ & 1.14 \\
\hline & 2013 & $16.2 \%$ & $16.1 \%$ & $16.2 \%$ & $22,645,830$ & 1.32 \\
\hline \multirow{2}{*}{3} & 2000 & $10.4 \%$ & $10.4 \%$ & $10.5 \%$ & $16,002,411$ & 1.00 \\
\hline & 2013 & $12.2 \%$ & $12.1 \%$ & $12.3 \%$ & $20,302,009$ & 1.19 \\
\hline \multirow{2}{*}{4} & 2000 & $6.5 \%$ & $6.5 \%$ & $6.5 \%$ & $11,666,351$ & 0.73 \\
\hline & 2013 & $7.9 \%$ & $7.8 \%$ & $7.9 \%$ & $15,163,561$ & 0.89 \\
\hline \multirow{2}{*}{5} & 2000 & $4.4 \%$ & $4.4 \%$ & $4.4 \%$ & $9,094,196$ & 0.57 \\
\hline & 2013 & $5.3 \%$ & $5.3 \%$ & $5.4 \%$ & $11,680,986$ & 0.68 \\
\hline
\end{tabular}

This increase in teenage jobs lends support to the demand-related hypotheses and contradicts the supply hypothesis and the price floor hypothesis.

\section{Composition of Adult Workers in Teenage Jobs}

From 2000 to 2013, adults increasingly filled teenage-type jobs. Among those adults, the proportion of immigrants rose, but the proportion of unskilled workers - those without a high school diploma - fell. These findings are robust to how stringently we define teenage jobs, from jobs in which teenagers were overrepresented in by a factor of two to those they were overrepresented in by a factor of five.

Figure 4.1 shows the increase in the proportion of immigrants among adults working the kinds of jobs that previously were worked by teenagers. In 2000, 16\%-17\% of teenage jobs were held by adult immigrants, increasing to $19 \%-21 \%$ in 2013 . From this analysis, it's not clear whether these results are a result of more immigrants among adults, the probability of immigrants working teenage jobs having risen, or the probability of other adults working teenage jobs having fallen. 
Figure 4.1: Proportion of Immigrants among Adults In Jobs with Teen Overrepresentation from Two to Five

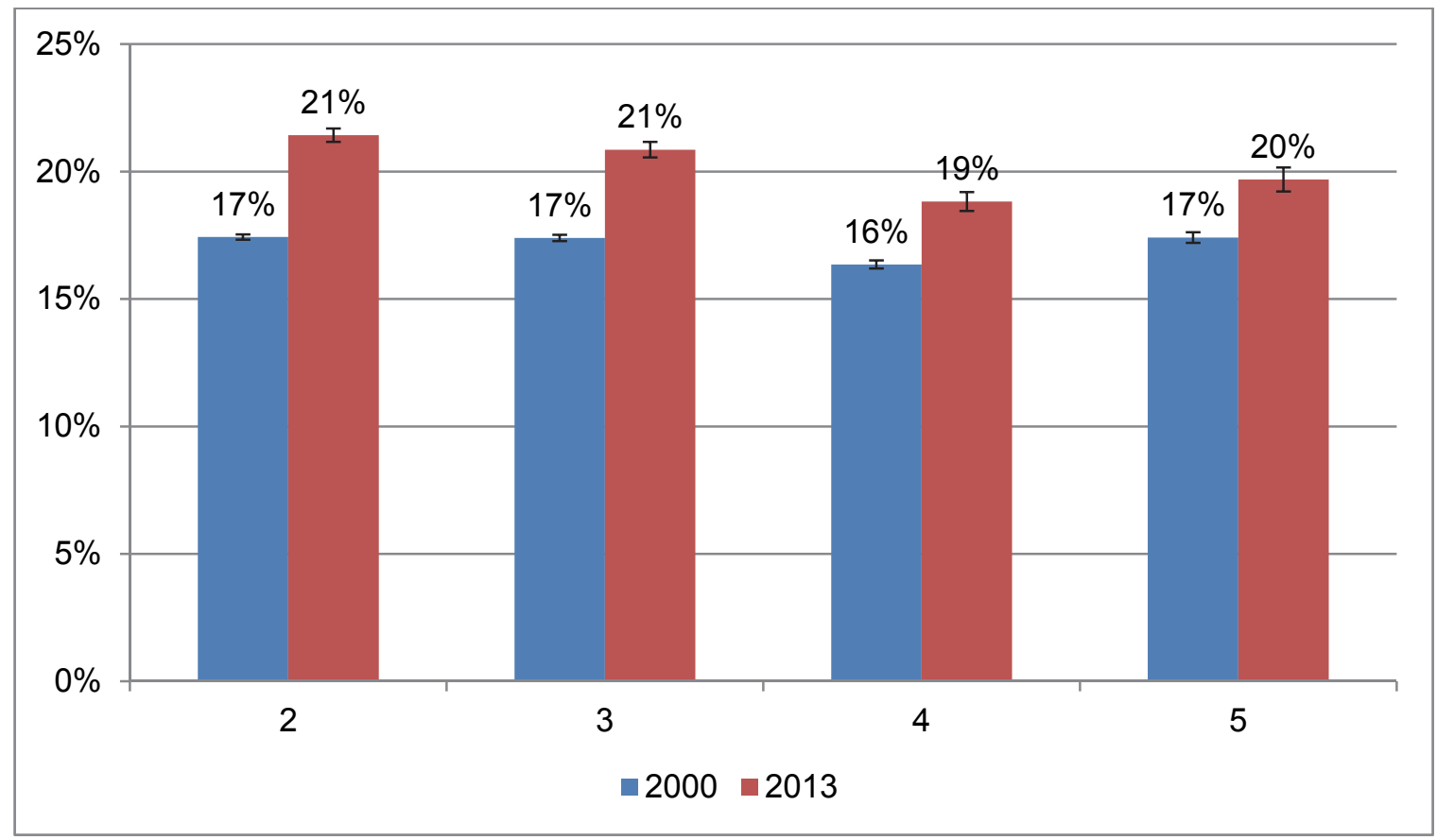

ACS 2000 and 2013

Error bars reflect $95 \%$ confidence intervals.

Figure 4.2 shows the decrease in the proportion of adults without high school diplomas working the kinds of jobs that previously were worked by teenagers. It's not clear whether this is related to fewer adults being high-school dropouts, high-school dropouts being less likely to work teenage jobs, or other adults being more likely to work those jobs. 
Fiaure 4.2: Proportion of Hiah School Dropouts amona Adults In Jobs with Teen

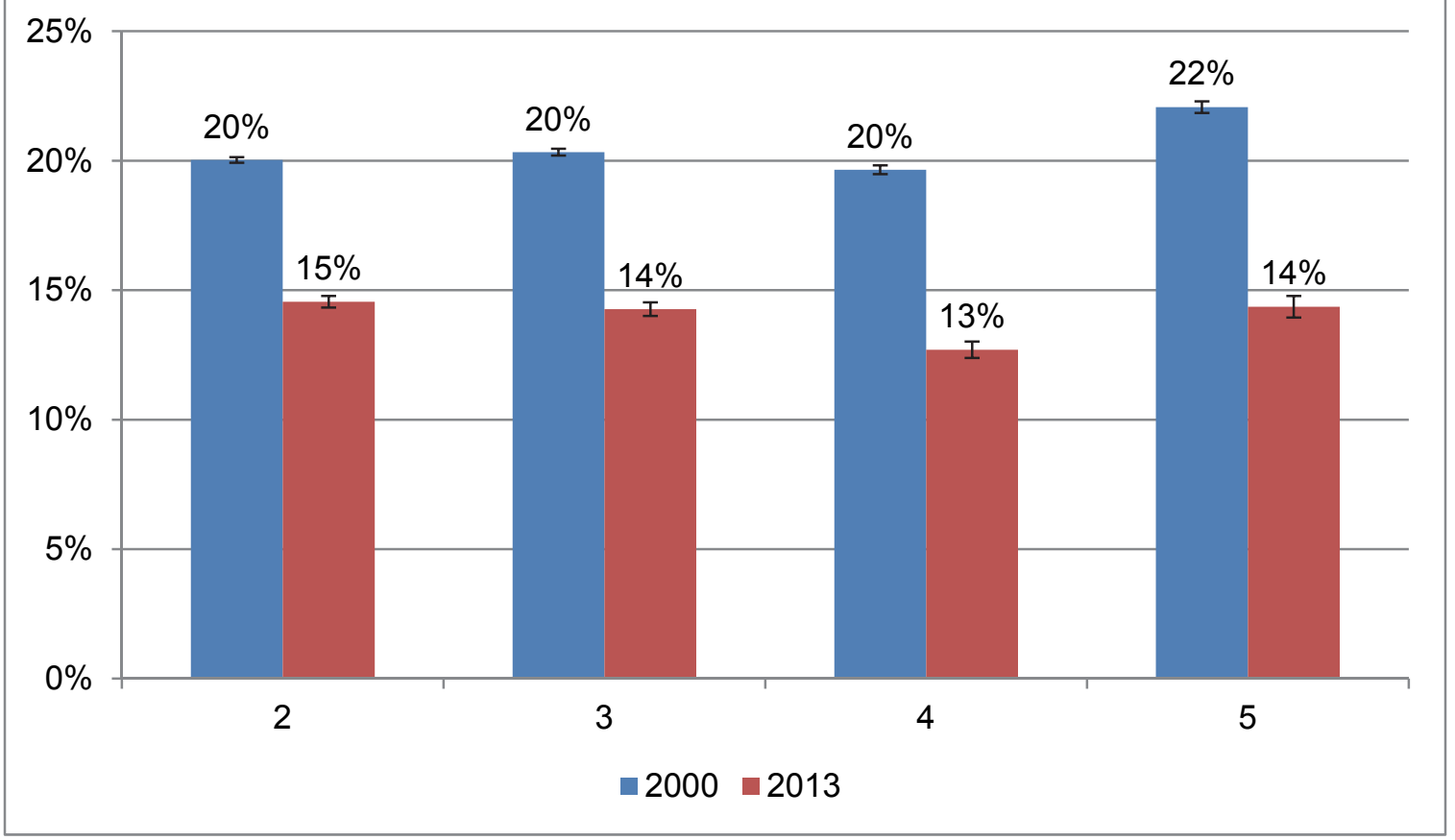

ACS 2000 and 2013

Error bars reflect $95 \%$ confidence intervals.

This evidence is supportive of the demand: immigrants hypothesis and contradictory of the demand: unskilled workers hypothesis.

\section{Evaluating the Evidence}

The following table, Table 4.2, summarizes each of the pieces of evidence shown in this chapter and how it relates to each of the hypotheses regarding the drivers of reduced teenage employment. 
Table 4.2: Evaluating the Evidence: Labor Market Changes

\begin{tabular}{|c|c|c|c|}
\hline Evidence & $\begin{array}{l}\text { Teenage jobs growth from } 2000 \\
\text { to } 2013 \text {. This is robust to the } \\
\text { definition of teenage job and in } \\
\text { terms of absolute numbers, ratio } \\
\text { to teenagers, and proportion of } \\
\text { jobs. }\end{array}$ & $\begin{array}{l}\text { Adult immigrants make up a } \\
\text { higher proportion of teen- } \\
\text { job workers, as well as a } \\
\text { higher proportion among } \\
\text { adults in teen jobs. }\end{array}$ & $\begin{array}{l}\text { Adult high-school dropouts } \\
\text { make up a lower proportion } \\
\text { of teen-job workers, as well } \\
\text { as a lower proportion among } \\
\text { adults in teen jobs. }\end{array}$ \\
\hline $\begin{array}{l}\text { Supply: } \\
\text { Education }\end{array}$ & $\begin{array}{l}\text { The evidence shows an } \\
\text { effect that is statistically } \\
\text { significant and goes in } \\
\text { opposite of the direction } \\
\text { predicted by the hypothesis. }\end{array}$ & \multirow{2}{*}{$\begin{array}{l}\text { This hypothesis makes } \\
\text { no predictions } \\
\text { regarding this } \\
\text { evidence. }\end{array}$} & $\begin{array}{l}\text { This hypothesis makes } \\
\text { no predictions regarding } \\
\text { this evidence. }\end{array}$ \\
\hline $\begin{array}{l}\text { Demand: } \\
\text { Unskilled } \\
\text { Labor }\end{array}$ & \multirow{3}{*}{$\begin{array}{l}\text { The evidence shows an } \\
\text { effect that is statistically } \\
\text { significant and goes in the } \\
\text { direction predicted by the } \\
\text { hypothesis. }\end{array}$} & & $\begin{array}{l}\text { The evidence shows an } \\
\text { effect that is statistically } \\
\text { significant and goes in } \\
\text { opposite of the direction } \\
\text { predicted by the } \\
\text { hypothesis. }\end{array}$ \\
\hline $\begin{array}{l}\text { Demand: } \\
\text { Immigrants }\end{array}$ & & $\begin{array}{l}\text { The evidence shows an } \\
\text { effect that is statistically } \\
\text { significant and goes in } \\
\text { the direction predicted } \\
\text { by the hypothesis. }\end{array}$ & \multirow{3}{*}{$\begin{array}{l}\text { This hypothesis makes } \\
\text { no predictions regarding } \\
\text { this evidence. }\end{array}$} \\
\hline $\begin{array}{l}\text { Demand: } \\
\text { Other Adult } \\
\text { Workers } \\
\end{array}$ & & \multirow{2}{*}{$\begin{array}{l}\text { This hypothesis makes } \\
\text { no predictions } \\
\text { regarding this } \\
\text { evidence. }\end{array}$} & \\
\hline $\begin{array}{l}\text { Wage Floor: } \\
\text { Minimum } \\
\text { Wage }\end{array}$ & $\begin{array}{l}\text { The evidence shows an } \\
\text { effect that is statistically } \\
\text { significant and goes in } \\
\text { opposite of the direction } \\
\text { predicted by the hypothesis. }\end{array}$ & & \\
\hline
\end{tabular}

The findings of this chapter are generally supportive of the demand-related hypotheses. As outlined in Chapter Two, the increase in the number of teenage jobs supports the demand hypotheses while contradicting the supply hypotheses and the minimum wage hypothesis. The increase in the proportion of immigrants among adults working teenage jobs supports the demand: immigration hypothesis, while the decrease in the proportion of adults without high school diplomas among adults working teenage jobs contradicts the demand: unskilled workers hypothesis 


\section{Chapter 5: Teenage Labor Market Issues}

This chapter will present evidence regarding how much teenagers report wanting to work, as well as changes in the wage rate of teenagers. We will look at to what extent lower employment among teenagers is a function of not wanting to work versus not being able to find a job, how expectations of how much teenagers should work have changed, and how teenage wages have changed. As discussed in Chapter Two, both supply- and demand-side explanations favor more teenagers not working because they don't want to work, as well as lower expectations for teenage employment, whereas the minimum wage explanation favors teenagers being unable to find jobs and similar (or higher) expectations for teenage employment. Supply- and minimum wage explanations favor higher teenage wages, with the minimum wage explanation favoring a narrower wage distribution and clustering around the minimum wage. Demand-side explanations favor lower teenage wages.

The evidence we find is mixed and sometimes ambiguous. The significant increase in teenagers who report not wanting to work contradicts the minimum wage hypothesis, which posits that the reduction will be due to teenagers who want to work but cannot find jobs. We find no evidence for an increase or decrease in the hours $12^{\text {th }}$ graders report wanting to work, which is ambiguous in terms of its support for all of the hypotheses. However, there is evidence for an increase in the number of hours that their parents want them to work, which supports the minimum wage hypothesis. Additionally, teenage hourly wages have remained static, which is also ambiguous in its support for all of the hypotheses. Finally, we present some additional evidence regarding the wage distribution which is also ambiguous regarding the minimum wage.

\section{Teenage Labor Market Status}

Nearly all of the decreased employment among teenagers consists of a shift from teenagers working to teenagers reporting they do not want to work. To show this, I use CPS data, supplementing information with whether teenage respondents without jobs are searching for a job or are not in the labor force (NILF) with whether respondents NILF report that they want a job. And as we see in Figure 5.1, the vast majority of the drop in teenage employment from March 2000 to March 2013 came from an increase in teenagers reporting that they did not want jobs. This presents evidence for the supply hypothesis and evidence against the demand- and minimum wage hypotheses. 
Figure 5.1: Labor Market Status and Reason for NILF

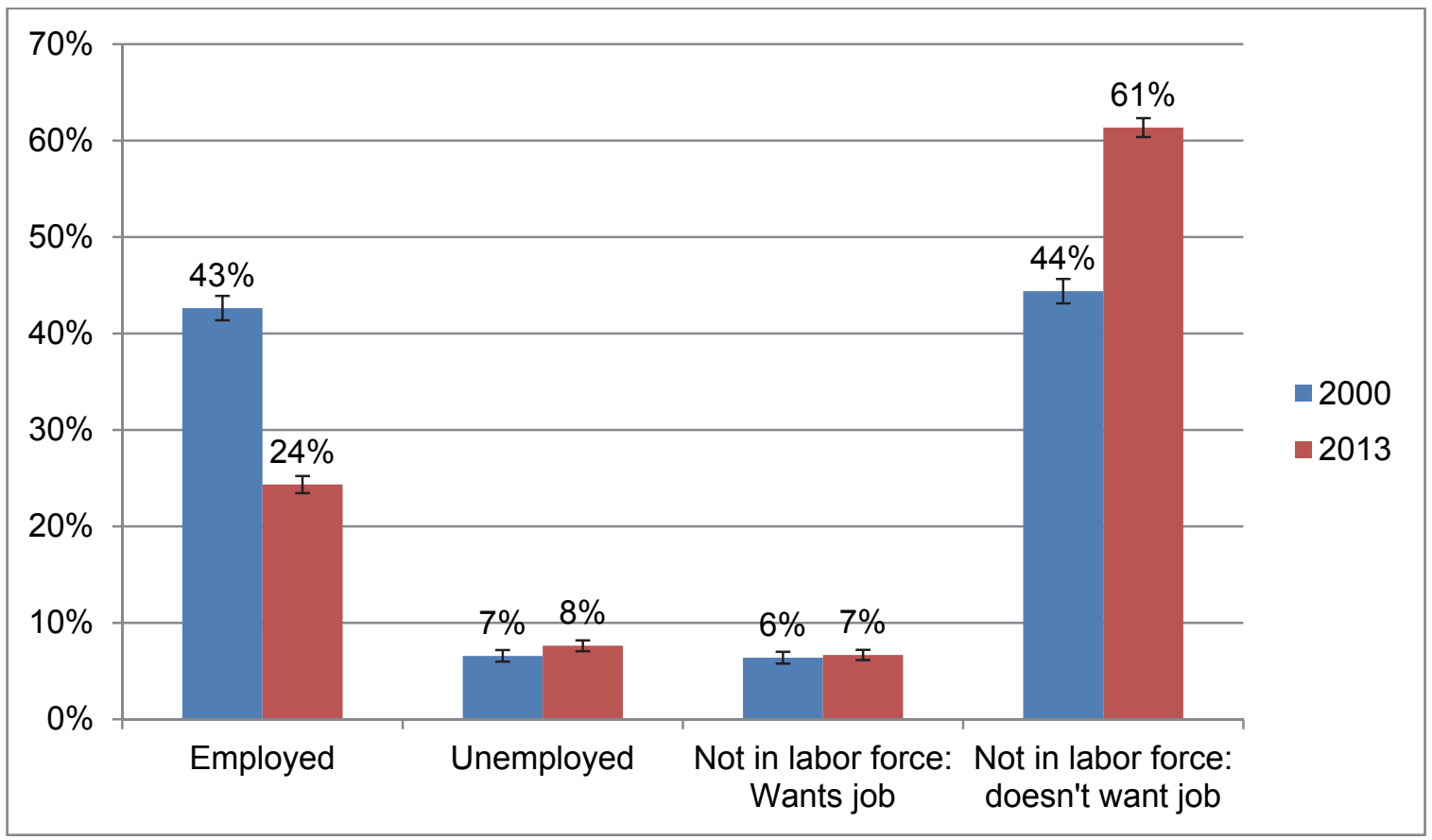

CPS, 2000 and 2013

Error bars reflect $95 \%$ confidence intervals.

\section{Expectations about Teenagers Working among $12^{\text {th }}$-Graders and Their Parents}

Expectations about teenagers working have changed in ambiguous ways. The following is based on two questions asked of a subset of $12^{\text {th }}$-grade respondents as part of the Monitoring the Future surveys in 2000 and 2013. The first question is as follows: "Think about the kinds of paid jobs that people your age usually have. If you could work just the number of hours that you wanted, how many hours per week would you PREFER to work during the school year?" There were no statistically significant differences in how much teenagers reported wanting to work, nor was there any overall pattern, nor has there been any statistically significant change in the distribution. The numbers are shown in Figure 5.2 $2^{15}$, with the results of an ANOVA to determine whether there was a change in the distribution shown in Table $5.1^{16}$. As shown in both the figure

${ }^{15}$ Both of these questions were only asked of a subset of the MTF respondents. MTF notes that they are "purely descriptive and may not be representative of the study population." https://www.icpsr.umich.edu/icpsrweb/DSDR/ssvd/studies/25382/datasets/0005/variables/V4435?series\%5B0\%5D= Monitoring +the+Future $+\% 28 \mathrm{MTF} \% 29+$ Series\&q=PREF \&alternateStudy $\% 5 \mathrm{~B} 0 \% 5 \mathrm{D}=\mathrm{MTF}+2008+\% 2812$ th + Grade $\% 29 \&$ dataset $\% 5 \mathrm{~B} 0 \% 5 \mathrm{D}=$ Form $+4+$ Data\&paging.startRow $=1$

${ }^{16}$ Results were the same using the Kolmogorov-Smirnov test for equality of distribution functions, which is specifically intended for this type of data - distribution data in which the categories are cumulative rather than truly categorical: there was no statistically significant change in distribution. 
and the table, there has been no detectible change in the distribution of hours that teenagers report wanting to work.

Figure 5.2: Preferences Regarding Weekly Hours Worked, $12^{\text {th }}$ Graders

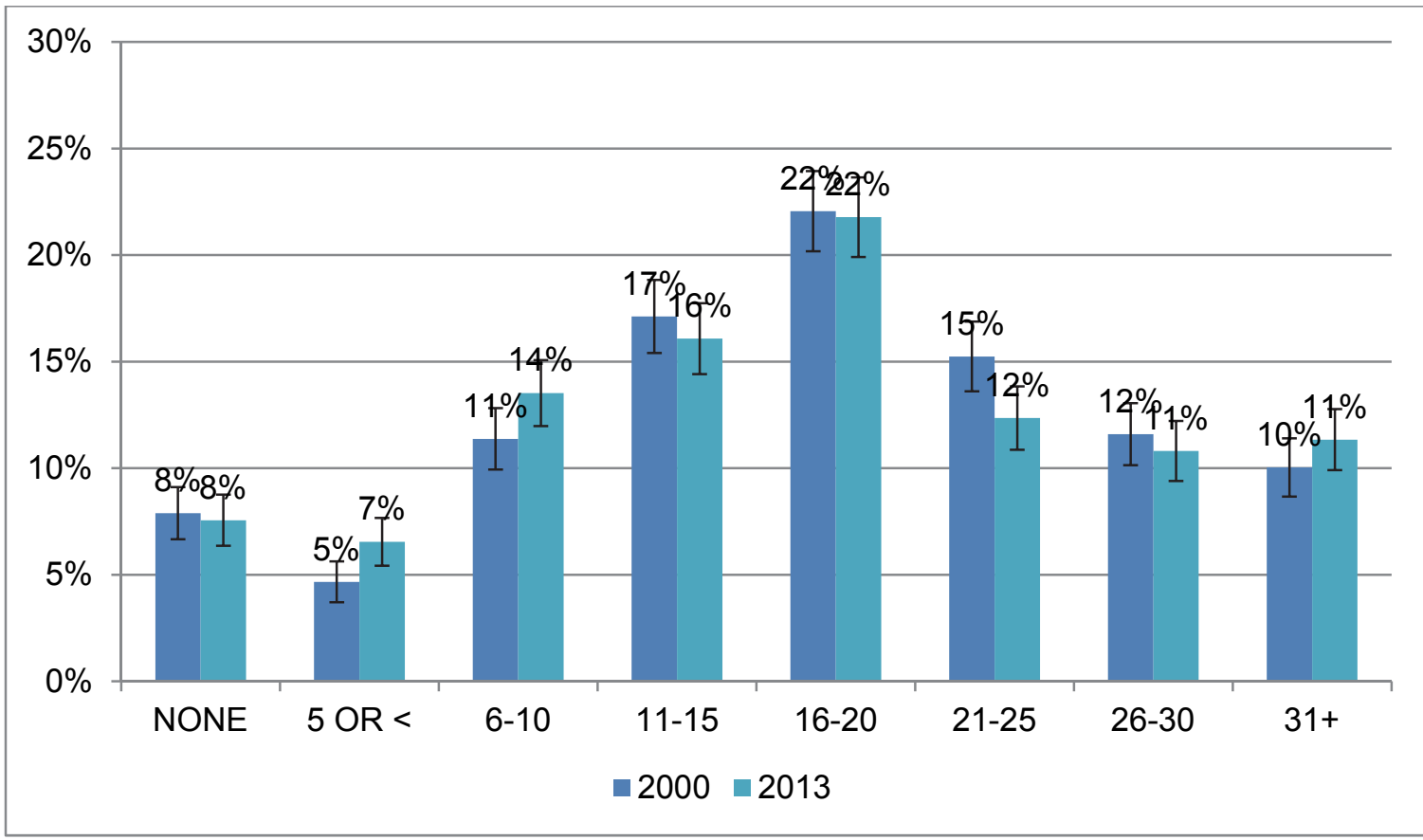

MTF, 2000 and 2013

Error bars reflect $95 \%$ confidence intervals.

Table 5.1: Preferences Regarding Weekly Hours Worked, $12^{\text {th }}$ Graders, ANOVA

\begin{tabular}{|l|c|}
\hline VARIABLES & $\begin{array}{c}\text { V4434 (Hours you prefer to work } \\
\text { during the school year) }\end{array}$ \\
\hline 2013 & $-0.0812(0.0647)$ \\
\hline Observations & 3,741 \\
\hline R-squared & 0.000 \\
\hline \multicolumn{2}{|c|}{$\begin{array}{c}\text { Standard errors in parentheses } \\
{ }^{* * *} p<0.01,{ }^{* *} p<0.05,{ }^{*} p<0.1\end{array}$}
\end{tabular}

MTF, 2000 and 2013

The second, related question is "How many hours per week do you think your PARENTS would prefer that you work in a paid job during the school year?" The results of this are shown in Figure 5.3. They show an increase in the number of hours respondents say their parents want them to work, with more teenagers saying their parents want them to work 21-25 hours, 26-30 hours, or $31+$ hours. The increase in the proportion reporting their parents want them to work $31+$ hours is statistically significant. A general pattern appears here, with only one of the bottom five categories experiencing an increase and all of the top three categories experiencing 
increases. From this, it looks like parents believe that teenage jobs have actually gotten more appealing, in support of the minimum wage hypothesis. We evaluate this more systematically in Table 5.2, in which the results an ANOVA show a statistically significant change in the distribution of responses from 2000 to $2013^{17}$.

Figure 5.3: Preferences Regarding Weekly Hours Worked, Parents of $12^{\text {th }}$ Graders

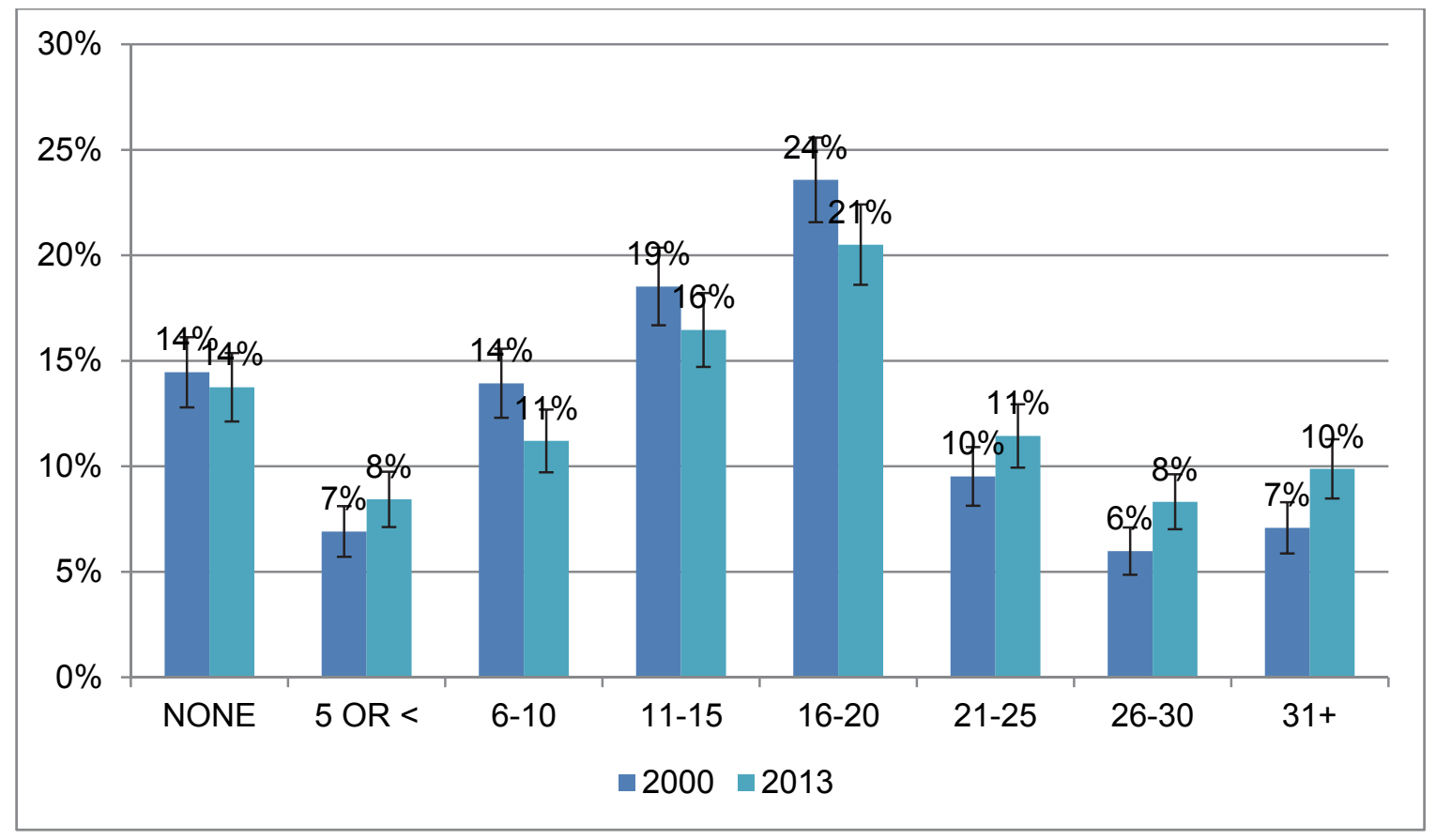

MTF, 2000 and 2013

Error bars reflect $95 \%$ confidence intervals.

Table 5.2: Parental Preferences Regarding Weekly Hours Worked, $12^{\text {th }}$ Graders, ANOVA

\begin{tabular}{|l|c|}
\hline VARIABLES & $\begin{array}{c}\text { V4434 (Hours your parents would prefer } \\
\text { you to work during the school year) }\end{array}$ \\
\hline 2013 & $0.208^{* * *}(0.0702)$ \\
\hline Observations & 3,453 \\
\hline R-squared & 0.003 \\
\hline & $\begin{array}{c}\text { Standard errors in parentheses } \\
{ }^{* * *} p<0.01,{ }^{* *} p<0.05,{ }^{*} p<0.1\end{array}$
\end{tabular}

These results are mixed. There is no evidence for a change in the degree to which teenagers prefer to work. This is ambiguous in its support of the minimum wage hypothesis. There is evidence for an increase in parental preferences for teenagers working. This supports the

${ }^{17}$ Results were the same using the Kolmogorov-Smirnov test for equality of distribution functions, which is specifically intended for this type of data - distribution data in which the categories are cumulative rather than truly categorical: there was a statistically significant change in distribution. 
minimum wage hypothesis. The other hypotheses made no claims regarding these pieces of evidence.

\section{Teenage Wages}

This section will show the distribution of wages among teenagers who reported previous-year income in 2000 to 2013. This is based on March CPS data from 2000 and 2013. At most parts in the wage distribution, inflation-adjusted wages have stayed the same from 2000 to 2013. I classify this as being consistent with but not supporting or contradicting any of the hypotheses, which variously predicted higher or lower teenage wages The lack of change in wages supports the idea that there have been both changes in supply and changes in demand.

Figure 5.4: Distribution of Hourly Wage among Teenagers Who Reported Having Earned Income, Inflation-Adjusted to Year 2000 Dollars, 2000 and 2013

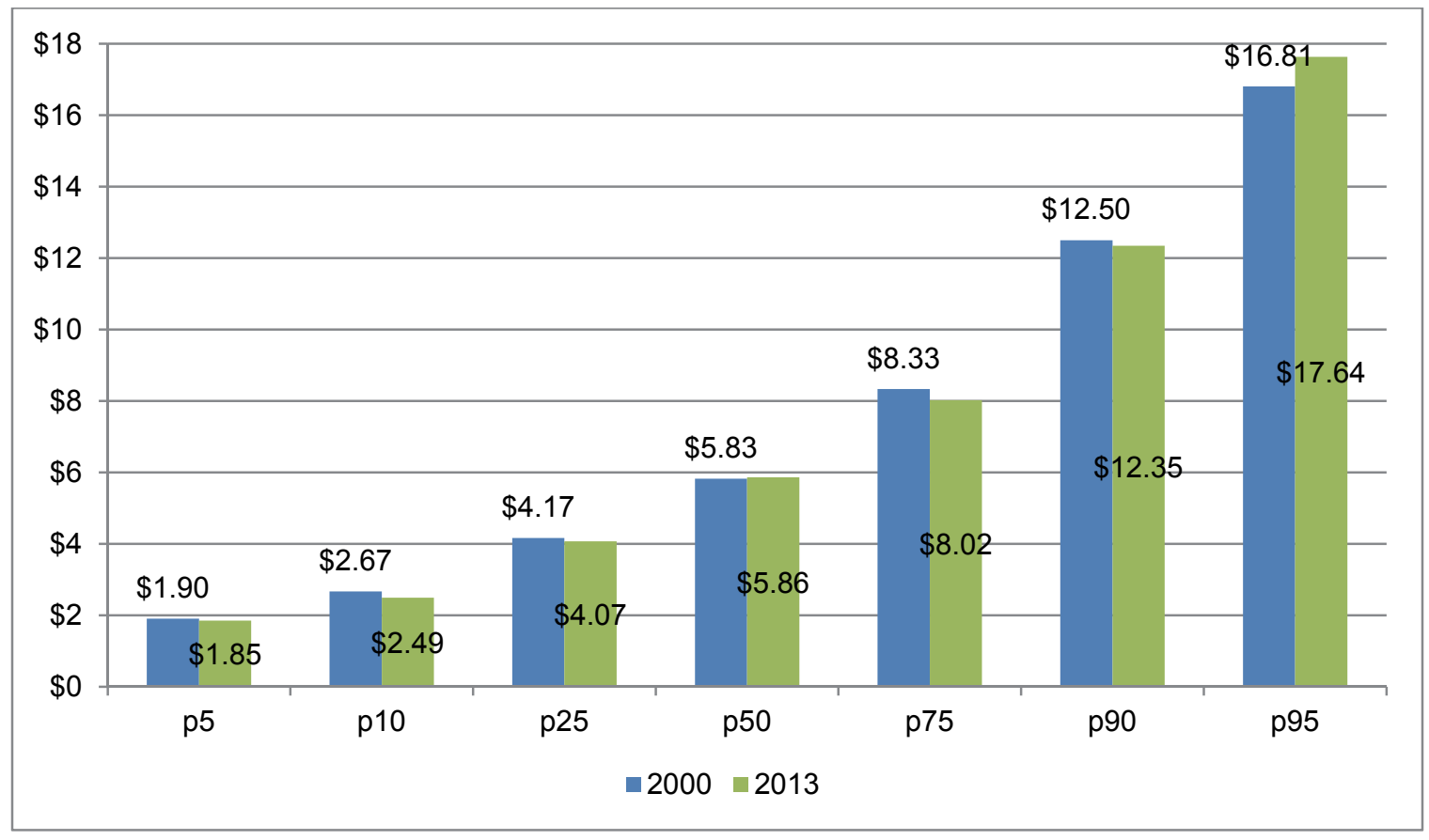

CPS (March) 2000 and 2013, CPI 2000 and 2013, CPI

\section{Teenage Wages, Relative to the Minimum Wage}

This section will show the change in the distribution of wages among working teenagers from 2013, relative to the minimum wage. This is based on March CPS data from 2000 and 2013, as well as state and federal minimum wage data. Figure 5.2 shows the distribution of teenage hourly wages as a proportion of the minimum wage in both 2000 and 2013. There are several things of note. First, in both years, more than a third of teenagers reported earning less 
than the minimum wage ${ }^{18}$. This limits the degree to which the minimum wage is likely to impact teenagers, since so many of them appear to either be working jobs that are exempt from the minimum wage or for employers who are committing wage fraud. However, among the other workers, we do see a pattern in terms of compression of wages relative to the minimum wage, with more teenagers reporting earning just over the minimum wage and fewer teenagers reporting earning significantly more than the minimum wage. This looks like the "spike" described in minimum wage literature (Brown, 1998), which does suggest that the minimum wage has become increasingly more binding upon workers.

Figure 5.5 shows the distribution of teenage wages reported in 2000 and 2013. As with Figure 5.4, Figure 5.5 summarizes wages for teenagers who reported previous-year earned income. We see two things of note in this data. First, significant proportions of teenagers report earning less than the minimum wage. In both years, over $40 \%$ of teenagers reported earning less than the minimum wage. This limits the degree to which minimum wage is likely to be influential. Second, among those teenagers reporting making more than the minimum wage, we do see the sort of spike that suggests an increasingly-binding minimum wage: a higher proportion of earners report getting exactly the minimum wage or just over the minimum wage (100\%-120\%), with fewer reporting earning significantly more than that.

Figure 5.5: Teenage Hourly Wages as a Proportion of Minimum Wage, 2000 and 2013

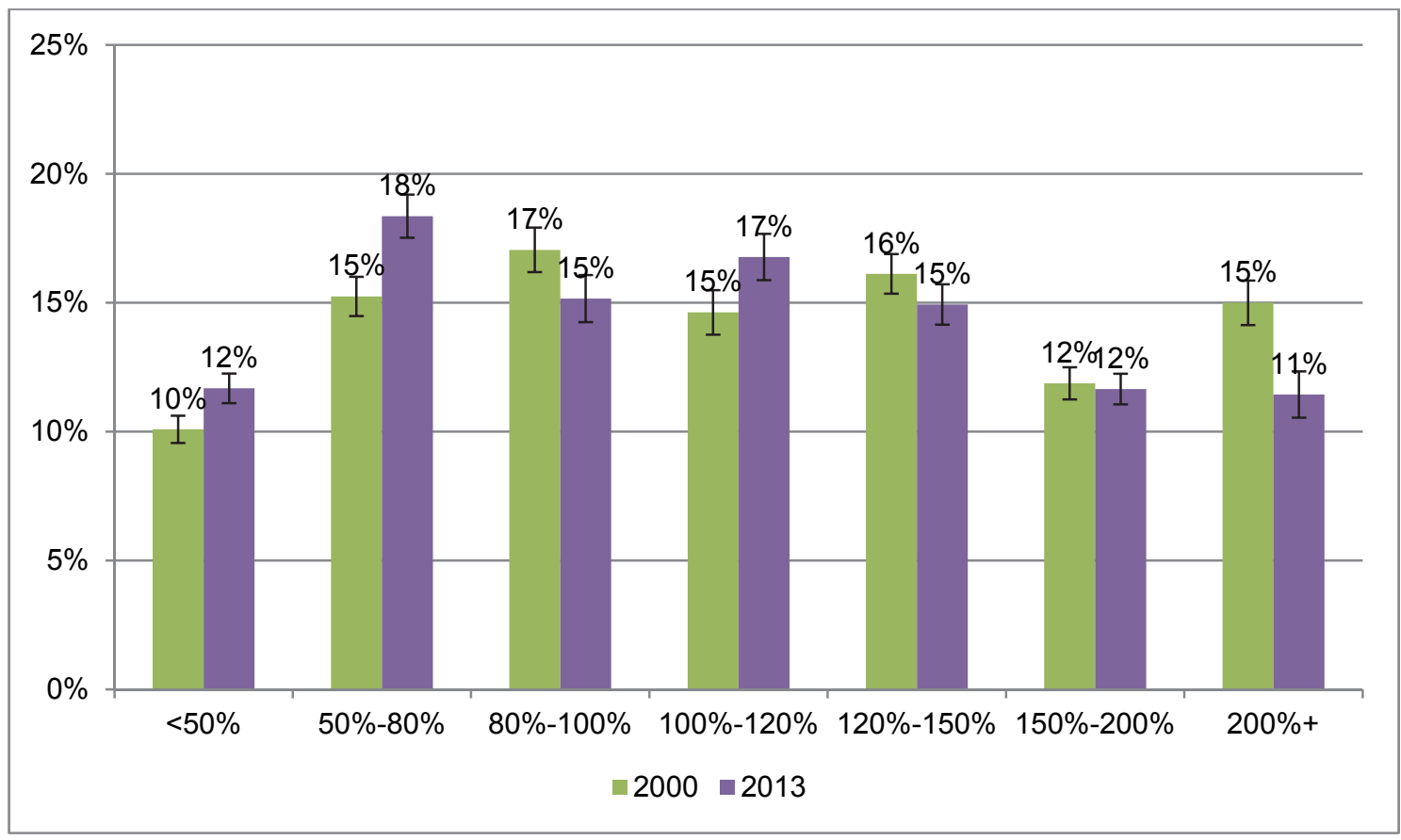

18 See Appendix B for more information on my derivation of hourly wage. This also includes exploring a different data set, through which I show that the finding that many teenagers are working less than minimum wage is not due to quirks of Census question wording or data collection. 
These wage results are ambiguous in their support of the minimum wage. While the significant proportion of teenagers reporting earning less than the minimum wage suggests that higher minimum wages are limited in the degree to which they could be affecting teenage workers, the changes in the rest of the wage distribution do suggest that the minimum wage is increasingly-binding, which suggests it could be having disemployment effects. The other hypotheses do not make predictions about this evidence.

\section{Evaluating the Evidence}

The following table, Table 5.3, summarizes each of the pieces of evidence shown in this chapter and how it relates to each of the hypotheses regarding the drivers of reduced teenage employment.

Table 5.3: Evaluating the Evidence: Teen Labor Market Issues

\begin{tabular}{|c|c|c|c|c|c|}
\hline Evidence & $\begin{array}{l}\text { Most of the } \\
\text { decrease in teenage } \\
\text { employment is due } \\
\text { to an increase in } \\
\text { teenagers who are } \\
\text { NILF and report not } \\
\text { wanting to work, not } \\
\text { teenagers who are } \\
\text { searching for work } \\
\text { or report wanting to } \\
\text { work }\end{array}$ & $\begin{array}{l}\text { There is no } \\
\text { evidence for a } \\
\text { change in the } \\
\text { distribution of } \\
\text { hours } 12^{\text {th }} \\
\text { graders report } \\
\text { wanting to work } \\
\text { during the year. }\end{array}$ & $\begin{array}{l}\text { There is } \\
\text { evidence an } \\
\text { increase in the } \\
\text { number of hours } \\
12^{\text {th }} \text { graders } \\
\text { report their } \\
\text { parents want } \\
\text { them to work } \\
\text { during the } \\
\text { school year. }\end{array}$ & $\begin{array}{l}\text { Teenage wages } \\
\text { have remained } \\
\text { static. }\end{array}$ & $\begin{array}{l}\text { A significant } \\
\text { proportion of } \\
\text { teenagers report } \\
\text { earning below the } \\
\text { minimum wage. } \\
\text { Among other } \\
\text { earners, there is } \\
\text { evidence for an } \\
\text { increasingly- } \\
\text { binding minimum } \\
\text { wage. }\end{array}$ \\
\hline $\begin{array}{l}\text { Supply: } \\
\text { Education }\end{array}$ & \multirow{4}{*}{$\begin{array}{l}\text { This hypothesis make } \\
\text { evidence. }\end{array}$} & \multirow{4}{*}{ no predictions reg } & \multirow{4}{*}{ rding this } & \multirow{5}{*}{$\begin{array}{l}\text { This evidence } \\
\text { either shows } \\
\text { multiple } \\
\text { statistically } \\
\text { significant } \\
\text { effects going in } \\
\text { different } \\
\text { directions or no } \\
\text { statistically } \\
\text { significant } \\
\text { effects. }\end{array}$} & \multirow{4}{*}{$\begin{array}{l}\text { This hypothesis } \\
\text { makes no } \\
\text { predictions } \\
\text { regarding this } \\
\text { evidence. }\end{array}$} \\
\hline $\begin{array}{l}\text { Demand: } \\
\text { Unskilled } \\
\text { Labor }\end{array}$ & & & & & \\
\hline $\begin{array}{l}\text { Demand: } \\
\text { Immigrants }\end{array}$ & & & & & \\
\hline $\begin{array}{l}\text { Demand: } \\
\text { Other Adult } \\
\text { Workers }\end{array}$ & & & & & \\
\hline $\begin{array}{l}\text { Wage } \\
\text { Floor: } \\
\text { Minimum } \\
\text { Wage }\end{array}$ & $\begin{array}{l}\text { The evidence shows } \\
\text { an effect that is } \\
\text { statistically } \\
\text { significant and goes } \\
\text { in opposite of the } \\
\text { direction predicted } \\
\text { by the hypothesis. }\end{array}$ & $\begin{array}{l}\text { This evidence } \\
\text { either shows } \\
\text { multiple } \\
\text { statistically } \\
\text { significant } \\
\text { effects going in } \\
\text { different } \\
\text { directions or no } \\
\text { statistically } \\
\text { significant } \\
\text { effects. }\end{array}$ & $\begin{array}{l}\text { The evidence } \\
\text { shows an effect } \\
\text { that is } \\
\text { statistically } \\
\text { significant and } \\
\text { goes in the } \\
\text { direction } \\
\text { predicted by the } \\
\text { hypothesis. }\end{array}$ & & $\begin{array}{l}\text { This evidence } \\
\text { either shows } \\
\text { multiple statistically } \\
\text { significant effects } \\
\text { going in different } \\
\text { directions or no } \\
\text { statistically } \\
\text { significant effects. }\end{array}$ \\
\hline
\end{tabular}


The findings of this chapter mostly relate to the minimum wage hypothesis, and they are mixed in terms of support for it. Most of the evidence lets us evaluate whether there is increasingly a gap between the proportion of teenagers who want jobs and those who are able to find them, as predicted by the minimum wage hypothesis. The proportion of teenagers reporting wanting jobs has gone down significantly, mirroring the decline in teenage employment. This contradicts the minimum wage hypothesis. However, the more detailed data from MTF on $12^{\text {th }}$ graders is more complicated. There has been no change in the distribution of hours that $12^{\text {th }}$ graders report wanting to work during the school year, which we classify as being ambiguous in support for the minimum wage. However, this same group reports an increase in the hours that their parents report them wanting work during the school year, which is more supportive of the minimum wage hypothesis.

We also present some information regarding teenage wages. At most points in the wage distribution among teenagers who report earning wage income, hourly wages are the same in 2000 and 2013. This is ambiguous in its support for all of the hypotheses. When comparing wages earned to the minimum wage in both years, we see that a significant proportion of teenagers report earning less than the minimum wage. This limits the degree to which the minimum wage is likely to be binding on teenagers. However, among more-than-minimum wage earners, the distribution we see is what we'd expect from an increasingly-binding minimum wage: a spike just above the minimum wage, with a smaller proportion of earners getting significantly above the minimum wage. We categorize this evidence as again ambiguous in its support of the minimum wage. 


\section{Chapter 6: Analytical Model}

This chapter will present evidence regarding teenage employment from a statistical model to test the hypotheses described in Chapter Two. We will consider to what extent the drop in employment among teenagers is statistically associated with various individual, county-, and state-level variables, including school status, the proportion of adult high school dropouts, relative wage earnings between workers of different educational strata, the proportion of adults who are unemployed, the proportion of immigrants among adults, and the minimum wage. As discussed in Chapter Two, each of the hypotheses makes different predictions regarding the outcomes of this analysis.

We find that changes in the characteristics of teenagers and their environments account for most of the drop in teenage employment, with the evidence generally supporting the hypothesis that teenagers are supplying less labor because of increased returns to education. The increase in the proportion of teenagers who are in school explains some of the reduction in teenage employment, as does the increase in the relative wages of college graduates to high school dropouts at the state level. Additionally, as was predicted by the supply: education hypothesis as described in Chapter Two, the gap has expanded between the employment rates of students and non-students, and this changing relationship between school enrollment and employment explains some of the drop in teenage employment. That is, being a student is now more negatively associated with employment in 2013 than in 2000. There is no evidence in favor of other hypotheses.

The structure of this chapter is as follows: The first sections describe the data sources used and outline the theoretical basis for the decomposition. The second section presents summary statistics on the data, and the third section models teenage employment separately in 2000 and 2013. The fourth section shows the results of the decomposition model and discusses how the findings relate to each hypothesis. Finally, I present a chart summarizing these findings.

\section{Data Source}

In this chapter, I reference several different Census data sets. First, to obtain counts of teenagers and where they live, whether they're employed, and whether they're in school, I use the 5\% Census sample from 2000 and the 2013 American Community Survey (ACS) PUMS data. The Census sample is the data from the $5 \%$ of Census respondents in 2000 who were given the long-form Census survey. After 2000, the long-form Census survey was discontinued and replaced with the ACS, an annual survey which records many of the same variables as did the 
long-form survey. The 5\% Census sample provides respondent-level data on about 800,00016 19 year-olds in 2000, with 2013 ACS containing about 200,000 teenagers.

Additionally, I use two other data sets to provide information on county- and state-level variables. These are 1999 and 2012 data from the CPS. These provide county ${ }^{19}$ - and state-level data on unemployment, the composition of adults, and adult wages. I use this instead of the $5 \%$ Census sample and 2013 ACS data in order to introduce a lag so as to reduce endogeneity issues, or those associated with my outcome of interest in some way influencing the independent variables $^{20}$. Finally, I use state-level data on minimum wages from 2000 and 2013.

\section{Decomposing the Gap}

In this chapter's analysis, we decompose the drop in teenage employment as a function of various factors. There are two broad categories that we'll be looking at: changes in employment due to changes in the composition of teenagers (for instance, the proportion attending school, or the variables at the county- and state-level) and changes due to the relationship between those variables and employment. The decomposition method can differentiate between composition changes and relationship changes, whereas a standard regression would just be able to model the effect of changes in the composition. The next section will discuss changes in composition, summarizing variables in both years and noting changes, while the section after that will do the same for changes in the relationships between these variables and employment. Finally, I will show the results of the actual decomposition.

Some of my hypotheses predict that either changes in the value of these characteristics or changes in the relationship between the characteristic and teenage employment will explain the reduction in employment. For instance, the minimum wage hypothesis would be supported by either higher minimum wages negatively affecting teenage employment or by minimum wages being increasingly binding - that is, there being a stronger negative relationship between minimum wage and employment among teenagers. Other hypotheses only predict that changes in the characteristics of teenagers or in their county- or state-level environments will explain the reduction in teenage employment. For instance, the hypothesis that increased returns to education are causing more teenagers to forgo work for school predicts that the increase in the relative wages of college graduates to other workers will explain the reduction in teenage employment.

\footnotetext{
${ }^{19}$ Because counties are only identifiable in either ACS or CPS data if they reach a certain population threshold, respondents in smaller counties are assigned to a "county" representing all of the smaller counties in their state.

${ }^{20}$ Because there is no long-form Census or ACS sample from 1999, I use CPS data for both 1999 and 2012 for the sake of consistency.
} 


\section{Explaining the Model}

The model I use is a variant of the Oaxaca-Blinder decomposition method, with several changes from the standard model. Because my independent variable, teenage employment, is discrete (and specifically binary) rather than continuous, I use a logit version of the model. Additionally, because I have many county and state-level variables, I cluster by county so that the standard errors better reflect this. I use the Stata package "Oaxaca" in order to do this analysis. This section will show how the decomposition is computed.

In equations 1 and 2, we separately model the proportion of employed teenagers in each year with the terms $\overline{Y_{2000}}$ and $\overline{Y_{2013}} . X$ is a vector of individual characteristics (school status), while $\mathrm{Z}$ is a matrix of state-level characteristics (unemployment rate, proportion of immigrants among adults, proportion of people with less than a high school diploma among adults, ratio of adult unemployment rate), and $\mathrm{A}$ is a matrix with that same set of characteristics, but at the county level ${ }^{21}$.

$$
\begin{aligned}
& \overline{Y_{2000}}=\overline{F\left(X_{2000} \beta_{1 ; 2000}+Z_{[1999]} \beta_{2 ; 1999}+A_{[1999]} \beta_{3 ; 1999}\right)} \\
& \overline{Y_{2013}}=\overline{F\left(X_{2013} \beta_{1 ; 2013}+Z_{[2012]} \beta_{2 ; 2012}+A_{[2012]} \beta_{3 ; 2012}\right)}
\end{aligned}
$$

In order to decompose $\overline{Y_{2000}}-\overline{Y_{2013}}$, or the reduction in employment between 2000 and 2013, we use the following equation. This is modified from the original Blinder-Oaxaca decomposition analysis, in which the outcome variable was continuous rather than discrete. $Y$ corresponds to employment status - employed or not employed - and therefore our $F$ corresponds to the logit model, or $F(X \beta)=\frac{\exp (X \beta)}{[1+\exp (X \beta)]}$.

The gap in the proportion of employed teenagers in 2000 and 2013 can be represented as:

$$
\begin{aligned}
& \overline{Y_{2000}}-\overline{Y_{2013}}= \\
& {\left[\overline{F\left(X_{2000} \beta_{1 ; 2000}+Z_{[1999]} \beta_{2 ; 1999}+A_{[1999]} \beta_{3 ; 1999}\right)}-\right.} \\
& \left.F\left(X_{2013} \beta_{1 ; 2000}+Z_{[2012]} \beta_{2 ; 1999}+A_{[2012]} \beta_{3 ; 1999}\right)\right]+ \\
& \overline{F\left(X_{2013} \beta_{1 ; 2000}+Z_{[2012]} \beta_{2 ; 1999}+A_{[2012]} \beta_{3 ; 1999}\right)}- \\
& \left.\overline{F\left(X_{2013} \beta_{1 ; 2013}+Z_{[2012]} \beta_{2 ; 2012}+A_{[2012]} \beta_{2012 ;}\right)}\right]
\end{aligned}
$$

For most decompositions, the critical distinction is between the composition term and the coefficient term; while that's not the major distinction here, we'll still go through and describe these two terms. First, the term $\overline{F\left(X_{2013} \beta_{1 ; 2000}+Z_{[2012]} \beta_{2 ; 1999}+A_{[2012]} \beta_{3 ; 1999}\right)}$ is the composition term; it represents the employment rate for teenagers that would be predicted if

\footnotetext{
${ }^{21}$ The equations in this chapter are modified from Yun (2004), which discusses the Oaxaca-Blinder method for nonlinear models.
} 
teenagers (and their counties and states) had the same characteristics in 2013 as they did in 2000. Therefore,

$\left[\overline{F\left(X_{2000} \beta_{1 ; 2000}+Z_{[1999]} \beta_{2 ; 1999}+A_{[1999]} \beta_{3 ; 1999}\right)}-\right.$

$\left.\overline{F\left(X_{2013} \beta_{1 ; 2000}+Z_{[2012]} \beta_{2 ; 1999}+A_{[2012]} \beta_{3 ; 1999}\right)}\right]$ represents the gap between the employment rate in 2000 and 2013 that is explained by changes in the composition of teenagers (and their counties and states.) The second half of the equation represents the remaining gap, or the proportion that is explained by changes in the relationship between the variables and the outcome (employment).

An additional advantage of using this model is that we can further decompose the contributions of each of these variables in order to determine which specific compositional or coefficient changes explain the gap. This is key to our use of the model, since we're not primarily interested in the breakdown of compositional vs. coefficient effects but rather of the contribution of each variable, as discussed in Chapter Two. The contributions of variables to the composition effect will be those which both are associated with teenage employment in 2000 and the values of which change from 2000 and 2013. If a variable is positively associated with teenage employment in 2000 and declines from 2000 to 2013, it is likely to explain some of the compositional difference in teenage employment. Or similarly, if it's negatively associated with teenage employment in 2000 and rises from 2000 to 2013, it is also likely to explain some of this difference. Coefficient terms will contribute to the overall difference if the relationship between that variable and employment among teenagers fell from 2000 to $2013^{22}$. For instance, if a variable previously was strongly associated with teenage employment but now is only weakly associated with it, that changing relationship might explain some of the coefficient piece of the decline.

One limitation of this analysis is the possibility of missing variables which are correlated with included variables but would point to different hypotheses, including hypotheses that I am not testing. For instance, if young adults in their 20 s are increasingly competing with teenagers, and young adults are also more likely than other adults to be unemployed, the exclusion of this variable could make the variables relating to unemployed adults explain more of the drop in teenage employment than they would if we had properly included the young adult variables. It is not possible to prove that there are no other variables which would have explanatory value. Including only variables which there is a strong theoretical reason for the inclusion of helps avoid either false positives (where null hypotheses that should not be rejected are rejected) or

\footnotetext{
22 Another possibility would be if the relationship between that variable and employment rose among teenagers from 2000 to 2013 for a variable that was negative in 2013. However, by the nature of my variables, none of them can be negative.
} 
raising the evidentiary bar so far, via the false discovery rate adjustment, such that hypotheses that should be rejected will not be rejected ${ }^{23}$.

\section{Characteristics of Teenagers by Year}

In this chapter, I will perform an analysis which will decompose the reduction into teenage employment into several different components, the broadest of which are the amount of the gap which is statistically associated with a change in the characteristics of teenagers and their environments and which are associated with changes in the relationship between those characteristics and employment. This section summarizes changes in those characteristics and explains which we anticipate may be meaningful as far as explaining the reduction in teenage employment. The gap that we will be trying to explain is the difference between the $41 \%$ of teenagers working in 2000 and the $28 \%$ working in 2013.

Table 6.1 shows the summary statistics for teenagers in 2000 and 2013: These results appear to support some of our hypotheses and not others, although we will wait to make judgements on this until the actual decomposition analysis. For instance, the supply hypothesis predicts an increase in the proportion of teenagers in school, and we do see this in the results: the proportion of teenagers in school rose from $80 \%$ to $85 \%$. It also predicts reductions in the relative wages of non-college graduates to college graduates, and we see this both with high school dropout wages and high school graduate wages. We additionally see increases in the proportion of adults who were unemployed, which is what we'd expect to see if adult workers were increasingly competing with teenagers for jobs, as discussed by the demand: other adult workers hypothesis. The economic situation for adults worsened, as shown by the unemployment rate increasing from $4 \%$ to $8 \%$. Relative wages of high school dropouts to college graduates fell, as did high school graduates to college graduates. However, with all of these issues, even though we know how the composition is changing, we don't know yet to what extent these changes will statistically explain the drop in employment.

23 One way of thinking about this is that we have some information about whether a variable is likely to truly explain variation in some dependent variable. These can be expressed in the form of a probability distribution. The higher the bar for inclusion in a model, the lower the probability of false positives and the higher the probability of false negatives. Using procedures like the Benjamini-Hochberg FDR reduce the expected proportion of false positives. However, if you added in many random, noisy variables with no actual explanatory power and then used the FDR procedure to compensate, it is still possible that some of those variables would not only look significant, but also make the truly predictive variables no longer look significant. 
Table 6.1: Summary Statistics

\begin{tabular}{|lr|r|r|r|}
\cline { 2 - 5 } \multicolumn{1}{c|}{} & \multicolumn{2}{c|}{$\mathbf{2 0 0 0}$} & \multicolumn{2}{c|}{2013} \\
\hline Variable & Mean & \multicolumn{1}{l}{ SD } & \multicolumn{1}{l|}{ Mean } & \multicolumn{1}{c|}{ SD } \\
\hline employed & 0.41 & 0.49 & 0.28 & 0.45 \\
\hline In School & 0.80 & 0.40 & 0.85 & 0.35 \\
\hline Proportion of HS Dropouts (County) & 0.14 & 0.06 & 0.11 & 0.05 \\
\hline Proportion of HS Dropouts (State) & 0.13 & 0.04 & 0.11 & 0.03 \\
\hline Ratio HS Dropout: College Grad Income (County) & 0.26 & .27 & 0.11 & 0.25 \\
\hline Ratio HS Dropout: College Grad Income (State) & 0.17 & 0.09 & 0.09 & 0.08 \\
\hline Ratio HS Grad: College Grad Income (County) & 0.57 & .21 & 0.42 & 0.31 \\
\hline Ratio HS Grad: College Grad Income (State) & 0.50 & 0.06 & 0.40 & 0.06 \\
\hline Proportion Unemployed (County) & 0.04 & 0.02 & 0.08 & 0.03 \\
\hline Proportion Unemployed (State) & 0.04 & 0.01 & 0.08 & 0.02 \\
\hline Proportion Immigrants (County) & 0.12 & 0.12 & 0.16 & 0.13 \\
\hline Proportion Immigrants (State) & 0.13 & 0.10 & 0.17 & 0.10 \\
\hline Minimum Wage & 5.30 & 0.33 & 7.57 & 0.45 \\
\hline $\mathrm{n}$ & 809,014 & & 172,957 & \\
\hline weighted n & $15,956,257$ & & $17,107,683$ & \\
\hline school & 1.80 & & school & 1.85 \\
\hline
\end{tabular}

5\% Census sample 2000; ACS 2013; CPS 1999 and 2013; State and federal minimum wages

\section{Modeling Employment Separately by Year}

In addition to changes in the composition of variables relating to the teenagers or their environments, another possible explanation for the drop in employment is changes in the relationship of those variables to teenage employment. I refer to these as coefficient effects. This section summarizes differences in the relationship between each of the variables in our model and teenage employment in 2000 and 2013 and explains which we anticipate may be meaningful as far as explaining the reduction in teenage employment.

In this empirical framework, we model the probability of employment among each teenage respondent as follows in equations 4 and 5. These are the same as equations 1 and 2, except our outcome of interest is individual-level employment, not proportion employed. Here $Y_{i t}$, the dependent variable, refers to the employment status of each respondent. $X_{i[t]}$ are the individuallevel characteristics in year $t$, while $Z_{s[t-1]}$ are the state-level characteristics in year t-1 and $A_{c}$ are the county-level characteristics in year t-1. Again, because $F(X \beta)$ is a logit model,

$$
\begin{gathered}
F(X \beta)=\frac{\exp (X \beta)}{[1+\exp (X \beta)]} . \\
Y_{i ; 2000}=F\left(X_{i[2000]} \beta_{1}+Z_{s[1999]} \beta_{2}+A_{c[1999]} \beta_{3}\right) \\
Y_{i ; 2013}=F\left(X_{i[2013]} \beta_{1}+Z_{s[2012]} \beta_{2}+A_{c[2012]} \beta_{3}\right)
\end{gathered}
$$


Table 6.2 shows the results of each of these analyses for 2000 and 2013. As with the results regarding changes in composition, these appear to support some of our hypotheses and not others, although we will wait to make judgements on this until the actual decomposition analysis. From these results, the supply hypothesis may supported in two ways: first, in both periods, school is negatively associated with working. Because we saw an increase in the proportion of teenagers in school, and this confirms that the relationship between being in school and working is negative, we now have a strong reason to suspect that the increase in the proportion of teenagers in school will explain some of the drop in employment. This would be a composition change. Additionally, the relationship between school status and employment has become more negative, suggesting that we may also see the changing relationship between school and employment explaining some of the drop in teenage employment. The relationship between proportion of high school dropouts and employment, while always negative, has gotten stronger at the state level: we may see this relationship explaining some of the reduction in teenage employment, even as we see the reduction in the proportion of high school dropouts (as shown in Table 6.1) predicting an increase in teenage employment. However, with all of these issues, even though we know how the relationship between the variables and employment is changing, we don't know yet to what extent these changes will statistically explain the drop in employment.

Table 6.2: Logit Results

\begin{tabular}{|c|c|c|}
\hline VARIABLES & 2000 & 2013 \\
\hline In School & $-0.811^{* * *}(0.0240)$ & $-0.949^{* * *}(0.0292)$ \\
\hline Proportion of HS Dropouts (County) & $-1.936^{\star \star *}(0.453)$ & $-2.423^{\star * \star}(0.594)$ \\
\hline Proportion of HS Dropouts (State) & $-0.586(0.671)$ & $-1.837(1.235)$ \\
\hline Ratio HS Dropout: College Grad Income (County) & $0.0353(0.0542)$ & $-0.0793(0.0984)$ \\
\hline Ratio HS Dropout: College Grad Income (State) & $0.606^{* *}(0.233)$ & $1.206^{* * *}(0.356)$ \\
\hline Ratio HS Grad: College Grad Income (County) & $-0.0411(0.0711)$ & $0.0624(0.0356)$ \\
\hline Ratio HS Grad: College Grad Income (State) & $0.369(0.462)$ & $-0.282(0.639)$ \\
\hline Proportion Unemployed (County) & $-1.182(0.800)$ & $-1.360(0.818)$ \\
\hline Proportion Unemployed (State) & $-7.453^{* * *}(2.460)$ & $-3.901(2.387)$ \\
\hline Proportion Immigrants (County) & $-0.806^{* *}(0.324)$ & $-0.706(0.354)$ \\
\hline Proportion Immigrants (State) & $0.0715(0.449)$ & $-0.593(0.596)$ \\
\hline Minimum Wage & $0.0181(0.0686)$ & $-0.0316(0.0578)$ \\
\hline Constant & $1.473^{\star \star *}(0.343)$ & $2.098^{* * *}(0.442)$ \\
\hline Observations & 805,850 & 171,378 \\
\hline
\end{tabular}

Standard errors, based on clustering at the county level, are in parentheses 5\% Census sample 2000; ACS 2013; CPS 1999 and 2013; State and federal minimum wages 


\section{${ }^{* * *} p<0.01,{ }^{* *} p<0.05,{ }^{*} p<0.1$ (Based on Benjamini-Hochberg FDR)}

Previously, we have explained the decomposition model and gone through the changes in the composition of teenagers and their environments, and the differences in how those were associated with teenage employment in 2000 and 2013: here, we will present the results of the decomposition model, going through which factors explain the reduction in teenage employment. As we will show, this decomposition analysis indicates that most of the 13 percentage point drop in teenage employment from 2000 to 2013 (about 59\% of that gap) is associated with changes in the composition of this group, including both respondent-level changes and changes in countyand state-level variables. In other words, if the relationships between these variables and employment had remained the same from 2000 to 2013, we would expect that the decrease in teenage employment would be $59 \%$ of the actual decrease. The remaining $41 \%$ is associated with the coefficients, or the changing relationships between these variables and teenage employment. This includes the composition term, which is the amount of the gap that goes unexplained by either changes in the composition or changes in the relationship of these variables to employment. There are three factors that are statistically significant, and they explain almost two-thirds of the employment decrease. All of them support the hypothesis that supply changes from reduced teenage employment due to higher returns to education are driving reductions in teenage employment.

The supply: education hypotheses and all the demand hypotheses predict an employment gap that is explained by a reduction in teenage schooling, and we do see this. The increase in the proportion of teenagers in school explains about $11 \%$ of the reduction in employment. In both years, teenagers in school were less likely to be employed relative to teenagers not in school, so the increase in the proportion of teenagers in school from 2000 to 2013 is associated with a reduction in employment among teenagers.

The supply: education hypotheses also predicts the second factor: the changing relationship between being in school and working, with the probability of working contingent on being in school falling, explains about $38 \%$ of the gap. As explained in Chapter Two, this hypothesis predicts that employment will decline among students but not among non-students: while we do see declines in both groups, as discussed in Chapter Three, as shown in this model, the particular decline in employment among teenagers in school does explain much of the gap. In 2000, being in school was negatively associated with working - but in 2013, as shown in Table 6.2, the relationship was much stronger, with teenagers in school being much less likely to work than previously.

The supply: education hypothesis also predicts the third factor, which is that the changing ratio between the wages of high school dropouts to college graduates at the state level explains 
about $16 \%$ of the gap ${ }^{24}$. In both 2000 and 2013, higher ratios of high school dropout to college graduate wages were associated with teenage employment: teenagers living in areas where high school dropouts were earning relatively more were also more likely to work. But from 2000 to 2013, the wages of high school dropouts relative to college graduates dropped all over the country. Because of the relationship between these relative wages and high school employment, the drop in the relative wages of high school dropouts is associated with a reduction in teenage employment.

Figure 6.1 shows the size of the employment drop from 2000 to 2013 and these results. The initial gap, labeled "employment gap" in the second column, is $13.2 \%$. As shown in the third column, the three factors that are statistically significant explain about two-thirds of the gap. The fourth column shows the magnitude of the remaining gap.

Figure 6.1: Decomposing the Employment Gap

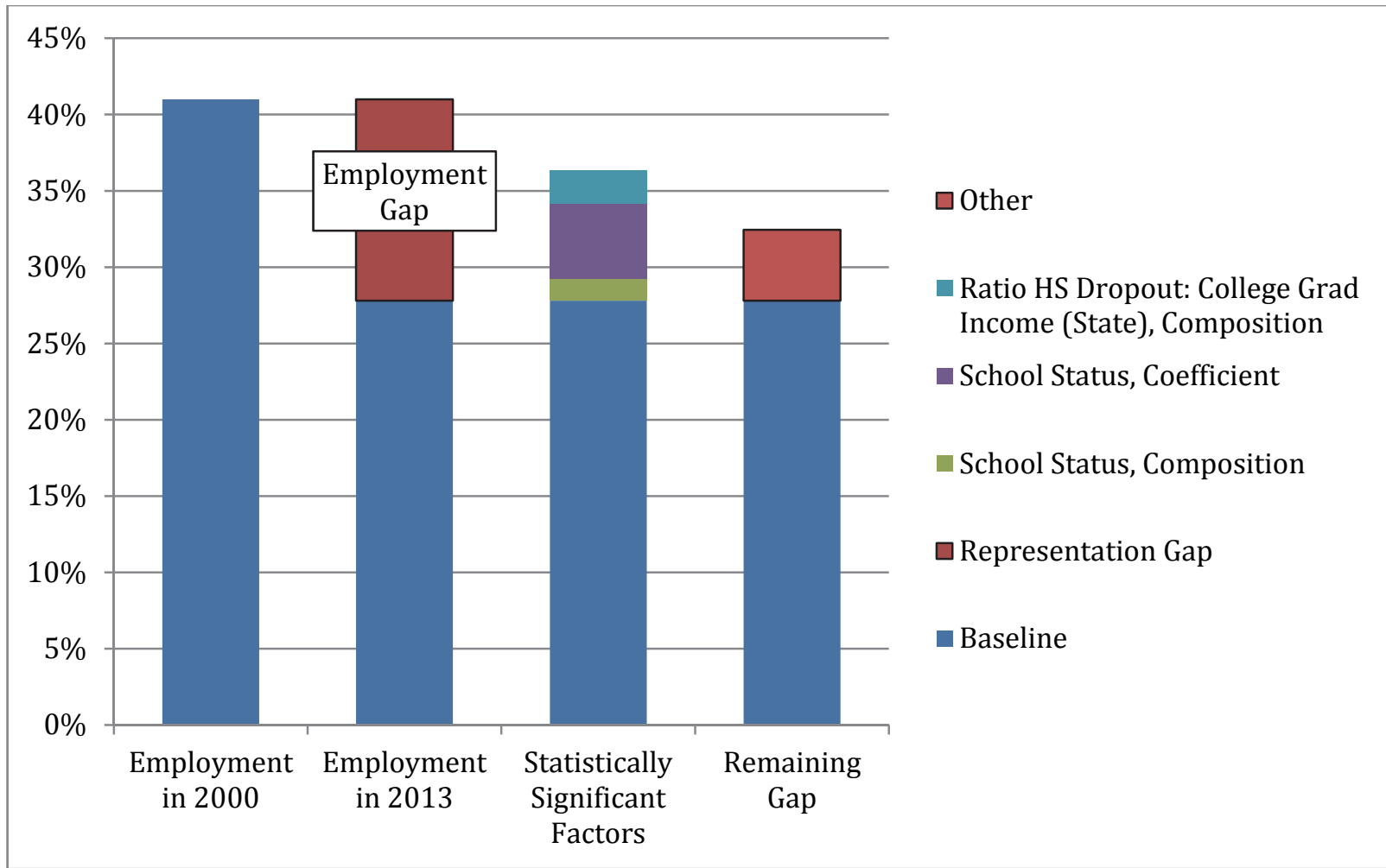

${ }^{24}$ The supply: education hypothesis actually should predict that relative wage changes should explain all of the gap in employment related to this hypothesis. However, the variables related to wage differences certainly do not capture all of the changes related to relative wages; rather, they capture the ratio of median values. "Returns to education" are a significantly more complicated concept. Because of this, we would expect for some of the effects related to this to show up in the education terms. 
Table 6.3 and Table 6.4 show the decomposition results in more detail. The interpretation of the effect terms from Table 6.3 are as follows, using the example of the composition term for "In School": the estimated contribution of changes in school status on teenage employment is .0142. This means that it is estimated that changes in schooling status are responsible for 1.4 points of the 13.2 point drop in teenage employment, or about $11 \%$, as shown in Table 6.4 .

Table 6.3: Decomposition Results

\begin{tabular}{|l|l|l|c|}
\hline VARIABLES & \multicolumn{1}{|c|}{ Composition } & \multicolumn{1}{c|}{ Coefficients } & Summary \\
\hline & & & \\
\hline In School & $\begin{array}{l}0.0142^{* * *} \\
(0.000702)\end{array}$ & $\begin{array}{l}0.0496^{* * *} \\
(0.00945)\end{array}$ & \\
\hline Proportion of HS Dropouts (County) & $-0.0143(0.00411)$ & $0.0101(0.0126)$ & \\
\hline Proportion of HS Dropouts (State) & $-0.0103(0.00702)$ & $0.0256(0.0228)$ & \\
\hline $\begin{array}{l}\text { Ratio HS Dropout: College Grad Income } \\
\text { (County) }\end{array}$ & $-0.00243(0.00331)$ & $0.00245(0.00256)$ & \\
\hline Ratio HS Dropout: College Grad Income (State) & $0.0217^{*}(0.00700)$ & $-0.00983(0.00728)$ & \\
\hline Ratio HS Grad: College Grad Income (County) & $0.00195(0.00136)$ & $-0.00840(0.00692)$ & \\
\hline Ratio HS Grad: College Grad Income (State) & $-0.00580(0.0131)$ & $0.0503(0.0376)$ & \\
\hline Proportion Unemployed (County) & $0.0120(0.00721)$ & $0.00280(0.0139)$ & \\
\hline Proportion Unemployed (State) & $0.0336(0.0205)$ & $-0.0551(0.0478)$ & \\
\hline Proportion Immigrants (County) & $0.00634(0.00329)$ & $-0.00306(0.00800)$ & \\
\hline Proportion Immigrants (State) & $0.00547(0.00552)$ & $0.0216(0.0138)$ & \\
\hline Minimum Wage & $0.0151(0.0278)$ & $0.0724(0.101)$ & \\
\hline & & & $0.0775^{\star *}(0.0257)$ \\
\hline Composition & & & $0.0546(.0483)$ \\
\hline Coefficients & & & \\
\hline Total & & 977,228 & 977,228 \\
\hline & 977,228 & & \\
\hline Observations & & & \\
\hline
\end{tabular}

Using a binomial logit regression, we modeled whether each teenager was employed as a function of the variables listed in this table. This framework creates separate models for employment among teenagers in 2000 and 2013. The numbers above are from a variant of the Oaxaca-Blinder decomposition, wherein the gap between the proportion of teenagers employed in 2000 vs. 2013 is broken into parts and ascribed to changes in either the composition of the variable from the 2000 to the 2013 model or changes in the coefficient on that variable, or the relationship between the variable and employment from the 2000 to the 2013 model. This table shows the full results of the regression. For instance, the first term, $.0142^{* * *}$ signifies that 1.4 points of the 13.2 point drop in employment can be statistically attributed ot the higher proportion of teenagers who are in school in the 2013 model, and that this quantity is statistically significant.

Standard errors, based on clustering at the county level, are in parentheses 5\% Census sample 2000; ACS 2013; CPS 1999 and 2013; State and federal minimum wages ${ }^{* * *} p<0.01,{ }^{* *} p<0.05,{ }^{*} p<0.1$ (Based on Benjamini-Hochberg FDR) 
Table 6.4: Summarizing Percentage Values

\begin{tabular}{|l|r|r|r|}
\hline VARIABLES & Composition & Coefficients & Summary \\
\hline In School & $11 \%^{* * *}$ & $38 \%^{* * *}$ & \\
\hline Proportion of HS Dropouts (County) & $-11 \%$ & $8 \%$ & \\
\hline Proportion of HS Dropouts (State) & $-8 \%$ & $19 \%$ & \\
\hline Ratio HS Dropout: College Grad Income (County) & $-2 \%$ & $2 \%$ & \\
\hline Ratio HS Dropout: College Grad Income (State) & $16 \%^{*}$ & $-7 \%$ & \\
\hline Ratio HS Grad: College Grad Income (County) & $1 \%$ & $-6 \%$ & \\
\hline Ratio HS Grad: College Grad Income (State) & $-4 \%$ & $38 \%$ & \\
\hline Proportion Unemployed (County) & $9 \%$ & $2 \%$ & \\
\hline Proportion Unemployed (State) & $25 \%$ & $-42 \%$ & \\
\hline Proportion Immigrants (County) & $5 \%$ & $-2 \%$ & \\
\hline Proportion Immigrants (State) & $4 \%$ & $16 \%$ & \\
\hline Minimum Wage & $11 \%$ & $55 \%$ & \\
\hline Composition & & & $59 \%$ \\
\hline Coefficients & & & $41 \%$ \\
\hline
\end{tabular}

Using a binomial logit regression, we modeled whether each teenager was employed as a function of the variables listed in this table. This framework creates separate models for employment among teenagers in 2000 and 2013. The numbers above are from a variant of the Oaxaca-Blinder decomposition, wherein the gap between the proportion of teenagers employed in 2000 vs. 2013 is broken into parts and ascribed to changes in either the composition of the variable from the 2000 to the 2013 model or changes in the coefficient on that variable, or the relationship between the variable and employment from the 2000 to the 2013 model. This table shows the percentages attributable to each variable. For instance, the first term, $11 \%^{* * *}$ signifies that $11 \%$ drop in employment can be statistically attributed ot the higher proportion of teenagers who are in school in the 2013 model, and that this quantity is statistically significant.

5\% Census sample 2000; ACS 2013; CPS 1999 and 2013; State and federal minimum wages ${ }^{* * *} p<0.01,{ }^{* *} p<0.05,{ }^{*} p<0.1$ (Based on Benjamini-Hochberg FDR)

We will now go through and discuss each of the pieces of evidence and how it relates to each of the hypotheses.

\section{Changes in Education}

Both the increase in the proportion of teenagers in school and the increasingly-negative association between being in school and working explain part of the drop in employment among teenagers. The former explains $11 \%$ of the drop in teenage employment, the latter $38 \%$. Both are statistically significant. This supports the supply: education hypothesis and is ambiguous in terms of the demand hypotheses, since the drop in teenage employment is supportive but the change in coefficients is not. 


\section{Proportion of High School Dropouts}

While the proportion of high school dropouts among adults decreased as shown in Table 6.1, the relationship between proportion of high school dropouts by county and state and employment among teenagers grew stronger. That is, while adult high school dropouts were negatively associated with teenagers working in 2000, this relationship was even more negative in 2013, as shown in Table 6.2. However, as shown in Table 6.3, there is no evidence that changes in either composition or coefficients were meaningfully associated with any changes in teenage employment. I categorize this evidence as ambiguous.

\section{The Proportion of Immigrants}

The proportion of immigrants among adults increased as shown in Table 6.1. In addition, the relationship between proportion of immigrants by county and state and employment among teenagers may have changed, as shown in Table 6.2: the negative relationship between immigrants and teenage employment on the county level was statistically significant in 2000, but not in 2013. However, as shown in Table 6.3, there is no evidence that changes in either composition or coefficients were meaningfully associated with any changes in teenage employment. I categorize this evidence as ambiguous.

\section{Returns to Education}

As shown in in Table 6.1, the relative wage income of high school graduates and high school dropouts to college graduates declined from 2000 to 2013, both on the state and county levels. The relationship between these variables and teenage employment changed in mixed ways between 2000 and 2013, as shown in Table 6.2. As shown in Table 6.4, one of the relative wage terms, Ratio HS Dropout: College Grad Income (State), is statistically significant and explains $16 \%$ of the drop in teenage employment. This constitutes evidence in favor of the supply hypothesis.

\section{Minimum Wage}

We saw in Table 6.1 that minimum wages increased from 2000 to 2013 . However, the relationship between minimum wage and teenage employment, as shown in Table 6.2, was not statistically significant in either year. In Table 6.4, we see that while the estimates of the effect of minimum wage on teenage employment are large, they are not statistically significant. I categorize this evidence as ambiguous.

\section{Proportion of Unemployed}

As Table 6.1 shows, the proportion of adults who are unemployed increased significant between 2000 and 2013. Since unemployment is negatively associated with employment among teenagers, as show in Table 6.2, we would expect this compositional change to explain some of 
the decrease in teenage employment. However, Table 6.2 also shows a weaker negative relationship between adult unemployment and teenage employment in 2013 than in 2000. In Table 6.4, we see that the estimates of the effect of adult unemployment on teenage employment are not statistically significant. I categorize this evidence as ambiguous.

\section{Evaluating the Evidence}

The table on the following page, Table 6.5, summarizes each of the pieces of evidence shown in this chapter and how it relates to each of the hypotheses regarding the drivers of reduced teenage employment. 
Table 6.5: Evaluating the Evidence: Analytical Model Results

\begin{tabular}{|c|c|c|c|c|c|}
\hline Evidence & $\begin{array}{l}\text { Both the increase in } \\
\text { the proportion of } \\
\text { teenagers in school } \\
\text { and the increasingly- } \\
\text { negative association } \\
\text { between being in } \\
\text { school and working } \\
\text { explain part of the } \\
\text { drop in employment } \\
\text { among teenagers. }\end{array}$ & $\begin{array}{l}\text { No effects } \\
\text { related to } \\
\text { changes in high } \\
\text { school dropouts } \\
\text { are statistically } \\
\text { significant. }\end{array}$ & $\begin{array}{l}\text { No effects } \\
\text { related to } \\
\text { changes in } \\
\text { immigrants are } \\
\text { statistically } \\
\text { significant. }\end{array}$ & $\begin{array}{l}\text { One of the } \\
\text { variables related to } \\
\text { relative wage by } \\
\text { educational } \\
\text { attainment has a } \\
\text { statistically } \\
\text { significant effect in } \\
\text { terms of explaining } \\
\text { the reduction in } \\
\text { teen employment. }\end{array}$ & $\begin{array}{l}\text { No effects } \\
\text { related to } \\
\text { changes in } \\
\text { minimum wage } \\
\text { are statistically } \\
\text { significant. }\end{array}$ \\
\hline $\begin{array}{l}\text { Supply: } \\
\text { Education }\end{array}$ & $\begin{array}{l}\text { The evidence shows } \\
\text { an effect that is } \\
\text { statistically } \\
\text { significant and goes } \\
\text { in the direction } \\
\text { predicted by the } \\
\text { hypothesis. }\end{array}$ & $\begin{array}{l}\text { This hypothesis } \\
\text { makes no } \\
\text { predictions } \\
\text { regarding this } \\
\text { evidence. }\end{array}$ & \multirow[t]{2}{*}{$\begin{array}{l}\text { This hypothesis } \\
\text { makes no } \\
\text { predictions } \\
\text { regarding this } \\
\text { evidence. }\end{array}$} & $\begin{array}{l}\text { The evidence } \\
\text { shows an effect } \\
\text { that is statistically } \\
\text { significant and } \\
\text { goes in the } \\
\text { direction predicted } \\
\text { by the hypothesis. }\end{array}$ & \multirow{4}{*}{$\begin{array}{l}\text { This hypothesis } \\
\text { makes no } \\
\text { predictions } \\
\text { regarding this } \\
\text { evidence. }\end{array}$} \\
\hline $\begin{array}{l}\text { Demand: } \\
\text { Unskilled } \\
\text { Labor }\end{array}$ & \multirow{3}{*}{$\begin{array}{l}\text { This evidence either } \\
\text { shows multiple } \\
\text { statistically } \\
\text { significant effects } \\
\text { going in different } \\
\text { directions or no } \\
\text { statistically } \\
\text { significant effects. }\end{array}$} & & & \multirow{4}{*}{$\begin{array}{l}\text { This hypothesis } \\
\text { makes no } \\
\text { predictions } \\
\text { regarding this } \\
\text { evidence. }\end{array}$} & \\
\hline $\begin{array}{l}\text { Demand: } \\
\text { Immigrants }\end{array}$ & & $\begin{array}{l}\text { This hypothesis } \\
\text { makes no } \\
\text { predictions } \\
\text { regarding this } \\
\text { evidence. }\end{array}$ & $\begin{array}{l}\text { This evidence } \\
\text { either shows } \\
\text { multiple } \\
\text { statistically } \\
\text { significant } \\
\text { effects going in } \\
\text { different } \\
\text { directions or no } \\
\text { statistically } \\
\text { significant } \\
\text { effects. }\end{array}$ & & \\
\hline $\begin{array}{l}\text { Demand: } \\
\text { Other Adult } \\
\text { Workers }\end{array}$ & & $\begin{array}{l}\text { This evidence } \\
\text { either shows } \\
\text { multiple } \\
\text { statistically } \\
\text { significant } \\
\text { effects going in } \\
\text { different } \\
\text { directions or no } \\
\text { statistically } \\
\text { significant } \\
\text { effects. }\end{array}$ & \multirow{2}{*}{$\begin{array}{l}\text { This hypothesis } \\
\text { makes no } \\
\text { predictions } \\
\text { regarding this } \\
\text { evidence. }\end{array}$} & & \\
\hline $\begin{array}{l}\text { Wage } \\
\text { Floor: } \\
\text { Minimum } \\
\text { Wage }\end{array}$ & $\begin{array}{l}\text { This hypothesis } \\
\text { makes no } \\
\text { predictions regarding } \\
\text { this evidence. }\end{array}$ & $\begin{array}{l}\text { This hypothesis } \\
\text { makes no } \\
\text { predictions } \\
\text { regarding this } \\
\text { evidence. }\end{array}$ & & & $\begin{array}{l}\text { This evidence } \\
\text { either shows } \\
\text { multiple } \\
\text { statistically } \\
\text { significant } \\
\text { effects going in } \\
\text { different } \\
\text { directions or no } \\
\text { statistically } \\
\text { significant } \\
\text { effects. }\end{array}$ \\
\hline
\end{tabular}


This chapter shows evidence from the statistical model that supports the supply hypotheses. In this model, the biggest statistically significant contributor is the changing relationship between being in school and working, with being in school increasingly negatively associated with employment. The second-biggest is the drop in the median wage income of high school dropouts: college graduates by state. The third statistically significant contributor is the increasing proportion of teenagers in school. These all support the supply hypothesis, which predicts that teenagers are responding to higher returns to college by not working. Other evidence is ambiguous or unrelated to the hypotheses. 


\section{Chapter 7: Adjudicating Between Explanations}

This chapter summarizes the evidence from the previous chapters for and against each of the hypotheses for reduced teenage employment introduced earlier. Table 7.1 shows which hypotheses each piece of evidence introduced supports, is consistent with, or contradicts. For explanations of what each color means, see Table 2.1 on evidence classification. For explanations of my decision to classify each piece of evidence as supporting, consistent with, or contradictory, see Chapter Two through Chapter Six. As evident from Table 7.1, each hypothesis finds some support, but there is significant variation in terms of how much, as well as some differences in the results of the informal evidence vs. the statistical model. The following sections will discuss all of the evidence and how it relates to each hypothesis.

Table 7.1: Evaluating the Evidence: All

\begin{tabular}{|c|c|c|c|c|c|}
\hline Evidence & $\begin{array}{l}\text { Supply: } \\
\text { Education }\end{array}$ & $\begin{array}{l}\text { Demand: } \\
\text { Unskilled } \\
\text { Labor }\end{array}$ & $\begin{array}{l}\text { Demand: } \\
\text { Immigrants }\end{array}$ & $\begin{array}{l}\text { Demand: } \\
\text { Other Adult } \\
\text { Workers }\end{array}$ & $\begin{array}{l}\text { Wage } \\
\text { Floor: } \\
\text { Minimum } \\
\text { Wage }\end{array}$ \\
\hline \multicolumn{6}{|l|}{$\begin{array}{l}\text { The proportion of teenagers in school has } \\
\text { increased. }\end{array}$} \\
\hline \multicolumn{6}{|l|}{ More teenagers intend to go to college. } \\
\hline \multicolumn{6}{|l|}{$\begin{array}{l}\text { There has been a non-statistically- } \\
\text { significant increase in time teenagers } \\
\text { spend on academic activities. }\end{array}$} \\
\hline \multicolumn{6}{|l|}{$\begin{array}{l}\text { Drops in employment are significant } \\
\text { among both students and non-students. }\end{array}$} \\
\hline \multicolumn{6}{|l|}{$\begin{array}{l}\text { Teenage jobs growth from } 2000 \text { to } 2013 \text {. } \\
\text { This is robust to the definition of teenage } \\
\text { job and in terms of absolute numbers, } \\
\text { ratio to teenagers, and proportion of jobs. }\end{array}$} \\
\hline \multicolumn{6}{|l|}{$\begin{array}{l}\text { Adult immigrants make up a higher } \\
\text { proportion of teen-job workers, as well as } \\
\text { a higher proportion among adults in teen } \\
\text { jobs. }\end{array}$} \\
\hline \multicolumn{6}{|l|}{$\begin{array}{l}\text { Adult high-school dropouts make up a } \\
\text { lower proportion of teen-job workers, as } \\
\text { well as a lower proportion among adults } \\
\text { in teen jobs. }\end{array}$} \\
\hline \multicolumn{6}{|l|}{$\begin{array}{l}\text { Most of the decrease in teenage } \\
\text { employment is due to an increase in } \\
\text { teenagers who are NILF and report not } \\
\text { wanting to work, not teenagers who are } \\
\text { searching for work or report wanting to } \\
\text { work }\end{array}$} \\
\hline $\begin{array}{l}\text { There is no evidence for a change in the } \\
\text { distribution of hours } 12^{\text {th }} \text { graders report } \\
\text { wanting to work during the year. }\end{array}$ & & & & & \\
\hline
\end{tabular}




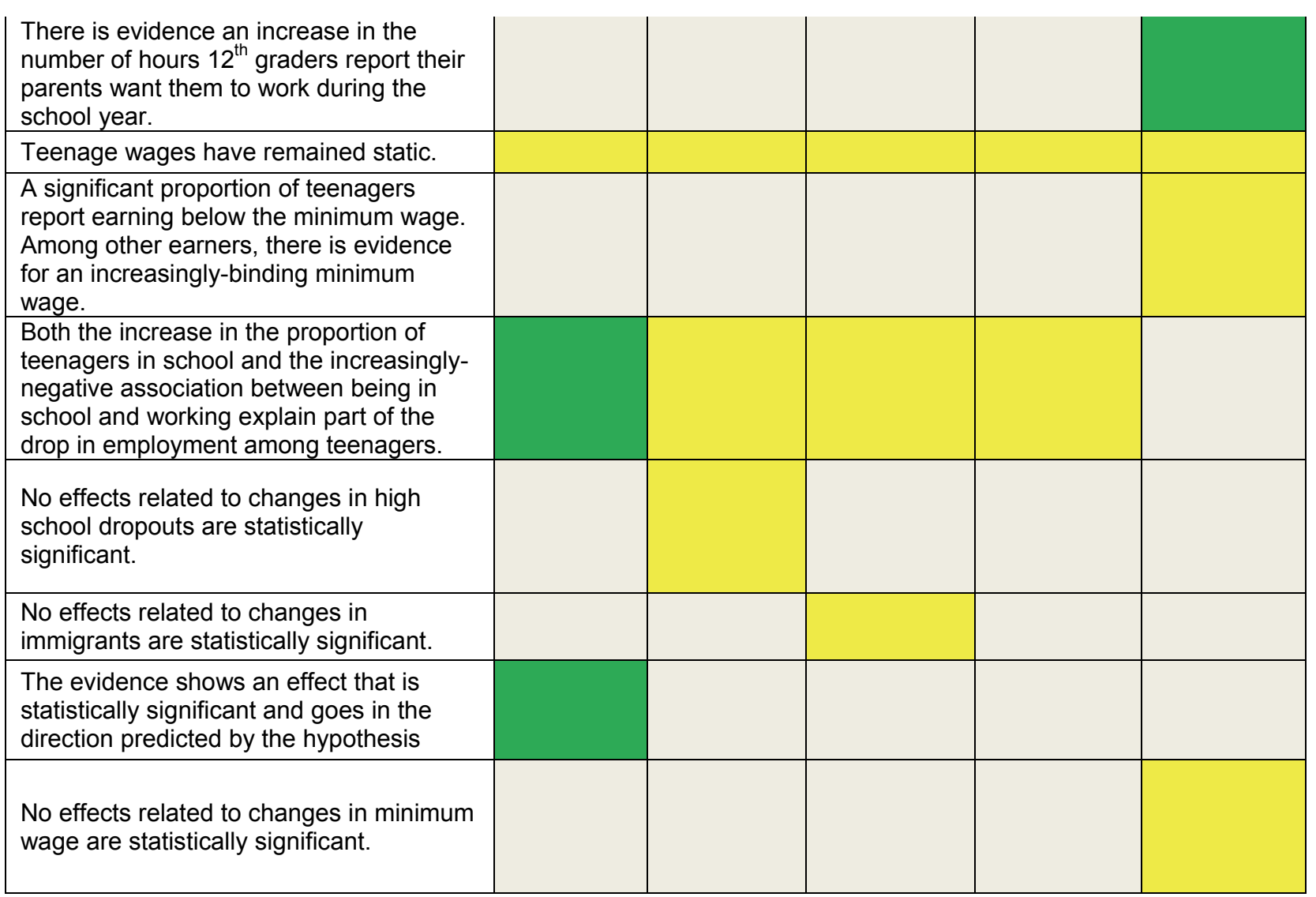

\section{Decreased Supply Due to Increased Returns to Education}

While the statistical model supports the supply hypothesis, the informal evidence is somewhat more mixed. First, as shown in Chapter Two, the supply hypothesis predicts both higher school attendance among teenagers and that higher attendance explains some of the decrease in employment. This is what we see in the evidence: more teenagers attend school, more teenagers intend to attend college, and the increase in teenagers attending school explains some of the reduction in teen employment in the statistical model.

However, the model also predicts that only students should experience reduced unemployment, which is not found to be the case. This prediction comes because increased returns to education - which we model as higher adult wages for those with more schooling - are equivalent to a higher expected endowment for those with more school and a lower expected endowment for those with less school. Therefore, teenagers who are in school will spend this on a combination of more leisure, via working less, and more income. Teenagers not in school will respond in the opposite way, though more work and less income. The evidence in fact shows a drop in employment among high school students, college students, and those not in school, which contradicts the hypothesis. 
Additionally, the theoretical model described in Chapter Two predicts a reduction in teenagetype jobs, and we don't find this to be the case, as discussed in Chapter Four. Across various different ways of categorizing jobs as being teenage jobs, as well as different ways of categorizing whether teen jobs increased or decreased, we find an increase in teenage jobs from 2000 to 2013 . This is at odds with what the supply hypothesis predicts, which is that a reduction in teenage labor supply would lead to fewer of these types of jobs.

Finally, the hypothesis predicts that we'll see both increased returns to education, and that these increased returns to education will have explanatory power for the reduction in teenage employment, and we find both of these to be the case. At the state and county level, median wage income among high school dropouts and high school graduates relative to college graduates has fallen, and we find this explains a small proportion of the reduction in teenage employment. Additionally, the change in the degree to which the ratio of high school dropout to college graduate wages at the state level predict youth employment also explains a significant proportion of the drop in youth employment.

Overall, the evidence for this hypothesis is generally positive.

\section{Decreased Demand}

The hypotheses that demand for teenage labor has dropped due to increased competition from adults all get significant support from the informal evidence but no support from the statistical model. Like the supply hypotheses, each of the demand-related hypotheses predict increased schooling, because one of the alternative uses of time, working, is now less remunerative. We find this to be the case: teenagers are in school at higher rates. The demandrelated hypotheses are also supported by the increase in teenage jobs: if other workers are increasingly competing for teenage jobs, we would expect to see more teenage jobs, and this is in fact what we see, across various definitions of teenage jobs and ways of evaluating increases or decreases. As discussed in Chapter Four, there has been growth in teenage jobs both in absolute terms and relative to other jobs, as well as relative to the number of teenagers.

\section{Competition from Unskilled Labor}

There is no support specific to the hypothesis that demand for teenage labor has declined due to competition from unskilled labor. First, adults with less than a high-school degree make up a lower proportion of adults in general as well as adults in teenage jobs in 2013 relative to 2000 . This is at odds with what we would expect to see if unskilled workers were increasingly competing with teenagers. Additionally, in the statistical model, no changes related to high school dropouts explain the drop in teenage employment.

Overall, the evidence for there being some demand-related changes is strong, but there is no evidence for this particular hypothesis. 


\section{Competition from Immigrations}

In addition to the support provided to all of the demand-related hypotheses by informal evidence, the hypothesis that adult immigrants are increasingly competing with teenagers for jobs is supported by some evidence specific to this hypothesis. First, immigrants make up a higher proportion of adults in general as well as of adults in teenage jobs in 2013 relative to 2000. This is what we would expect to see if immigrants were increasingly competing with teenagers. However, in the statistical model, no changes related to immigrants explain the drop in teenage employment.

Overall, the evidence for this hypothesis is mixed but positive: most of the evidence in support of it points to a demand-related change, but not necessarily one related to immigration.

\section{Competition from Adults in General}

The hypothesis that adults in general are increasingly competing with teenagers for jobs is not supported by the evidence specific to this hypothesis. From the statistical model, we see no evidence that either an increase in adult unemployment or a changing relationship between adult unemployment and teenage employment explains the drop in teenage employment.

Again, the evidence for there being some demand-related changes is strong, but there is no evidence for this particular hypothesis.

\section{Minimum Wage Effects}

There is the least evidence for the minimum wage, with the informal evidence frequently being contradictory or ambiguous, and the results from the statistical model also being ambiguous. The minimum wage hypothesis predicts a decrease in employment among both students and non-students. This is because the minimum wage hypothesis is conceptualized as a wage rate change: higher wages for some teenagers combined with zero wages (due to lack of job availability) for others, with no expectation that ability to find a job will be dependent on school status. (This is similar to the demand hypothesis, which also predicts an exogenous wage decrease.) The evidence is consistent with this prediction: we see a drop in employment both among students and non-students.

The minimum wage hypothesis also predicts a reduction in total number of teenage jobs, which is contradicted by the evidence on this. An increasingly-binding minimum wage would result in fewer of these jobs: in fact, across both definitions of teenage jobs and ways of looking at increases or decreases, including relative to other types of jobs, teenage-type jobs have grown.

The minimum wage hypothesis also predicts that the reduction in teenage employment is involuntary: that is, more teenagers should report wanting to work than previously, but not be able to find jobs. The evidence for this is largely negative. The drop in teenage employment is 
nearly all accounted for by an increase in teenagers who are not searching for jobs and report not wanting to work ${ }^{25}$. Additionally, there has been no change in the distribution of hours that $12^{\text {th }}$ graders report wanting to work during the school year, although they do report that their parents want them to work more.

The evidence on wage changes is also mixed. The minimum wage hypothesis predicts an increase in hourly wages as well as a change in the distribution of wages relative to the minimum wage. We do not see an increase in hourly wages. Additionally, over $40 \%$ of teenagers who reported earning income in both 2000 and 2013 reported earning less than the minimum wage. This limits the degree that we would expect the minimum wage to affect employment, because teenagers are either heavily in jobs that are exempt from the minimum wage or are working for employers who are committing wage fraud. However, among teenagers reporting earning more than the minimum wage, the evidence is consistent with what we' $d$ expect from an increasinglybinding minimum wage: a higher proportion of teenagers reported earning just over the minimum wage, with fewer earning significantly more than the minimum wage.

Additionally, from the statistical model, we see no evidence that either an increase in minimum wages or a changing relationship between minimum wages and teenage employment explain the drop in teenage employment.

Overall, the evidence for this hypothesis is negative.

\section{Conclusion}

All of these hypotheses have some evidence in favor and some evidence contradicting them, but based on both the informal evidence and the statistical model, overall evidence is most positive for the supply hypothesis. Evidence is also strong for there having been some kind of demand shift. However, the only demand hypothesis with evidence specifically in its favor is the immigration hypotheses, and even for that, evidence is limited. The next chapter discusses the policy implications of these results.

${ }^{25}$ It is difficult to say to what extent this may reflect changing expectations in response to the changing availability of jobs. 


\section{Chapter Eight: Policy Implications and Recommendations}

Based on the literature discussion in Chapter One and the analysis in the rest of this report, we conclude first that the average effects of teenage employment may be small and second that teenagers increasingly abstaining from employment in order to focus on school is likely a major driver of the reduction in teenage employment. In combination, these argue that focusing on raising teenage employment in general is a mistake: if teenagers are attending school at higher rates and forgoing working while in school at higher rates, possibly in recognition of higher returns to education, this is a positive response to changing economic conditions.

However, there is a subset of teenagers whose employment is not a function of increased school attendance, and improving outcomes for that group of teenagers is more properly the focus of public policy. Those teenagers are those who are neither in school nor working. These teenagers are atypical in a variety of ways: they are older, more likely to be black or Hispanic, and more likely to come from households below the poverty line. Additionally, they have a variety of other characteristics which may explain their lack of employment and education: they are more likely to be in prison, disabled, or to have children. By viewing teenagers as a homogenous group, as with the general literature on the effects of teenage employment, we may miss out on this group, which accounts for less than $10 \%$ of teenagers.

There are a variety of different government programs aimed at increasing youth employment. These directly hire teenagers, subsidize private employers to do so, or attempt to give teenagers life skills and vocational training. The first two types of programs are not well-studied, and what evidence exists is not especially positive regarding there being employment or educational effects that last beyond the actual program. The federal tax break for employing teenagers is not available at all for a large majority of disengaged teenagers because they are too old to qualify for it, and the local programs for the employment of teenagers also tend to include younger teenagers and high school students. Additionally, while these programs are extremely common, there's little program evaluation occurring, and what does exist has not shown significant positive effects. However, there are two major programs focusing on life and vocational skills which are well-targeted toward disengaged teenagers and have been shown to have positive employment outcomes. These are the National Guard Youth ChalleNGe and Job Corps. There should be more rigorous assessment of the direct-hire and subsidy programs, and their efficacy should be compared to ChalleNGe and Job Corps in the making of funding decisions.

\section{Disengaged Teenagers}

While for some teenagers, lack of employment means less spending money and more summer school, for others it is part of a general disengagement from both work and school. It is 
this latter group who are more properly the focus of public policy, and current efforts toward youth employment mixed in terms of how well they target this group. As shown in Figure 8.1, the proportion of teenagers neither in school nor working rose from 2000 to 2013, but is still below earlier levels. The proportion of teenagers who are both not working and not in school rose from about $7 \%$ in 2000 to $9 \%$ in 2013 , or about 1.2 to 1.4 million $16-19$ year-olds. ${ }^{26}$ This is still lower as a percentage than it was during the late 80 s and down from a local minimum, or trough, in 2009.

Figure 8.1: Proportion of Teenagers in neither Work nor School, 1986-2014

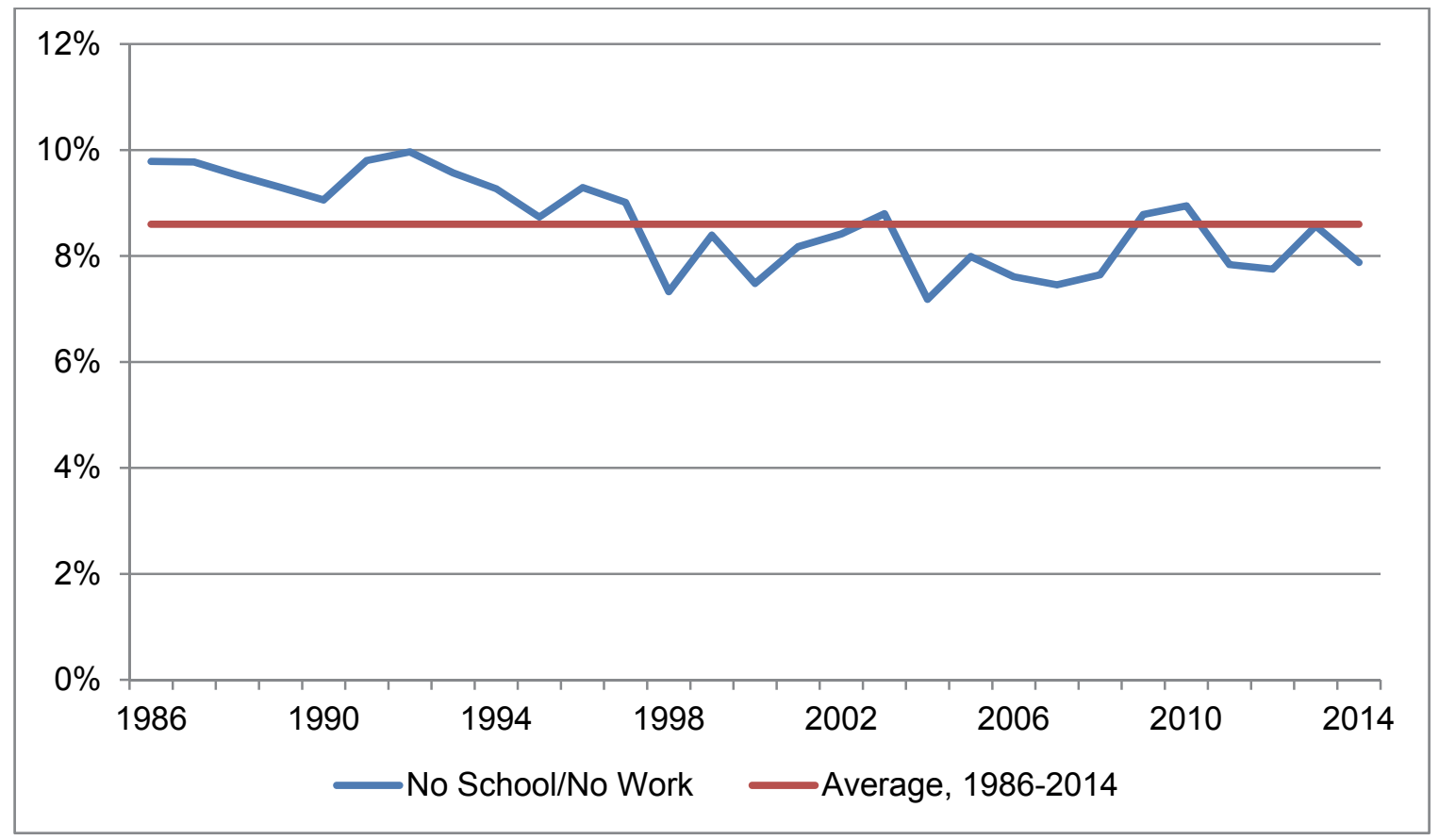

CPS, March 1986-2014

This section will describe these disengaged teenagers, who differ from their engaged peers along a variety of dimensions. In 2013, there were about 1.3 million teenagers neither working nor in $\operatorname{school}^{27}$ : these teenagers differed from more-engaged teenagers in a variety of ways. For instance, compared to teenagers who are in school or working, disengaged teenagers are disproportionately Black or Hispanic, from households below the poverty line ${ }^{28}$, imprisoned or in

${ }^{26}$ Because ACS data doesn't go back before 2000, this is March CPS data. Because it is March data, it won't totally line up with the yearlong ACS survey results. Prior to 1986, CPS did not collect data on schooling status.

27 This section is based on 2013 ACS data. For Figure 8.1, I wanted the longitudinal data, but for describing teenagers in 2013, ACS is better-suited because of its much bigger sample size: there are 975 "disengaged" teenagers in March 2013 data, compared to 12,295 in 2013 ACS data.

28 As discussed in Chapter One, teenagers not working is unlikely to be the cause of household poverty status because teenagers earn such a low proportion of household income, even in impoverished households. 
medical institutions. They also tend to be older teenagers, and so are more likely to have finished high school (but are less likely to have any college experience).

\section{Disengaged Teenagers are Older}

As shown in Figure 8.2, teenagers who are disengaged from both work and school are on average older than engaged teenagers: almost half are 19 and one-third are 18, compared to about almost a uniform distribution among engaged teenagers. As I will discuss later, the tax break for hiring teenagers is only for a subset of 16- and 17-year-olds, meaning that it almost entirely misses disengaged teenagers.

Figure 8.2: Age by Engagement Status

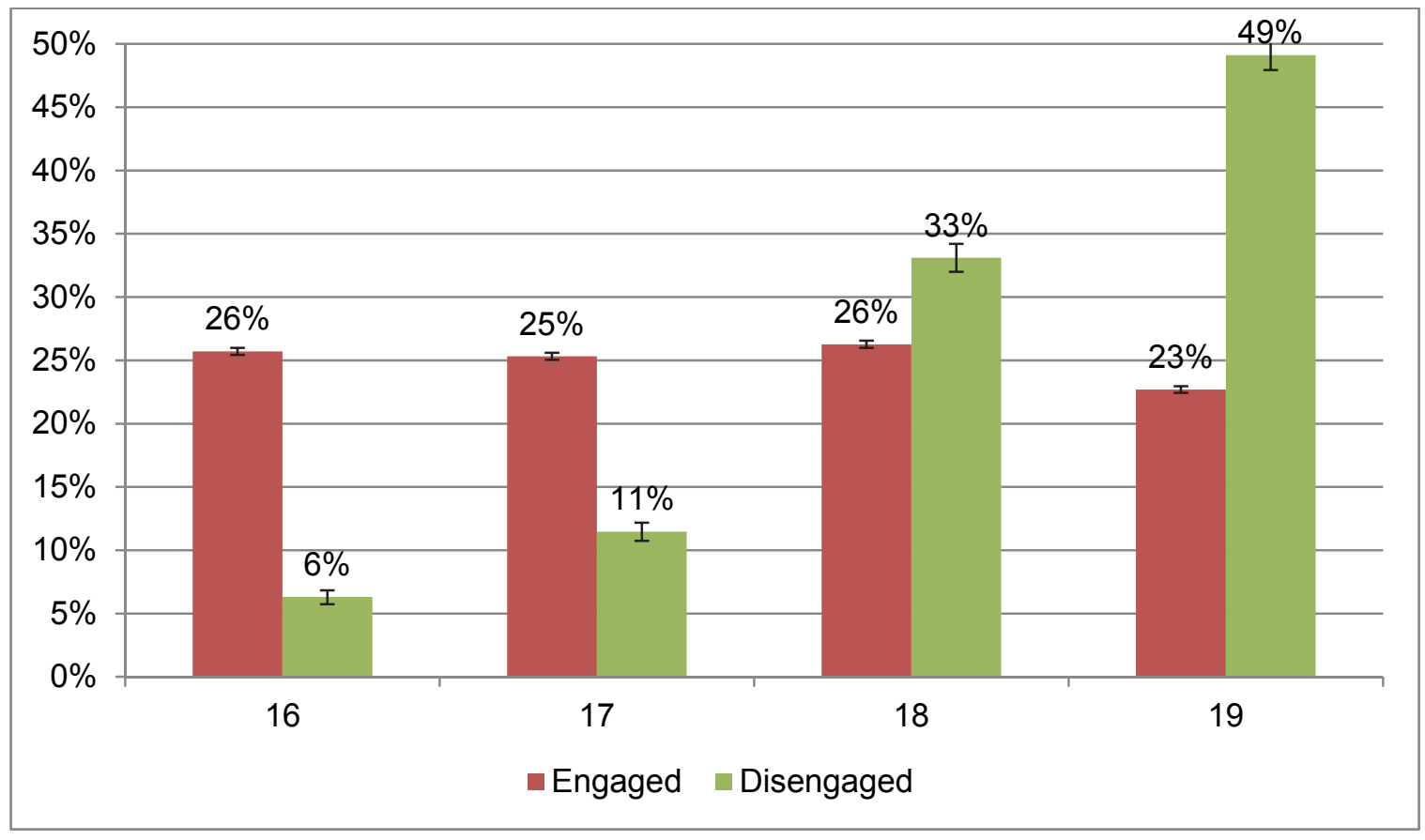

ACS 2013

Error bars reflect $95 \%$ confidence intervals.

\section{Disengaged Teenagers are more likely to be Black or Hispanic}

As shown in Figure 8.3, teenagers who are disengaged from both work and school have a different racial/ethnic distribution than teenagers who are engaged with work and/or school. Black teenagers are overrepresented the most, making up 23\% of disengaged teenagers but only $14 \%$ of engaged teenagers. Hispanic teenagers are also overrepresented among disengaged teenagers. However, while these groups are overrepresented, disengagement among teenagers is certainly not solely a minority issue: white teenagers still make up the largest group of disengaged teenagers. 
Figure 8.3: Racial/Ethnic Group by Engagement Status

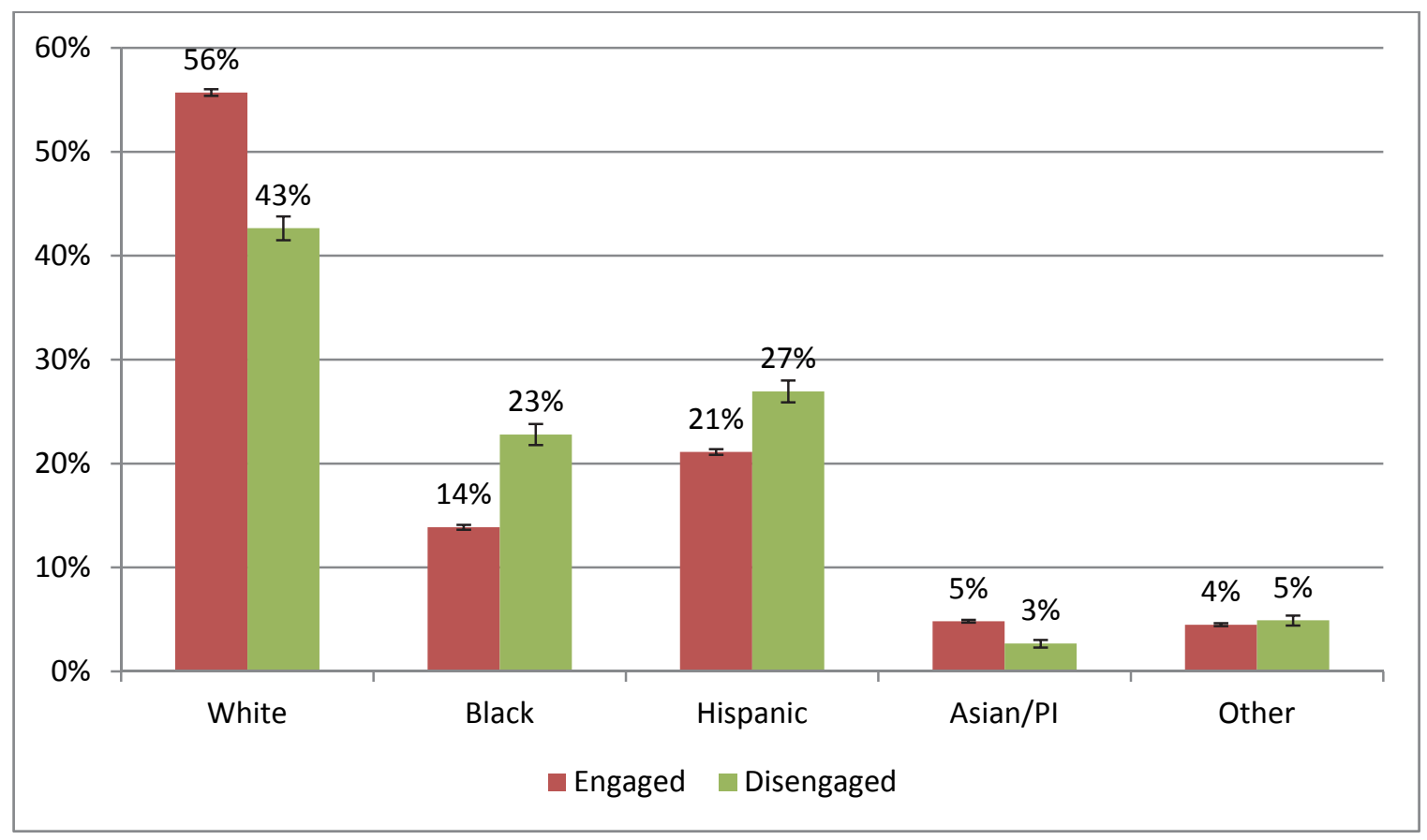

ACS 2013

Error bars reflect $95 \%$ confidence intervals.

Disengaged Teenagers are more likely to come from Households below the Poverty Line

As shown in Figure 8.4, teenagers who are disengaged from both work and school are more likely to come from impoverished households relative to teenagers who are engaged with work and/or school. Forty-one percent of disengaged teenagers come from households with incomes below the poverty line, relative to only $28 \%$ among engaged teenagers. 
Figure 8.4: Household Income by Engagement Status

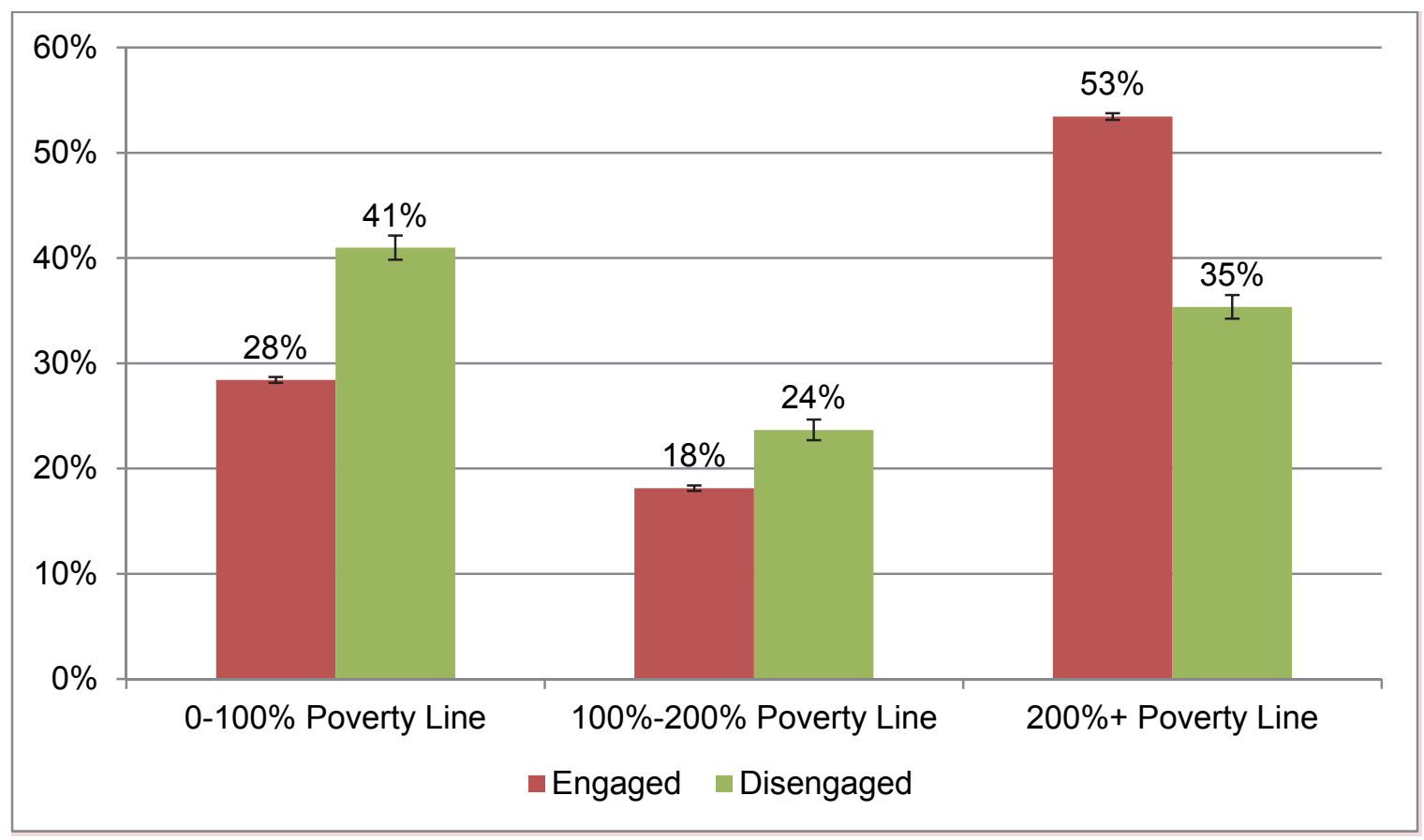

ACS 2013

Error bars reflect $95 \%$ confidence intervals.

Disengaged Teenagers Are More Likely To Be Imprisoned, Less Likely to Live in Dorms

As shown in Figure 8.5, teenagers who are disengaged from both work and school are more likely to be institutionalized in group quarters like jail, prison, or hospital settings like nursing homes or mental institutions, but less likely to be non-institutionalized group quarters, like dormitories, military barracks, or boarding houses. However, only a small minority - about 5\% of disengaged teenagers are in institutionalized group quarter settings. Therefore, currently being institutionalized does not appear to be a major contributor to being in this group. However, it is possible that arrests, imprisonment, or other types of institutionalization are contributing in larger ways to this group via causing teenagers to drop out of school and/or lose jobs, and then remain out-of-school and then not working even after the period of institutionalization ends. 
Figure 8.5: Group Quarters by Engagement Status

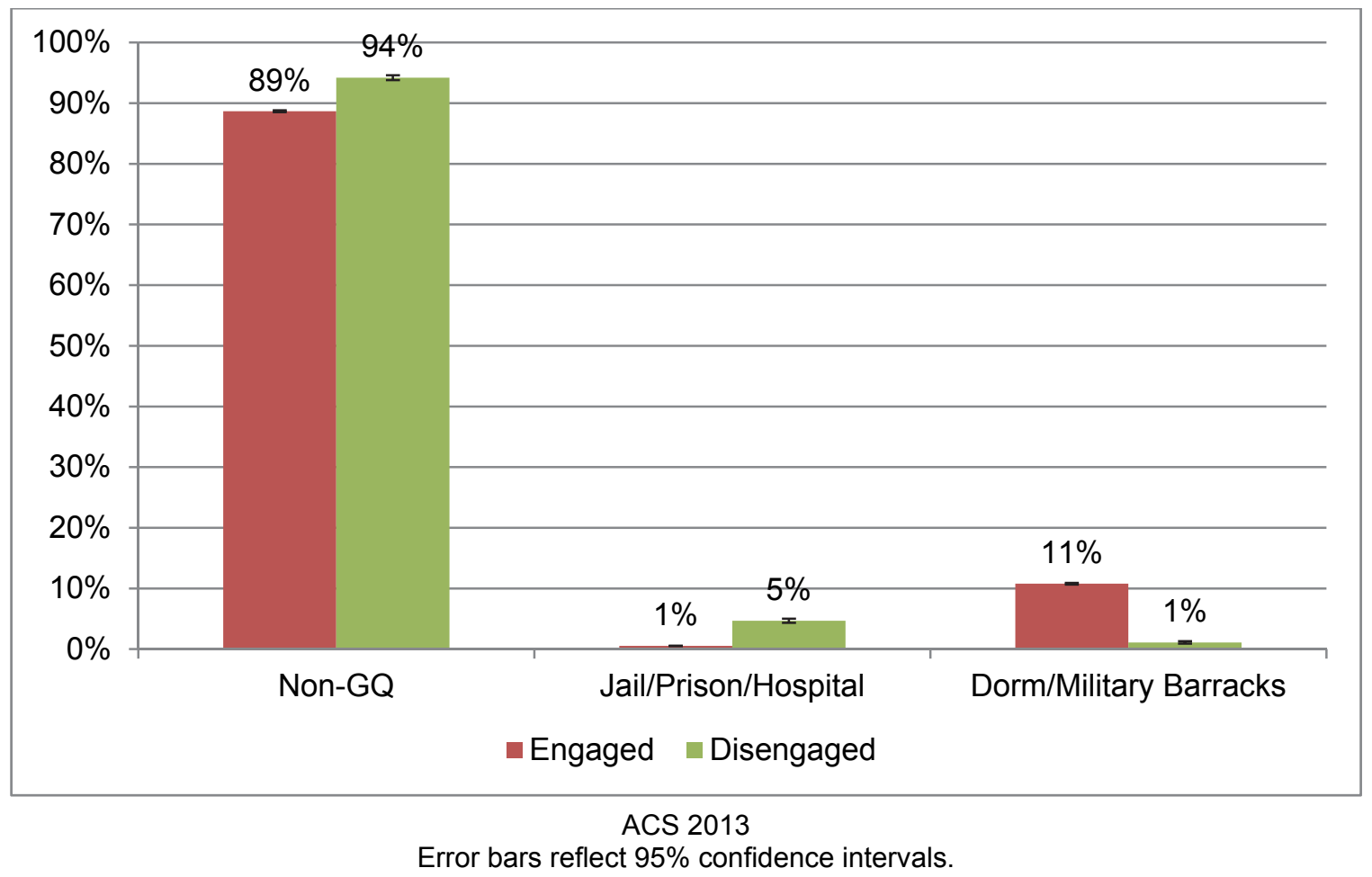

Disengaged Teenagers Are More Likely To Be High School Graduates, Less Likely to Have Any College

As shown in Figure 8.6, teenagers who are disengaged from both work and school are more likely to have completed high school but less likely to have attended college. This is due to disengaged teenagers being older than their engaged peers. Almost two-fifths do not have a high school diploma or a GED, with most of the remaining having a regular high school diploma but no college. Because unemployment is so high and wages so low for adults without a high school diploma, that group presents the greatest employment challenges. This is not shown, but the median non-high-school-completer (which includes both the "no high school" and "some high school, no diploma" group) finished only the tenth grade. 
Figure 8.6: Educational Attainment by Engagement Status

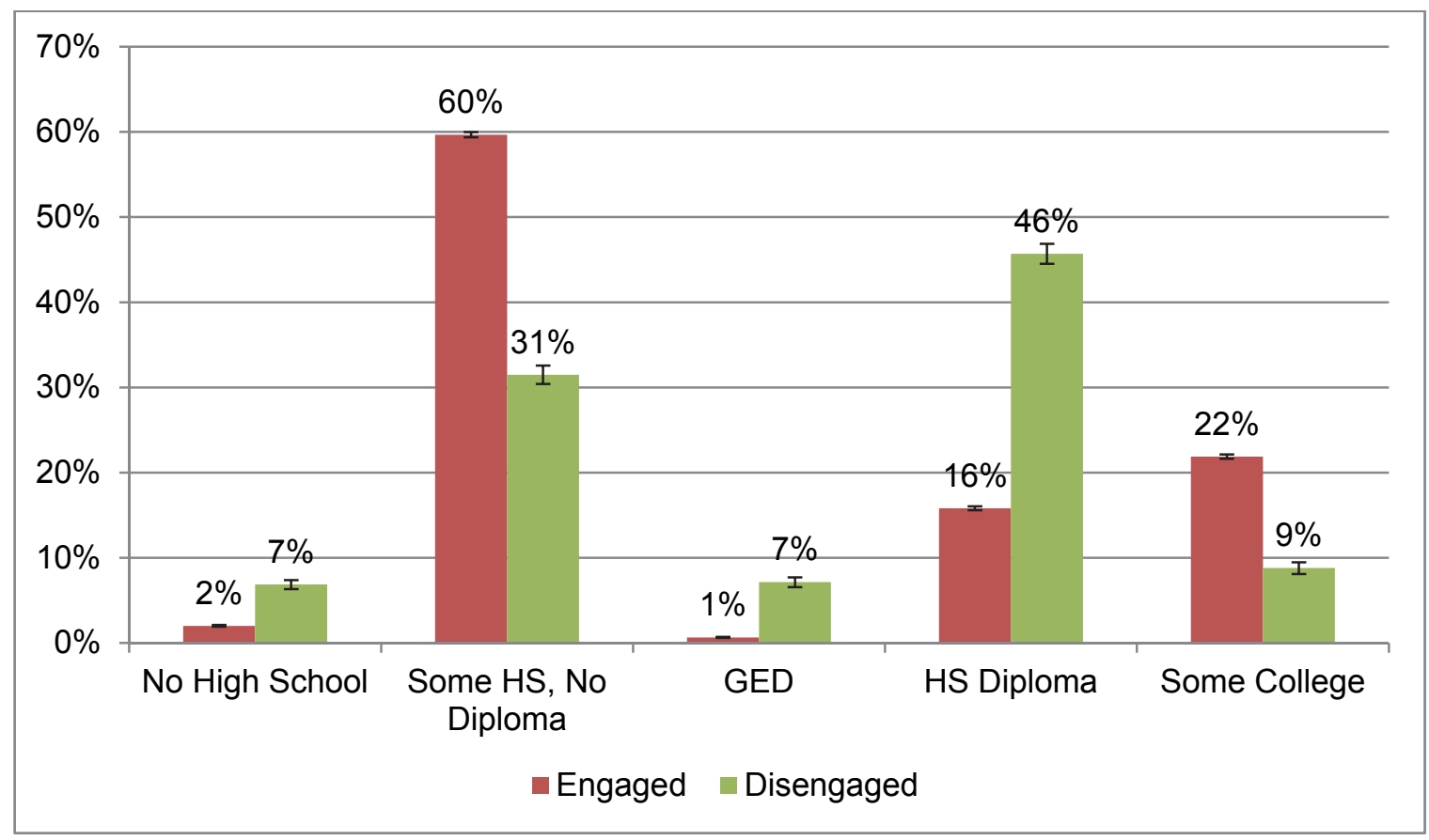

ACS 2013

Error bars reflect $95 \%$ confidence intervals.

\section{Disengaged Teenagers Are Urban, Rural, and Suburban}

While it is somewhat difficult to tell what the geographical profile of disengaged teenagers is because ACS provides complete information on less than half of teenagers ${ }^{29}$, from what we can see it appears that disengaged teenagers have similar geographic profiles in terms of urban/suburban/rural status as teenagers who are engaged in school or work. Most live in the cities or suburbs, with a minority of each group living in towns or rural areas.

${ }^{29}$ The smallest geographical unit on which information is disseminated for the ACS microdata is Public Use Microdata Area, or PUMA. If PUMA is wholly not in a metro area, it is classified as "not in a metro area", which is all "rural/town." If it is partially within a metro area, it is classified as "not identifiable," which I call "unclear." If it is wholly within a metro area and wholly within the central/principal city of a metro area, it is classified as "central/principal city", which I refer to as "urban," and if it is wholly outside that central city, as "outside central/principal city," which I call "suburban." If it is wholly within a metro area but partially within the central city and partially outside of it, it is referred to as "central/ principal city status unknown," which I refer to as urban/suburban (unclear). 
Figure 8.7: Educational Attainment by Geographical Status

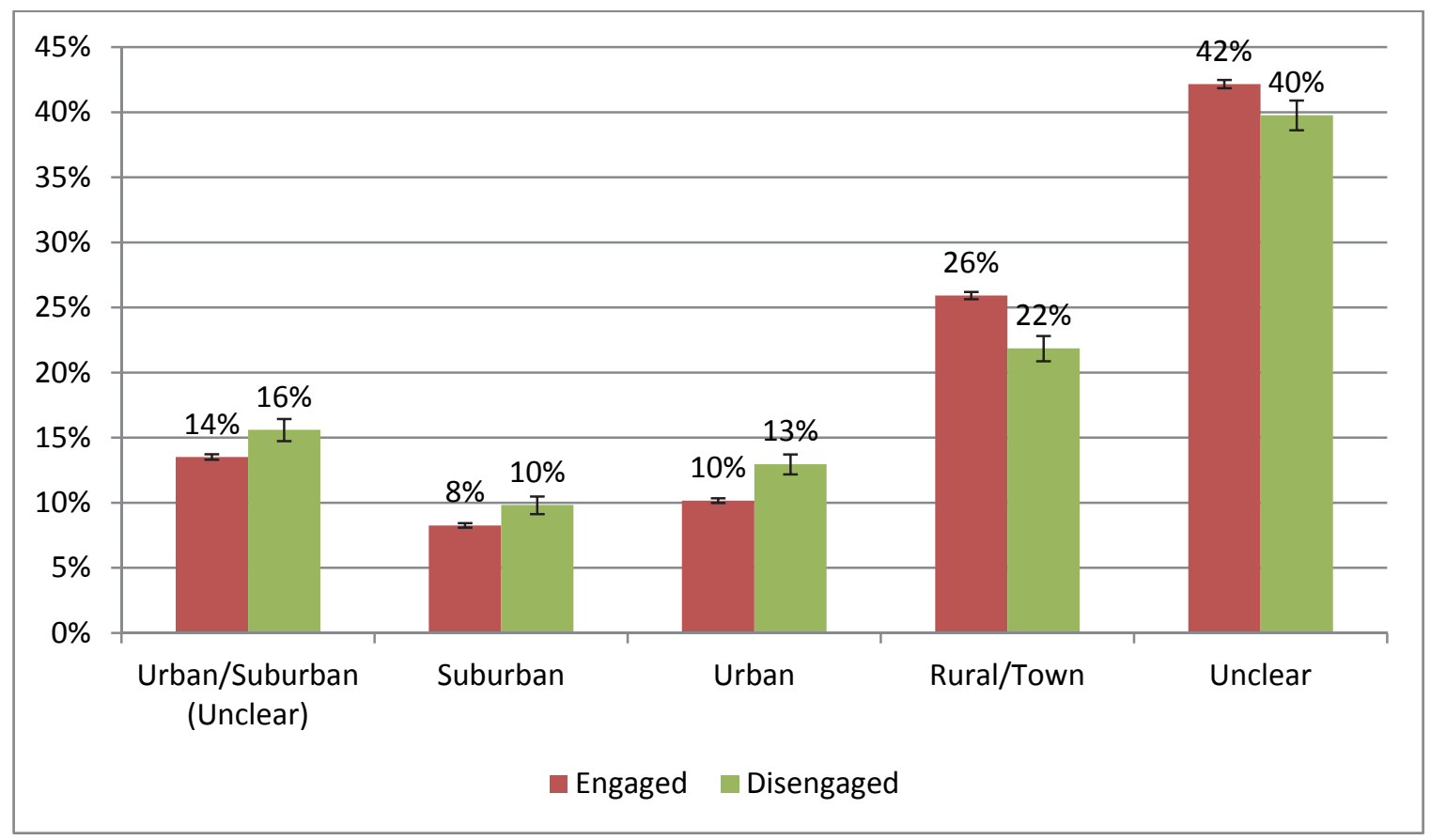

ACS 2013

Error bars reflect $95 \%$ confidence intervals.

\section{Disengaged Teenagers Are Different in Other Ways: More Likely to Have Children, More Likely to be Disabled}

There are a few additional ways in which disengaged teenagers have different profiles than teenagers who are engaged in work or school. Almost $12 \%$ of disengaged teenagers report some form of disability, relative to only about $5 \%$ of engaged teenagers ${ }^{30}$. The most common reported disability among both engaged and disengaged teenagers was cognitive, but disengaged teenagers were more likely to have every form of reported disability - cognitive difficulties, ambulatory difficulties, sensory difficulties (hearing or seeing), and independent living difficulties. Disengaged teenagers are also more likely to live in households with their own children: more than $6 \%$ of them reported this, relative to less than $2 \%$ among teenagers engaged

\footnotetext{
${ }^{30}$ Among teenagers, the disability status variables that I work with in this chapter are only weakly related to either whether a respondent reports having "a health problem or a disability which prevents him/her from working or which limits the kind or amount of work" or whether the respondent reports receiving supplementary security income for reasons of disability. I determined this by looking at recent Current Population Survey data: American Community Survey data, which all of this chapter's figures and analysis are based on, does not include either work disability or supplementary security income information. Looking at the CPS data, work disability among teenagers has risen slightly from 2000 to 2013 , from an estimate of $2.16 \%$ to $2.34 \%$. Additionally, the proportion of teenagers receiving disability income rose from $.86 \%$ in 2001 (there is no 2000 data) to $.94 \%$. The rate of work disabilities in 2013 is much higher among disengaged teens than among those who are engaged: $6.5 \%$ vs. $1.9 \%$. Disengaged teenagers are also significantly more likely to report receiving supplementary security income: $2.4 \% \mathrm{vs} . .8 \%$.
} 
in school or work. Disengaged teenagers are also somewhat more likely to be immigrants and to be married and less likely to be fluent English speakers.

\section{Lack of Engagement Likely Stems from a Variety of Factors}

From the data from the previous section, it is likely that disengagement from school or work stems from a whole variety of small factors including imprisonment, no or limited English skills, disability, living with their own children who may rely on them for child care, or having stopped education before completing the ninth grade. About 30\% of disengaged teenagers are affected by at least one of these issues, relative to about $12 \%$ of teenagers who are engaged in school or work. However, over $40 \%$ of disengaged teenagers are both unaffected by all of these issues and have at least a regular high school diploma. Among disengaged teenagers, there are a variety of different barriers to employment.

\section{Modeling Lack of Engagement}

When modeling disengagement among teenagers in 2013, I found that many of the factors discussed in this chapter predict engagement status. I included in my model the following variables: age, race, poverty status, group quarters status, educational attainment, metropolitan area status, immigrant status, whether the respondent lives with one or more of their own children, marital status, English fluency, and disability. I used a logit regression model and examined the odds ratios. I found that the statistically significant factor $(p<.01)$ most strongly predicting disengagement was age: controlling for other factors, being 18 is associated with a 5.4 times greater probability of being disengaged than being 15, and being 19 is associated with a 12.0 times greater probability. Additionally, having no high school or a GED/alternative credential was strongly associated with being disengaged, relative to having some high school or a regular high school diploma: having no high school was associated with a 7.0 times probability of being disengaged, relative to having some school, and having a GED or other alternative credential with a 4.2 times greater probability. ${ }^{31}$ Having children was associated with a 2.8 probability of being disengaged relative to not having children, and being disabled with a 2.0 probability. Factors including not being in a household with income of at least $200 \%$ of the poverty line, being black or Hispanic, not being fluent in English, and not living in a metropolitan area (city or suburb) were also associated in a statistically significant way, but less dramatically. Immigration status had no explanatory power, nor was there a distinction between living in a household below the poverty line vs. between $100 \%-200 \%$. There was no distinction

\footnotetext{
${ }^{31}$ Having some college is the most strongly negative associated with being disengaged, with a probability of being disengaged of .02 relative to having no high school. However, this is not a particularly meaningful finding: we're defining teenagers as disengaged if they are not in school and not working, and very few teenagers have had time to complete high school, enroll in college, and drop out of college.
} 
between having a missing value for metropolitan status vs. living in a rural area or town. Together, all of these variables explain about $20 \%$ of the variation in disengagement status.

\section{Programs to Increase Youth Employment Vary Significantly in Terms of Program Evaluation, Targeting the Disengaged}

There are three general categories of government programs aimed at increasing the employment of teenagers $^{32}$. The first are programs at the state and local level that directly assist in employing teenagers, either by giving them jobs working for the government or by partnering with private sector employers. The second is a federal tax credit subsidizing the employment of various populations including a subset of teenagers: 16 and 17-year-olds in certain geographical areas during the summer. The third are programs that focus more broadly on youth development, attempting to increase both education and employment among teenagers who are not in school. The first two categories of programs do not appear to be particularly well-targeted at disengaged teenagers. They tend to be focused in urban areas, while disengaged teenagers are spread out in urban, suburban, and rural areas. Additionally, neither focus on older teenagers, with direct employment programs tending to employ younger teenagers who are still in high school as well as older teenagers, and the tax credit actively excluding older teenagers. The third type of program is much better-targeted at disengaged teenagers, using both education and employment status as criteria for selection.

The way all of these programs are structured present almost an ideal context for program evaluation, but for the first two categories, little appears to be occurring. This makes increasing program evaluation and re-allocating funding based on results the low-hanging fruit in terms of policy improvement on this issue.

\section{Direct-Hire Programs}

Government programs for the employment of teenagers during the summer are extremely common: according to Gelber (p. 2, 2014) "the fifty most populous cities in the country have all had summer youth employment programs in the last five years." These programs are broadly rather than narrowly targeted: they tend to be available for younger as well as older teenagers. These programs are not specifically tailored toward the employment of disengaged teenagers. While there are perhaps good reasons for this - for instance, we wouldn't want to cause teenagers to drop out of high school in order to be eligible for work programs - there are other

\footnotetext{
32 One could classify public high school as a program aimed at increasing the employment - or at least employability - of teenagers, but, as public high school is already universal and it would be difficult to either evaluate it or expand it, I do not include it here.
} 
ways to target these teenagers, like limiting eligibility to older teenagers, without introducing bad incentives.

These programs have two traits that would make them a good subject of program evaluation. First, because they are locally run, there is likely to be variation in terms of many attributes. Second, there is likely to be more demand from teenagers than available funding ${ }^{33}$, meaning that a randomization process (lotteries) can be used to obtain treatment and control groups for study.

\section{The Work Opportunity Tax Credit}

The Work Opportunity Tax Credit is a tax credit ${ }^{34}$ available to businesses that hire members of certain groups including unemployed veterans, ex-felons, the recipients of certain meanstested programs, and a subset of teenagers. The subset of teenagers that this credit is available for are 16- and 17-year-olds who are working during the summer months and live in any of thirty different locations. The list of locations is mostly urban, but also includes several more-rural counties. $^{35}$ Because it is only available for employing younger teenagers, it would not be available for hiring the large majority of disengaged teenagers, most of whom are 18 or 19.

Several features of this program, while not necessarily good policy features, do make it a good candidate for study. First, the age cutoffs mean it would be possible to look at employment outcomes for teenagers who just missed out on eligibility versus those who were eligible. Second, because of how geographical eligibility was determined (that is, based not just on the economic attributes of a particular area but also on the quality of plans put forth by local governments $^{36}$ ), it would likely be possible to find geographical comparison groups that are similar in terms of economic conditions.

\section{Life Skills/Vocational Ed Programs}

The third category of programs to increase youth employment focus more broadly on job and life skills, rather than on directly on immediate employment. Two major programs in this area are the National Guard Youth ChalleNGe program and Job Corps. Both of these have significant similarities relative to the first two categories: they are longer-term, residential, only open to people who are not currently in school, and focus on a broad set of skills. The entrance criteria are also better-targeted toward disengaged youth. Like with direct hire summer programs, acceptance into these programs has a random element. Additionally, both have been found to have positive effects on educational attainment and employment several years after selection into

\footnotetext{
33 This was the case in New York City (Gelber, 2014). This has also recently been the case in Wilmington, DE; Windsor, CA; Selma, AL; and Medford, MA, among others.

34 A tax credit lowers the filer's tax bill, as opposed to a tax deduction, which lowers taxable income.

35 http://www.doleta.gov/business/incentives/opptax/eligible.cfm\#SYE

${ }^{36}$ http://portal.hud.gov/hudportal/HUD?src=/hudprograms/empowerment_zones
} 
the program. However, both programs are also expensive, so their efficacy does not necessarily mean that they would out-perform other types of programs.

The National Guard Youth ChalleNGe program is open to unemployed high school dropouts between 16-18. The most-intensive element is a 20 -week residential program in which participants live in barracks and adhere to a very structured schedule of activities including those related to leadership, life-coping skills, fitness, job skills, and academics (Millensky, 2011). In 2005-2006, there was a study of 1,200 participants from across the ChalleNGE sites, an average of three years after they entered the program. Researchers also studied a control group consisting of people who applied to the program but were not selected in the lottery. They found positive results on education and employment related to program participation. First, $72 \%$ of ChalleNGE participants had graduated from high school or earned a GED, relative to $55 \%$ of the control group. Since some of the program sites offered participants the ability to earn a high school diploma or GED, this may reflect either credentials earned in the program or earned afterward. However, program participants were also significantly more likely to have accrued college credits, at $35 \%$ vs. $19 \%$, and to be currently enrolled in college courses, at $11 \%$ vs. $8 \%$. Employment outcomes were also more positive for the program participants. They were more likely to have been employed at some point during the last year, at $88 \%$ vs. $85 \%$, and reported higher earnings. They were also more likely to be currently employed, at $58 \%$ vs. $51 \%$.

Another report, "A Cost-Benefit Analysis of the National Guard Youth ChalleNGe Program", attempts a more comprehensive cost-benefit analysis of the program, also looking at 2005-2007 participants. Like the previous report, this finds higher GED and high school diploma attainment, higher college attendance, and higher employment and earnings. Using comparisons of participants to NLSY97 respondents, the biggest effect that the researchers find is an expected increase in lifetime earnings of about $\$ 46,000$ per participant. Other benefits are minor. They conclude that the benefits significantly outweigh the costs, which they assess as about $\$ 15,000$, most of which is the direct cost of operating the program.

Job Corps is another program that serves youth to prepare them for the labor market, but also does not focus on immediate employment. Participants can get remedial education to prepare them for the GED, as well as vocational training (Schochet, 2001). Like the ChalleNGe program, there is also a residential element, with participants living together on-site. The program is somewhat costlier than ChalleNGe, at about $\$ 19,500$ per participant for an average of eight months. An evaluation of the program took place four years after program assignment and involved about 7,000 people who had been randomly assigned to the program and 5,000 control group participants who had applied but not been assigned. Researchers looked specifically at the $77 \%$ of youth who entered the study without having completed high school or earned a GED. They found that assignees were more likely to earn a GED (42\% vs. 27\%) or vocational certificate (38\% vs. 15\%) - but less likely to earn a high school diploma - 5\% vs. 8\%. Average earnings were slightly lower for assignees than non-assignees during the first quarters after assignment - likely because assignees were more likely to participate in the program instead of 
working. However, about six quarters after assignment, average assignee income surpassed nonassignee income, and in the fourth year after assignment, assignees on average earned about \$17/week more than non-assignees. Employment rates were also slightly higher.

\section{Existing Program Evaluation is Limited, Not Encouraging}

During the last twenty years, evaluation of direct youth employment programs has been extremely limited and not particularly encouraging. The highest-quality and most recent evaluations have been on New York City's youth summer jobs program. One set of analyses found that participants in the program, relative to non-participants, did not experience positive employment or educational benefits over the following few years. (Gelber, 2014). A study on earlier program years did find some positive effects on school attendance (Leos-Urbel, 2014). A report on a program in Philadelphia found no positive later employment outcomes for participants relative to non-participants (McClanahan, 2004). Other assessments of youth employment programs have not actually assessed later youth outcomes: a Department of Laborsponsored assessment reported that "the study was unable to assess how meaningful youth experiences were or how their experiences could affect them and their communities over time" (Bellotti, 2010). That is, they did not track any later employment or educational outcomes.

Because of how common (and likely varied) local programs are, how limited evaluation is, and how mixed current results are, there is a strong case to be made for increasing research on the effectiveness of teen direct employment programs. Evaluation of teen employment programs requires increased recordkeeping and follow-up with participants, and thus would likely require either increased funding or diverting some funds currently going for youth employment programs. By figuring out which program elements are having positive impacts (or which participants are being positively impacted), we can improve existing programs. And if efficacy is extremely low across-the-board, we can end those programs and experiment with other, moretargeted ways to get disengaged youth re-engaged - which might include programs like ChalleNGe and Job Corps, which do not have a goal of immediate employment. 


\section{Appendix A: Information on Variables Used}

Table A.1: Notes on Variables Used: Figures

\begin{tabular}{|l|l|}
\hline Figure & Data Source/Variables \\
\hline Figure 1.1: Employment Rates, 1962-2013 & March CPS: year, age, empstat \\
\hline $\begin{array}{l}\text { Figure 1.2: Proportion of Teenagers Living on } \\
\text { Their Own, 2000-2013 }\end{array}$ & March CPS: year, age, relate \\
\hline $\begin{array}{l}\text { Figure 1.3: Proportion of Teenagers Earning At } \\
\text { Least 5\%, 10\%, 20\%, and 50\% of Total Household } \\
\text { Income }\end{array}$ & March CPS: year, age, incwage, ftotval \\
\hline $\begin{array}{l}\text { Figure 3.1: Proportion of Teenagers Attending } \\
\text { School, March and July 2000 and 2013 }\end{array}$ & March/July CPS: year, age, schlcoll \\
\hline $\begin{array}{l}\text { Figure 3.2: Likelihood of Attending Two- or Four- } \\
\text { year College }\end{array}$ & $\begin{array}{l}\text { MTF (12 } 2^{\text {th }} \text { grade): YEAR OF ADMINST, R } \\
\text { WL DO 4YR CLG, R WL DO 2YR CLG }\end{array}$ \\
\hline $\begin{array}{l}\text { Figure 3.3: Likelihood of Attending Four-year } \\
\text { College }\end{array}$ & MTF (12 ${ }^{\text {th }}$ grade): YEAR OF ADMINST, R \\
WL DO 4YR CLG \\
\hline $\begin{array}{l}\text { Figure 3.4: Average Daily Minutes on Academic } \\
\text { Activities }\end{array}$ & ATUS: teyear, teage, t06* (all variables \\
\hline $\begin{array}{l}\text { Figure 3.5: Employment by Educational Status, } \\
\text { March and July 2000 and 2013 }\end{array}$ & $\begin{array}{l}\text { March/July CPS: year, age, schlcoll, } \\
\text { empstat }\end{array}$ \\
\hline $\begin{array}{l}\text { Figure 4.1: Proportion of Immigrants among } \\
\text { Adults In Jobs with Teen Overrepresentation from } \\
\text { Two to Five }\end{array}$ & ACS: year, occ1990, ind1990, age, citizen \\
\hline $\begin{array}{l}\text { 4.2: Proportion of High School Dropouts among } \\
\text { Adults In Jobs with Teen Overrepresentation from } \\
\text { Two to Five }\end{array}$ & ACS: year, occ1990, ind1990, age, educ \\
\hline $\begin{array}{l}\text { Figure 5.1: Labor Market Status and Reason for } \\
\text { NILF }\end{array}$ & March CPS: year, age, empstat, wantjob \\
\hline
\end{tabular}




\begin{tabular}{|c|c|}
\hline $\begin{array}{l}\text { Figure 5.2: Preferences Regarding Weekly Hours } \\
\text { Worked, } 12^{\text {th }} \text { Graders }\end{array}$ & $\begin{array}{l}\text { MTF }\left(12^{\text {th }} \text { grade): YEAR OF ADMINST, \# }\right. \\
\text { HRS PREF WORK }\end{array}$ \\
\hline $\begin{array}{l}\text { Figure 5.3: Preferences Regarding Weekly Hours } \\
\text { Worked, Parents of } 12^{\text {th }} \text { Graders }\end{array}$ & $\begin{array}{l}\text { MTF }\left(12^{\text {th }} \text { grade): YEAR OF ADMINST, }\right. \\
\text { PRT \#HR PREF WRK }\end{array}$ \\
\hline $\begin{array}{l}\text { Figure 5.4: Distribution of Hourly Wage among } \\
\text { Teenagers Who Reported Having Earned Income, } \\
\text { Inflation-Adjusted to Year } 2000 \text { Dollars, } 2000 \text { and } \\
2013\end{array}$ & $\begin{array}{l}\text { March CPS: incwage, age, year, uhrswork, } \\
\text { wkswork1; CPI }\end{array}$ \\
\hline $\begin{array}{l}\text { Figure 5.5: Teenage Hourly Wages as a Proportion } \\
\text { of Minimum Wage, } 2000 \text { and } 2013\end{array}$ & $\begin{array}{l}\text { March CPS: incwage, age, year, uhrswork, } \\
\text { wkswork1; minimum wages }\end{array}$ \\
\hline Figure 6.1: Decomposing the Employment Gap & $\begin{array}{l}\text { March CPS: county, statefip, age, year, } \\
\text { educ, citizen, empstat, incwage; ACS: year, } \\
\text { age, school, county, statefip; minimum } \\
\text { wage }\end{array}$ \\
\hline $\begin{array}{l}\text { Figure 8.1: Proportion of Teenagers in neither } \\
\text { Work nor School, 1986-2014 }\end{array}$ & March CPS: year, age, empstat, schlcoll \\
\hline Figure 8.2: Age by Engagement Status & ACS: year, age, empstat, school \\
\hline $\begin{array}{l}\text { Figure 8.3: Racial/Ethnic Group by Engagement } \\
\text { Status }\end{array}$ & $\begin{array}{l}\text { ACS: year, age, empstat, school, race, } \\
\text { hispan }\end{array}$ \\
\hline $\begin{array}{l}\text { Figure 8.4: Household Income by Engagement } \\
\text { Status }\end{array}$ & ACS: year, age, empstat, school. poverty \\
\hline Figure 8.5: Group Quarters by Engagement Status & ACS: year, age, empstat, school, gq \\
\hline $\begin{array}{l}\text { Figure 8.6: Educational Attainment by } \\
\text { Engagement Status }\end{array}$ & ACS: year, age, empstat, school, educd \\
\hline $\begin{array}{l}\text { Figure B.1: Summary Statistics for Hourly Wage: } \\
\text { CPS (2013) }\end{array}$ & $\begin{array}{l}\text { March CPS: incwage, age, year, uhrswork, } \\
\text { wkswork1 }\end{array}$ \\
\hline $\begin{array}{l}\text { Figure B.2: Summary Statistics for Hourly Wage: } \\
\text { Monitoring the Future }\left(12^{\text {th }} \text { Graders, } 2013\right)\end{array}$ & $\begin{array}{l}\text { MTF }\left(12^{\text {th }} \text { grade }\right) \text { YEAR OF ADMINST, } \\
\text { HRS/W WRK SCHYR, R } \$ \text { /AVG WEEK } \\
\text { JOB }\end{array}$ \\
\hline
\end{tabular}


Table A.2: Notes on Variables Used: Tables

\begin{tabular}{|l|l|}
\hline Table & Data Source/Variables \\
\hline $\begin{array}{l}\text { Table 3.2: Comparing Minutes/Day Spent on } \\
\text { Education, 2003-2013 }\end{array}$ & $\begin{array}{l}\text { ATUS: teyear, teage, t06* (all variables } \\
\text { beginning with “t06”) }\end{array}$ \\
\hline $\begin{array}{l}\text { Table 4.1: Number of Teen Jobs, 2000 and } \\
2013\end{array}$ & ACS: year, occ1990, ind1990, age \\
\hline $\begin{array}{l}\text { Table 5.1: Preferences Regarding Weekly } \\
\text { Hours Worked, 12th Graders, ANOVA }\end{array}$ & $\begin{array}{l}\text { MTF (12 } 2^{\text {th }} \text { grade): YEAR OF ADMINST, \# } \\
\text { HRS PREF WORK }\end{array}$ \\
\hline $\begin{array}{l}\text { Table 5.2: Parental Preferences Regarding } \\
\text { Weekly Hours Worked, 12th Graders, ANOVA }\end{array}$ & $\begin{array}{l}\text { MTF (12 } \\
\text { \#HR Prade): YEAR OF ADMINST, PRT }\end{array}$ \\
\hline $\begin{array}{l}\text { Table 6.1: Summary Statistics, Table 6.2: Logit } \\
\text { Results, Table 6.3: Decomposition Results, } \\
\text { Table 6.4: Summarizing Percentage Values }\end{array}$ & $\begin{array}{l}\text { March CPS: county, statefip, age, year, educ, } \\
\text { citizen, empstat, incwage; ACS: year, age, } \\
\text { school, county, statefip; minimum wage }\end{array}$ \\
\hline
\end{tabular}




\section{Appendix B: Deriving Hourly Wage and Alternative Specifications}

This appendix briefly describes the derivation of the hourly wage in CPS data. As I show in Chapter Five, a significant portion of teenagers report earning less than the minimum wage in both 2000 and 2013. To determine whether this is an artifact of the particular data set, perhaps having to do with question wording or survey admission, I then analyze wage data for $12^{\text {th }}$ graders from the MTF data set. I also find significant proportions of respondents reporting earning less than the minimum wage there as well, strengthening the case that this is not an artifact of anything specific to CPS data.

To determine hourly wage from CPS, the three variables I use, and their definitions from IPUMS, are the following:

- INCWAGE indicates each respondent's total pre-tax wage and salary income--that is, money received as an employee--for the previous calendar year

- WKSWORK1 reports the number of weeks, in single weeks, that the respondent worked for profit, pay, or as an unpaid family worker during the preceding calendar year.

Respondents were prompted to count weeks in which they worked for even a few hours and to include paid vacation and sick leave as work.

- UHRSWORK reports the number of hours per week that respondents usually worked if they worked during the previous calendar year. Individuals were asked this question if: 1) they reported working at a job or business at any time during the previous year or 2) they acknowledged doing "any temporary, part-time, or seasonal work even for a few days" during the previous year.

It is likely that teenagers are working more irregular hours, or possibly multiple part-time jobs throughout the year. While most adults who report earning income in the previous year say they worked for the whole year ( 52 weeks), this is not the case for teenagers. Most of these adults also say they worked for at least 40 hours a week, relative to less than a quarter of teenagers. Irregular and possibly multiple part-time jobs throughout the year increase the possibility for confusion regarding how to answer questions regarding number of hours worked. For instance, it's not clear how a teenager who worked for a few hours per week during the school year but more hours per week during the summer should answer the question. This raises the possibility that the wage data for teenagers is much less accurate than for adults. 
My formula for deriving hourly wages is the following: hourly wage $=$ incwage/(wkwwork1 * uhrswork.)

Figure B.1 shows hourly wages for teenagers and adults using 2013 ACS data. While the $10^{\text {th }}$ percentile among adults is above the federal minimum wage for 2012 of $\$ 7.25$, the $25^{\text {th }}$ percentile for teenagers is considerably below it.

Figure B.1: Summary Statistics for Hourly Wage: CPS (2013)

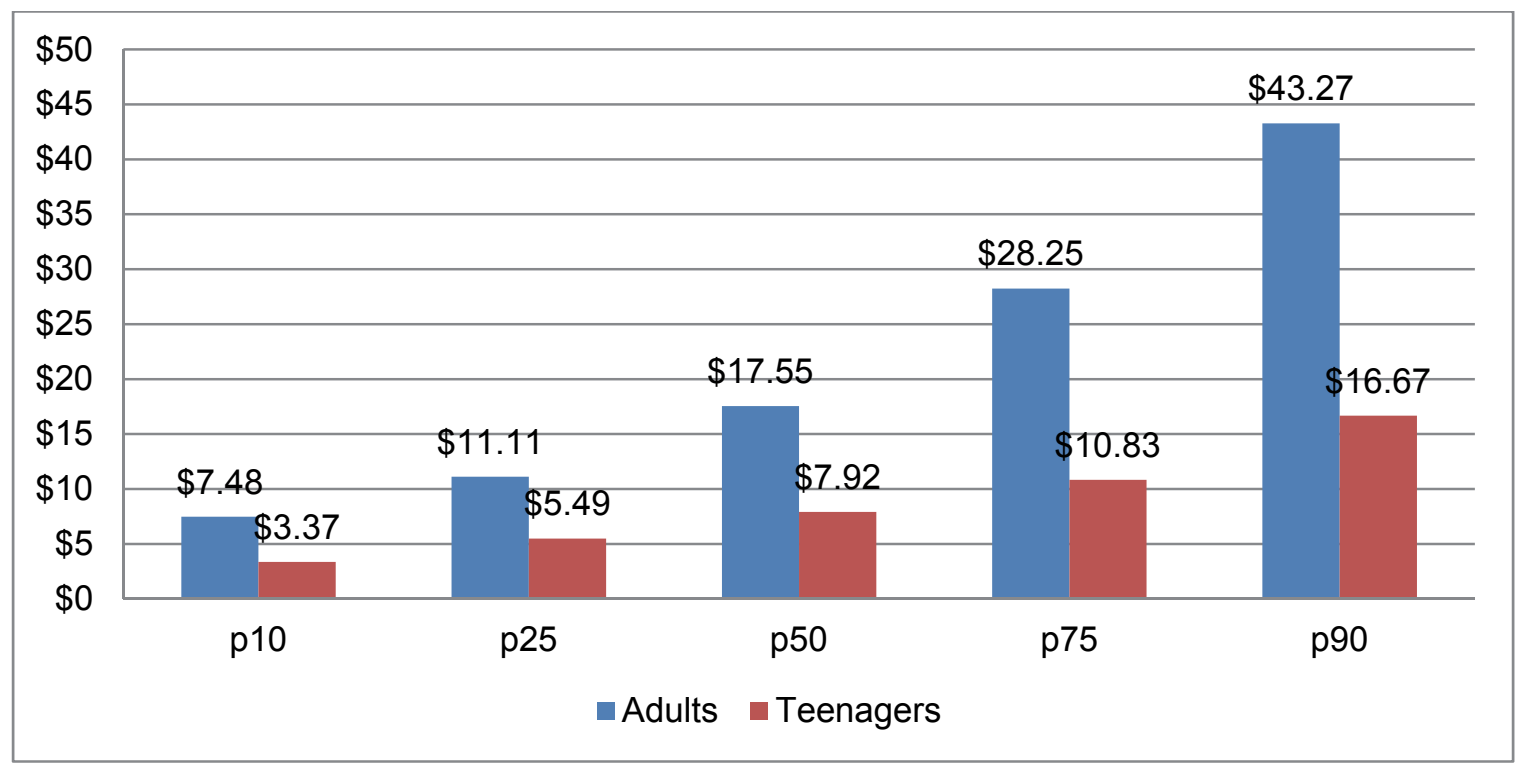

ACS 2013

Unless teenagers are misunderstanding the question, this is not a function of greater selfemployment among teenagers: $93 \%$ of teenagers with wage income reported that they had worked for private employers, with most of the rest working for local government.

In order to assess whether the findings regarding sub-minimum wage workers in Census data are an artifact of some Census-specific attribute, I also looked at MTF questions on hours worked and wages earned. The question on hours worked asks the twelfth-grade respondents "On the average over the school year, how many hours per week do you work in a paid or unpaid job?", and there are eight different response options, each corresponding to an interval of hours. The next question asks "During an average week, how much money did you get from a job or other work," with the ten options each corresponding to an interval in terms of dollars. I used the same general mechanism to obtain hourly wage as I did for Census data: dividing money earned by hours worked. Because the data for both of these was intervalled, I used the midpoint of each response option. For instance, teenagers who reported working 6-10 hours and earning between $\$ 36-\$ 50$ were coded as working 8 hours and earning $\$ 43$, for a wage of $\$ 5.38$. 
In this analysis, I found that the sub-minimum wages reported are certainly not an artifact of any Census-specific issue: in MTF, many $12^{\text {th }}$ graders also report earning less than minimum wage, as shown below in Figure B.2. This graph excludes the teenagers who report working but earning no money, who account for about $10 \%$ of $12^{\text {th }}$ graders in 2000 and about $30 \%$ of them in 2013. I find that about $48 \%$ of teenage workers who make above-zero wages report earning less than the state minimum wage in 2000 , and $49 \%$ in 2013 . These are very inexact figures due to the intervalling, but they bolster the case that many teenagers are earning less than the minimum wage.

Figure B.2: Summary Statistics for Hourly Wage: Monitoring the Future $\left(12^{\text {th }}\right.$ Graders, 2013)

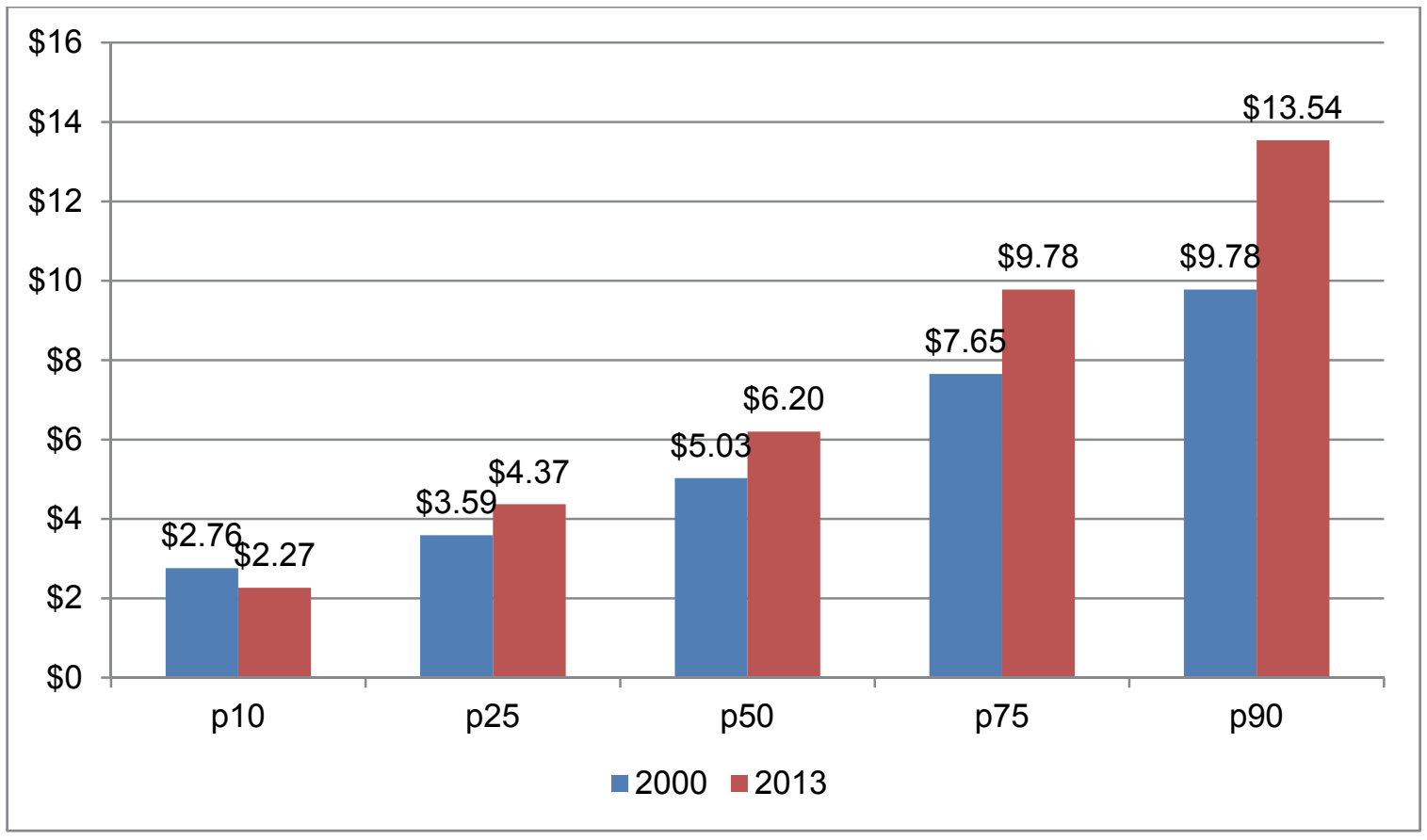

MTF 2013 


\section{Appendix C: Data Sets Used}

While the text of the dissertation includes some information about each of the data sets employed, Appendix $\mathrm{C}$ describes each of them in more depth.

\section{Census Surveys}

Each Census data set has particular strengths, weaknesses, and years of availability: because of this, I use a variety of them both in the informal evidence chapters and in the analytical model chapter. The analytical model uses the 5\% sample of the 2000 Census, the 2013 ACS. and the 1999 and 2012 March CPS. Other chapters use other years of sample Census data, CPS data, and ACS data, as well as July CPS data for information on the summer months. This section will describe the commonalities and differences between the four data sets used in the analytical model, as this may be relevant to my analysis, with occasional notes about the other years of those data sets.

First, there are many commonalities between these four data sets. In addition to households, the population surveyed by all of them include people living in group quarters like nursing homes, hospice facilities, correctional institutions, monasteries, worker's camps (like some migrant farmworkers) and shelters ${ }^{37}$. They also include foreign citizens ${ }^{38}$, unless they are only in the United States temporarily. None attempt to exclude undocumented immigrants, and Pew, which estimates the number of undocumented immigrants in the United States, has used the 2000 $5 \%$ sample, ACS, and March CPS to measure the total number of immigrants (Pew Hispanic Center, 2013). The employment status variable is comparable across all of these surveys: although there are slight wording differences, enumerator instruction differences, and levels of variable aggregation, being employed mean the same thing across the surveys. That is, respondents are categorized as being employed if they did any paid work the previous week, did unpaid work for a family business, had a job but did not work at it last week, or are serving active duty in the Armed Forces.

Additionally, all of these surveys include information on school enrollment status, county, state, age and other demographic information, wage income, usual hours worked and weeks worked in the previous year, occupation, industry, citizenship status, educational attainment, and

\footnotetext{
${ }^{37}$ Early ACS surveys excluded people living in group quarters, but these people were included both in the $5 \%$ sample from 2000 and 2013 ACS.

38 http://www.census.gov/population/www/censusdata/resid_rules.html
} 
poverty status. However, there are some differences in how that information is collected - what categories of responses exist, what questions respondents are asked, and what information Census enumerators are given.

\section{Census, 5\% Sample}

In 2000, the Census department performed an in-depth survey of $5 \%$ of the people and housing units that were included in the 2000 decennial Census. These additional questions were known as the long-form questionnaire. I use the 5\% sample of 2000 Census to provide data on teenage employment status in 2000, as well as on other teenage respondent variables for that year including school status, demographic information, and geographical area. On the variables of interest, there is significant continuity between the long-form Census and later ACS surveys. While there was an ACS survey in 2000, it's much smaller than the 5\% Census sample (and even considerably smaller than the later ACS samples) and it doesn't contain information on what county respondents live in.

One area in which both the 5\% sample and 2013 ACS differ from the CPS samples is the educational status variable. First, while the school enrollment question on the ACS and the longform Census only distinguish between enrollment and non-enrollment, CPS asks whether the respondent is enrolled full-time or part-time in high school or college. While ACS and the longform Census do include a "grade level attending" variable, the results do not entirely line up with the results from CPS. That is, some teenagers report they are attending grades below high school, whereas this is not an option on the CPS school attendance variable. Second, the question classifies respondents as attending school if they have attended school or college in the last three months, as opposed to in CPS, where they are only classified as attending school if they are currently attending school. This means that, during the summer, respondents who were taking classes several months ago but are not taking summer classes will be classified as students in the $5 \%$ Census sample but not in the July CPS.

Finally, the data collection time frame for the 5\% sample is unique among the four data sets I rely heavily on: it began in November 1999 and continued through December 2000.

\section{American Community Survey}

The ACS replaced the longform Census survey, with one year of overlap in 2000 in which the ACS sample used was very small. I use the 2013 ACS to provide data on teenage employment status in 2013, as well as on other teenage respondent variables for that year including school status, demographic information, and geographical area. On the variables of interest, there is significant continuity between the long-form Census and later ACS surveys.

Both 2013 ACS and the 5\% Census sample have somewhat different school enrollment variables than CPS. While the school enrollment question on the ACS and the longform Census only distinguish between enrollment and non-enrollment, CPS asks whether the respondent is 
enrolled full-time or part-time in high school or college. While ACS and the longform Census do include a "grade level attending" variable, the results do not entirely line up with the results from CPS. That is, some teenagers report they are attending grades below high school, whereas this is not an option on the CPS school attendance variable. Second, the question classifies respondents as attending school if they have attended school or college in the last three months, as opposed to in CPS, where they are only classified as attending school if they are currently attending school. This means that, during the summer, respondents who were taking classes several months ago but are not taking summer classes will be classified as students in ACS but not in the July CPS.

Finally, data collection for the ACS survey is year-round.

\section{The Current Population Survey, March 1999 and 2012}

In my analytical model, I use March 1999 and 2012 CPS data to provide county- and statelevel data. The variables I create by aggregating adult responses are adult unemployment rate, proportion of immigrants among adults, and median wage income by educational strata. I then merged these county- and state-level variables with the respondent-level 5\% 2000 Census data and 2013 ACS data so that each teenager has respondent-level characteristics, county-level characteristics, and state-level characteristics. In addition, I use CPS data from various years for a variety of the informal evidence: most of this is from the March survey, but I use several July surveys as a source of information on whether teenagers are in summer school. The major reason I don't use CPS data as a source of teenagers for the analytical model is that it's much smaller than both the 5\% Census sample and the 2013 ACS data set.

\section{Other Surveys}

In addition to the Census data, I use several other data sets throughout the paper. Here I will describe them and discuss how they compare to the Census data in areas in which there is overlap. The only one of these that I use in the analytical model is the minimum wage data: the other provide background and informal evidence.

\section{Minimum Wage data}

The U.S. Department of Labor provides longitudinal information on state minimum wages ${ }^{39}$ : I use this information both in my informal evidence and my analytical model. In most cases, this is straightforward: the state either does not have a minimum wage higher than the federal minimum wage, in which case the federal minimum wage applies, or has a higher minimum wage that applies to all employers, in which case that wage applies. There are a few exceptions,

${ }^{39}$ http://www.dol.gov/whd/state/stateMinWageHis.htm 
however. In 2000 and 2013, Vermont had a minimum wage that applied only to employers of two or more: I counted that wage as being the minimum wage for the state. Just in 2013, a handful of other states also had minimum wage laws which only applied to employers of more than a certain number (four in Illinois, two in Michigan), or with a certain amount of receipts (this is just Montana). In these cases, I also count the higher wages as being the minimum wages for the state. There are also various other states that have minimum wages that only apply to certain businesses: however, these minimum wages are all lower than the federal minimum wage in 2000 and 2013, so the federal minimum wage takes precedence.

\section{American Time Use Survey}

I use the American Time Use Survey (ATUS) for information on how much time teenagers are spending on education-related activities. ATUS is a nationally-representative one-day time diary. The earliest ATUS survey is from 2003. The data I refer to in this report is from the MultiYear ATUS Microdata Files.

\section{Monitoring the Future: A Continuing Study of American Youth (12th-Grade Survey)}

The University of Michigan's Institute for Social Research conducts the annual "Monitoring the Future: A Continuing Study of American Youth" surveys of $8^{\text {th }}, 10^{\text {th }}$, and $12^{\text {th }}$ grade students. In this dissertation, I use MTF data on $12^{\text {th }}$ graders in order for two purposes. First, I examine how education plans and attitudes toward teenage employment are changing. Second, I use MTF's information on hours worked and wages to compute hourly wages to determine whether the fact that a significant proportion of teenagers in Census data who appear to be earning less than the minimum wage is actually an artifact of some unique characteristic of Census data. Some candidates for this include Census question wording or the fact that respondents may be parents or other family members who are not perfectly aware of the teenager's work schedule or earnings.

In order to assess changing attitudes and goals, I look at two questions on ideal number of hours worked and two questions on educational plans. The work-related questions ask teenagers how many hours they would prefer to work during the school year and how many hours their parents would prefer they work during the school year. The questions on future plans ask teenagers "How likely is it that you will do each of the following things after high school?", and then separately provide as options "Graduate from a two-year college program" and "Graduate from a four-year college program, in addition to other educational and work options. 


\section{Appendix D: Literature on the Effects of Teenage Employment}

This appendix presents some of the literature on the effects of teenage employment in more length than in Chapter One. That chapter also discusses some of the shortcomings of this literature, which include that it's all non-experimental.

Table D.1 summarizes some of the literature on the relationship between adolescent employment and adult labor market outcomes. Inclusion criteria for this table are the following:

- The adolescent employment variables must be for respondents between 15-22

- The adult employment outcomes must be for age 22 or later

- Papers must be published between 1980-2015, in order to make it more likely that the results still are informative regarding current generations of workers

- Papers must do original research rather than review other articles

- Populations studied must be American populations

- They must either be published journal articles or NBER working papers.

These criteria exclude a great deal of tangentially-related literature, including various papers on simultaneous educational and work behavior of adolescents, literature on predictors of adolescent work behavior, and literature solely measuring educational or employment outcomes of young adults.

\section{Table D.1: Papers on Adolescent Work Behavior and Later Employment and Educational Outcomes}

Paper Citation

Ahituv, Avner, and Marta Tienda. "Employment, Motherhood, and School Continuation Decisions of Young White, Black, and Hispanic Women." Journal of Labor Economics 22.1 (2004).

Alon, Sigal, Debra Donahoe, and Marta Tienda, "The Effects of Early Work Experience on Young Women's Labor Force Attachment," Social Forces, Vol. 79, No. 3, 2001, pp. 1005-1034.

http://www.jstor.org/stable/2675616

Baum, C. L., \& Ruhm, C. J. (2014). The changing benefits of early work experience (No. w20413). National Bureau of Economic Research.
Findings

Based on NLSY79, working more hours in high school was associated with negative educational outcomes for young black and Hispanic women, but not for young white women. However, working overall had positive effects on educational outcomes.

Early work experiences for young women are associated with later labor market outcomes at age 25-28. Working in high school and college make young women more likely to be employed later on. However, early job turnover is associated with negative future outcomes. There are average wage benefits to working in high school on adult wages (23-29), but they have diminished, from $8.8 \%$ for the NLSY79 cohort to $4.4 \%$ for the NSLY97 one for working 20 hours/week senior year of high school (relative to not working). The effect on number of weeks and hours worked is also still positive but has decreased. 
Becker, Brian E., and Stephen M. Hills. 1980. "Teenage Unemployment: Some Evidence of the Long-Run Effects on Wages." Journal of Human Resources 15:354-72.

Becker, Brian E., and Stephen M. Hills. 1983. "The Long-Run Effects of Job Changes and Unemployment among Male

Teenagers." Journal of Human Resources 17:197-211.

Carr, Rhoda V., James D. Wright, and Charles J. Brody, "Effects of High School Work Experience a Decade Later: Evidence from the National Longitudinal Survey," Sociology of Education, Vol. 69, No. 1, 1996, pp. 66-81. http://www.jstor.org/stable/2112724

Chaplin, D. (1996). High school employment: Meaningful connections for at-risk youth.

Freedman-Doan. (2011). "Twelfth-Grade Student Work Intensity Linked to Later Educational Attainment and Substance Use: New Longitudinal Evidence." Developmental Psychology, 47 (2): 344-363.

Hotz, V. Joseph, Lixin Colin Xu, Marta Tienda, and Avner Ahituv, "Are There Returns to the Wages of Young Men from Working While in School?," The Review of Economics and Statistics, Vol. 84, No. 2, 2002, pp. 221-236. http://www.jstor.org/stable/3211773

Meyer, Robert H., and David A. Wise. 1982. "High School Preparation and Early Labor Force Experience." Pp. 277-347 in The Youth Labor Market Problem: Its Nature, Causes and

Consequences, edited by W.B. Freeman and David A. Wise. University of Chicago Press.

Rich, Lauren. 1996. "The Long-Run Impact of Teenage Work Experience: A Reexamination." Review of Black Political Economy 25:11-36.
Based on NSL of Young Men, this looks at teenage unemployment and later (20s and early 30s) wage rates, this study finds ambiguous effects of unemployment on later wage rate: having been unemployed appears positive for both young black and young white men, but this is diminished somewhat for longer spells of unemployment.

Based on NSL of Young Men, this looks at teenage unemployment and later wage rates, concluding that short periods of teenage unemployment have generally positive outcomes, as does teenage labor market experience in general.

Based on NLSY79, working in high school had small negative effects on educational attainment - high school workers were less likely to complete college - but positive effects in terms of employment and income in their 20s.

Working in high school is significantly positively associated with earnings 8-11 years later for atrisk youth, even though it is also negatively associated with educational attainment. Smaller but still positive employment benefits were found for youth who were not at-risk.

Work intensity in high school is positively associated with educational attainment 12 years later, with high school students who work more than 20 hours a week having been more likely to have not completed high school, conditioning on various factors.

Young men's work status in high school and work status in college tend to be positively associated with employment rate at 23 and 28, although not always positively and statistically significantly for all subgroups by race/educational level completed. However, most of what appear to be estimates increases in wages associated with working are really just omitted variable bias, calling into question previous researchers' results about "sizeable and persistent returns to young men's subsequent wages from working while enrolled in high school or college."

Using the National Longitudinal Study of 1972 High School

Seniors, researchers find a positive relationship between working in high school and both working later and wage rate later in the four years after high school completion, after controlling for various personal and family characteristics. Using NLSY79, researchers find that number of hours worked in high school is positively associated with number of hours worked after high school, even eight years later and when conditioning on various personal and family characteristics. 
Ruhm, C. J. (1995). The extent and consequences of high school employment. Journal of Labor Research, 16(3), 293-303.

Stephenson, Jr., Stanley P. (1981). "In-School Labour Force Status and Post-School Wage

Rates of Young Men." Applied Economics, 13 (3): 279302.
No negative educational effects of working in high school were found. Respondents who worked as seniors in high school had significantly higher wages 6-9 years later than their peers, were more likely to have employer-provided benefits, and were in higher-status occupations, controlling for a variety of factors.

Using NSLY79, researchers find that, controlling for various characteristics, working in the last year of school was positively associated with higher post-school wage rates, controlling for various characteristics. This is somewhat confusing: the "in their last year of school" group appears to include both high school and college students.

Table D.2 contains additional information on the literature on other outcomes of adolescent employment discussed in Chapter One.

Table D.2: Papers on Other Outcomes

Cite Findings

Aassve, A., Billari, F. C., Mazzuco, S., \& Ongaro, F. (2002). Leaving home: A comparative analysis of ECHP data. Journal of European social policy, 12(4), 259-275.

Buck, N., \& Scott, J. (1993). She's leaving home: But why? An analysis of young people leaving the parental home. Journal of Marriage and the Family, 863-874.

Jacob, M., \& Kleinert, C. (2008). Does unemployment help or hinder becoming independent? The role of employment status for leaving the parental home. European sociological review, 24(2), 141-153.

Johnson, D. S., \& Lino, M. (2000). Teenagers: Employment and Contributions to Family Spending. Monthly Lab. Rev., 123, 15.
Using CPS (Census) data, researchers document the changes in living situations of people in their 20s from 1983 to 1994 , showing an increase in $25-29$ year-olds living with their parents and a decrease in 20-24 year-olds and 25-29 year-olds living with spouses.

Using the Panel Study of Income Dynamics, researchers find that work hours are associated with leaving home among young women, and income is associated with leaving home among young men, conditioning on various characteristics. Unemployment rate in the area is negatively associated with likelihood of leaving home.

Looking at two birth cohorts in West Germany, the researchers find that employment status is positively associated with household formation among young adults. Unemployment duration is also negatively associated with household formation for single people, but not for young adults with partners.

Using the Consumer Expenditure Survey, researchers find that households in which 14-17 year-olds are employed tend to spend more money on clothing for teenagers, entertainment, and transportation, suggesting that teenage wages do not generally go to family necessities. 
Painter, Matthew A. "Get a job and keep it! High school employment and adult wealth accumulation." Research in Social Stratification and Mobility 28.2 (2010): 233249.

Whittington, L. A., \& Peters, H. E. (1996). Economic incentives for financial and residential independence. Demography, 33(1), 82-97.
Using NSLY79, the researcher finds that, as adults, high school employment is positively associated with home ownership. This is the case in 1986, 1995, and 2004 - so, throughout a range of young adulthood to middle age. Differences are large, over 20 percentage points between the lowest-employed-in-high-school and highest-employedin-high-school group in both 1995 and 2004. However, they are not statistically significant. In the model which controls for various characteristics (including educational attainment, which may not be appropriate), the higher-duration employment groups had higher probabilities of home ownership than the lowest-employment group.

Using the Panel Study of Income Dynamics, researchers find that potential wages are associated with likelihood of leaving home among young people, conditioning on various characteristics. They model potential wages as a function of personal characteristics. Researchers speculate that decreased wage opportunities for young people may be driving the later age of leaving home. 


\section{References}

Aassve, A., Billari, F. C., Mazzuco, S., \& Ongaro, F. (2002). Leaving home: A comparative analysis of ECHP data. Journal of European social policy, 12(4), 259-275.

Acemoglu, D. (1998). Why do new technologies complement skills? Directed technical change and wage inequality. Quarterly journal of economics, 1055-1089.

Alon, Sigal, Debra Donahoe, and Marta Tienda, "The Effects of Early Work Experience on Young Women's Labor Force Attachment," Social Forces, Vol. 79, No. 3, 2001, pp. 1005 1034. http://www.jstor.org/stable/2675616

Altonji, J. G., \& Card, D. (1991). The effects of immigration on the labor market outcomes of less-skilled natives. In Immigration, trade and the labor market (pp. 201-234). University of Chicago Press.

Ashenfelter, Orley, P. R. G. Layard, and David E. Card, Handbook of labor economics, 1st ed., 3 vols, Handbooks in economics, Amsterdam ; New York New York, N.Y., U.S.A.: NorthHolland ;Sole distributors for the U.S.A. and Canada, Elsevier Science Pub. Co., 1986.

Baranowska-Rataj, A., \& Magda, I. (2014). Inequality in the risk of job loss between young and prime-age workers: Can it be explained by human capital or structural factors? (No. 73).

Baum, C. L., \& Ruhm, C. J. (2014). The changing benefits of early work experience (No. w20413). National Bureau of Economic Research

Becker, Brian E., and Stephen M. Hills. 1980. "Teenage Unemployment: Some Evidence of the Long-Run Effects on Wages." Journal of Human Resources 15:354-72.

Becker, Brian E., and Stephen M. Hills. 1983. "The Long-Run Effects of Job Changes and Unemployment among Male Teenagers." Journal of Human Resources 17:197-211

Bellotti, Jeanne, et al. "Reinvesting in America's Youth: Lessons from the 2009 Recovery Act Summer Youth Employment Initiative." Mathematica Policy Research, Inc. (2010).

Benjamini, Yoav, and Yosef Hochberg. "Controlling the false discovery rate: a practical and powerful approach to multiple testing." Journal of the Royal Statistical Society. Series B (Methodological) (1995): 289-300.

Borjas, G. J., Freeman, R. B., Katz, L. F., DiNardo, J., \& Abowd, J. M. (1997). How much do immigration and trade affect labor market outcomes?. Brookings papers on economic activity, 1-90 
Brown, Charles. "Minimum wage laws: Are they overrated?." The Journal of Economic Perspectives (1988): 133-145.

Bryk, Anthony S., and Stephen W. Raudenbush. Hierarchical linear models: applications and data analysis methods. Sage Publications, Inc, 1992.

Buck, N., \& Scott, J. (1993). She's leaving home: But why? An analysis of young people leaving the parental home. Journal of Marriage and the Family, 863-874.

Carr, Rhoda V., James D. Wright, and Charles J. Brody, "Effects of High School Work Experience a Decade Later: Evidence from the National Longitudinal Survey," Sociology of Education, Vol. 69, No. 1, 1996, pp. 66-81. http://www.jstor.org/stable/2112724

Chaplin, D. (1996). High school employment: Meaningful connections for at-risk youth.

Freedman-Doan. (2011). "Twelfth-Grade Student Work Intensity Linked to Later Educational Attainment and Substance Use: New Longitudinal Evidence.” Developmental Psychology, 47 (2): 344-363.

Gelber, A., Isen, A., \&, J. B. (2014). The Effects of Youth Employment: Evidence from New York City Summer Youth Employment Program Lotteries (No. w20810). National Bureau of Economic Research.

Gelman, Andrew, and Eric Loken. "The garden of forking paths: Why multiple comparisons can be a problem, even when there is no 'fishing expedition'or 'p-hacking' and the research hypothesis was posited ahead of time." Downloaded January 30 (2013): 2014.

Glick, Jennifer E., and Seung Yong Han. "Socioeconomic Stratification from Within: Changes Within American Indian Cohorts in the United States: 1990-2010." Population Research and Policy Review 34.1 (2015): 77-112

Heller, S. B. (2014). Summer jobs reduce violence among disadvantagedyouth. Science, 346(6214), 1219-1223.

Hotz, V. Joseph, Lixin Colin Xu, Marta Tienda, and Avner Ahituv, "Are There Returns to the Wages of Young Men from Working While in School?," The Review of Economics and Statistics, Vol. 84, No. 2, 2002, pp. 221-236. http://www.jstor.org/stable/3211773

Jacob, M., \& Kleinert, C. (2008). Does unemployment help or hinder becoming independent? The role of employment status for leaving the parental home. European sociological review, 24(2), 141-153.

Johnson, D. S., \& Lino, M. (2000). Teenagers: Employment and Contributions to Family Spending. Monthly Lab. Rev., 123, 15.

King, Miriam et al. Integrated Public Use Microdata Series, Current Population Survey: Version 3.0. [Machine-readable database]. Minneapolis: University of Minnesota, 2010. 
Leos-Urbel, Jacob. "What is a Summer Job Worth? The Impact of Summer Youth Employment on Academic Outcomes." Journal of Policy Analysis and Management 33.4 (2014): 891-911.

Lin, Carl. Less myth, more measurement: Decomposing excess returns from the 1989 minimum wage hike. No. 6269. Discussion Paper series, Forschungsinstitut zur Zukunft der Arbeit, 2012.

Meyer, Robert H., and David A. Wise. 1982. "High School Preparation and Early Labor Force Experience." Pp. 277-347 in The Youth Labor Market Problem: Its Nature, Causes and Consequences, edited by W.B. Freeman and David A. Wise. University of Chicago Press.

McClanahan, Wendy S., Cynthia L. Sipe, and Thomas J. Smith. "Enriching Summer Work: An Evaluation of the Summer Career Exploration Program."Public/Private Ventures (2004).

Millenky, Megan, et al. "Staying on course: Three-year results of the National Guard Youth ChalleNGe evaluation." MDRC Paper (2012).

Mroz, Thomas A, and Timothy H Savage, "The long-term effects of youth unemployment," Journal of Human Resources, Vol. 41, No. 2, 2006, pp. 259-293.

Mulligan, C. B. (1999). Substitution over Time: Another Look at Life-Cycle Labor Supply. In NBER Macroeconomics Annual 1998, volume 13 (pp. 75-152). MIT Press.

Neumark, David, and William Wascher. Minimum wages and employment: A review of evidence from the new minimum wage research. No. w12663. National Bureau of Economic Research, 2006.

Orel, F. D., \& Kara, A. (2014). Supermarket self-checkout service quality, customer satisfaction, and loyalty: Empirical evidence from an emerging market. Journal of Retailing and Consumer Services, 21(2), 118-129.

Painter, Matthew A. "Get a job and keep it! High school employment and adult wealth accumulation." Research in Social Stratification and Mobility 28.2 (2010): 233-249.

Paternoster, Raymond, et al. "The effect of teenage employment on delinquency and problem behaviors." Social Forces 82.1 (2003): 297-335.

Pew Hispanic Center. "A nation of immigrants: A portrait of the 40 million, including 11 million unauthorized." Washington, DC: Pew Research Center(2013).

Powers, D. A., \& Pullum, T. W. (2006). Multivariate decomposition for nonlinear models. Austin, TX, USA: Department of Sociology and Population Research Center Universtiy of Texas at Austin.

Rich, Lauren. 1996. "The Long-Run Impact of Teenage Work Experience: A Reexamination." Review of Black Political Economy 25:11-36. 
Ruggles, Steven et al. Integrated Public Use Microdata Series: Version 5.0 [Machine-readable database]. Minneapolis: University of Minnesota, 2010.

Ruhm, C. J. (1995). The extent and consequences of high school employment. Journal of Labor Research, 16(3), 293-303.

Schochet, Peter Z., John Burghardt, and Steven Glazerman. "National Job Corps Study: The Impacts of Job Corps on Participants' Employment and Related Outcomes [and] Methodological Appendixes on the Impact Analysis." (2001).

Smith, C. L. (2012). The impact of low-skilled immigration on the youth labor market. Journal of Labor Economics, 30(1), 55-89.

Whittington, L. A., \& Peters, H. E. (1996). Economic incentives for financial and residential independence. Demography, 33(1), 82-97.

Yun, Myeong-Su (2004). Decomposing differences in the first moment. Economics letters, 82(2), 275-280. 